\title{
Hot-wire Assisted
}

Atomic Layer Deposition

\section{of Tungsten Films}

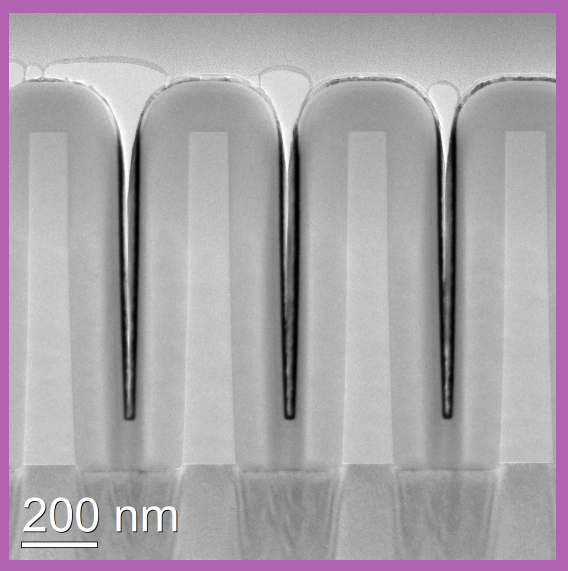

Mengdi Yang 


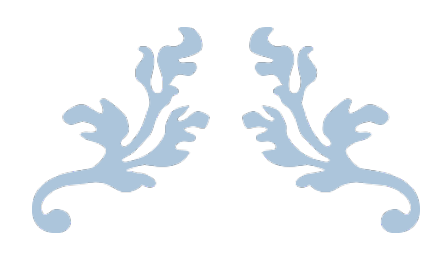

\section{HOT-WIRE ASSISTED \\ ATOMIC LAYER \\ DEPOSITION OF \\ TUNGSTEN FILMS}

Mengdi Yang

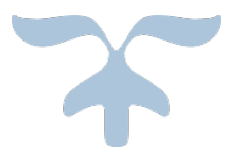




\section{Ph.D. Graduation Committee:}

Chairman:

Secretary:

Supervisor:

Co-supervisor:

Committee members: prof. dr. P.M.G. Apers

prof. dr. P.M.G. Apers

prof. dr. J. Schmitz

dr. A.K. Kovalgin

prof. dr. ir. J.R. van Ommen

dr. J.-W. Maes

prof. dr. ir. R.A.M. Wolters

prof. dr. F. Roozeboom

prof. dr. ing. A.J.H.M. Rijnders
University of Twente

University of Twente

University of Twente

University of Twente

Delft University of

Technology

ASM International N.V.

University of Twente

Eindhoven University of

Technology

University of Twente

This research was funded by NWO Domain Applied and Engineering Sciences (NWOTTW), project “plasma-free atomic layer deposition”, nr. 12846 and carried out at MESA+ Institute for Nanotechnology, University of Twente.

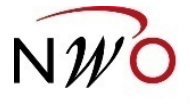

Title: Hot-wire assisted atomic layer deposition of tungsten films

ISBN: 978-90-365-4469-6

DOI: 10.3990/1.9789036544696

https://doi.org/10.3990/1.9789036544696

Copyright (C) 2018 by Mengdi Yang, Enschede, The Netherlands.

All rights reserved

Front cover: TEM images of a $13 \mathrm{~nm} \mathrm{~W}$ film grown by HWALD inside $\mathrm{Al}_{2} \mathrm{O}_{3}$-coated $\mathrm{Si}$ trenches (Chapter 4).

Back cover: Totoro, source: https:/www.drawingtutorials101.com/how-to-draw-totorofrom-my-neighbor-totoro 


\title{
HOT-WIRE ASSISTED ATOMIC LAYER DEPOSITION OF TUNGSTEN FILMS
}

\section{DISSERTATION}

\author{
to obtain \\ the degree of doctor at the University of Twente, \\ on the authority of the rector magnificus, \\ prof. dr. T.T.M. Palstra, \\ on account of the decision of the graduation committee, \\ to be publicly defended \\ on Friday, $2^{\text {nd }}$ February, 2018 at 16.45
}

by

Mengdi Yang

born on $10^{\text {th }}$ February, 1989

in Wuhan, Hubei, China 
This dissertation is approved by

prof. dr. J. Schmitz

dr. A.K. Kovalgin (promoter)

(co-promoter) 
To my family

La vie, voyez-vous, ça n'est jamais si bon ni si mauvais qu'on croit.

---- Guy de Maupassant 《Une Vie》

生活不可能像你想象得那么好, 但也不会像你想象得那么糟

——莫泊桑《人生》 (Translated into Chinese)

人的脆弱和坚强都超乎自己的想象。有时, 可能脆弱得一句话就泪流满面, 有时, 也发现自己咬着牙走了很长的路。 



\section{Contents}

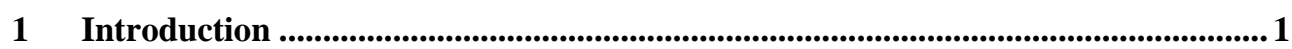

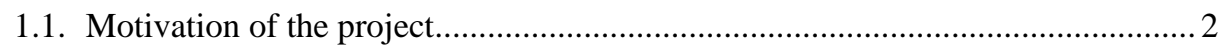

1.2. Introduction to atomic layer deposition ................................................................ 3

1.3. From thermal to radical enhanced ALD............................................................. 3

1.4. Application of HWALD in tungsten deposition ................................................... 5

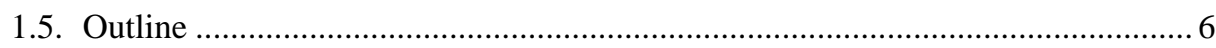

2 HWALD reactors: design and supply of atomic hydrogen .....................................11

2.1. Thin film deposition facilities ........................................................................ 12

2.1.1. Cold-wall reactor .................................................................................. 13

2.1.2. Hot-wall reactor ……………………………………............................. 14

2.2. Hot-wire temperature calibration ...................................................................... 15

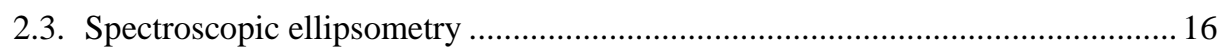

2.3.1. Optical model used for SE .................................................................. 17

2.3.2. Thickness verification ............................................................................... 18

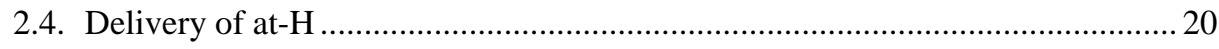

2.4.1. Te etching by at-H pulses in the cold-wall reactor .................................... 21

2.4.2. Factors influencing on Te etch rate .......................................................... 23

2.4.3. Back-stream diffusion ................................................................................. 24

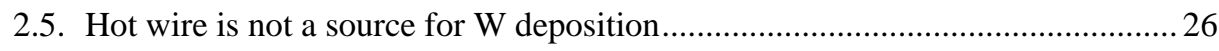

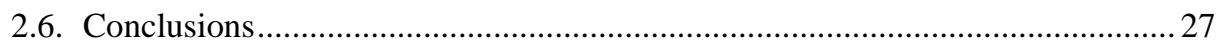

3 High resistivity $\beta$-phase HWALD W grown in a cold-wall reactor ......................... 29

3.1. Introduction .................................................................................................... 30

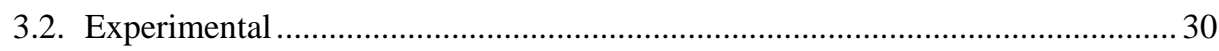

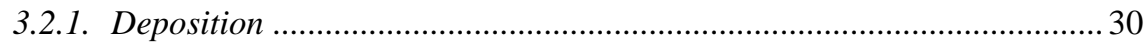

3.2.2. Film characterization ........................................................................... 31

3.3. In-situ study of the interplay between CVD, etching and ALD modes................. 32

3.3.1. The existence of CVD and etching modes................................................. 32 
3.3.2. Etching mode of deposited $W$ films......................................................... 36

3.3.3. Optimization towards the dominant HWALD process .............................. 39

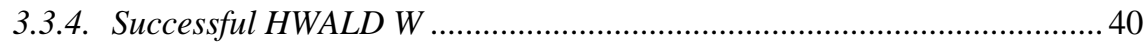

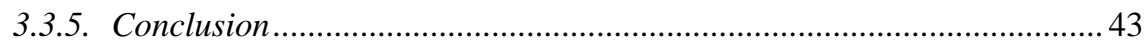

3.4. A Comparison of Tungsten Films Grown by CVD and HWALD ...................... 43

3.4.1. Deposition of tungsten by three methods ............................................. 43

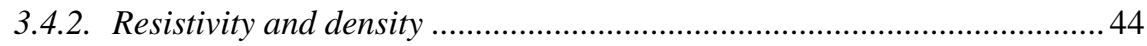

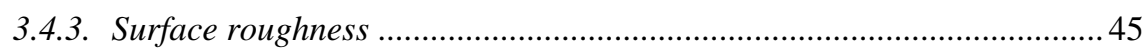

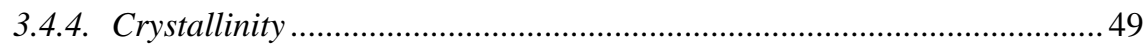

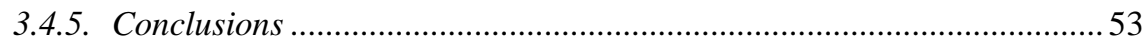

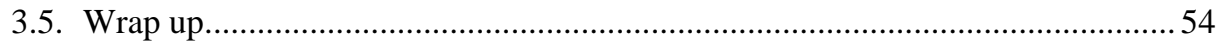

4 Low-resistivity $\alpha$-phase HWALD W grown in a hot-wall reactor........................57

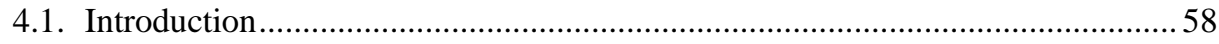

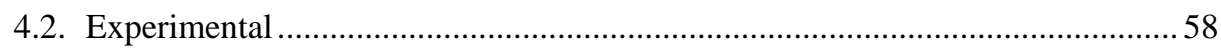

4.2.1. Deposition of HWALD tungsten films................................................... 58

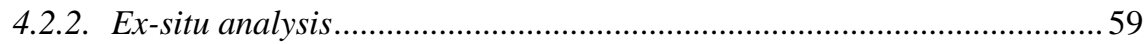

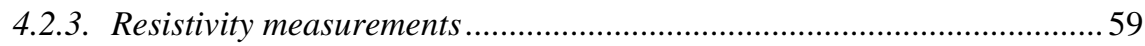

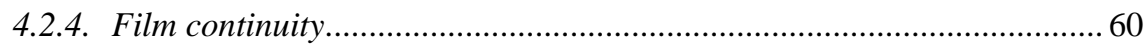

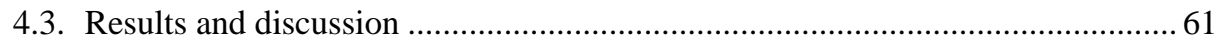

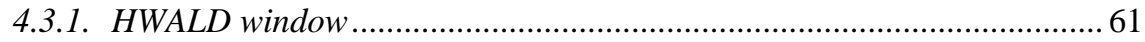

4.3.2. Surface roughness and film composition ..............................................65

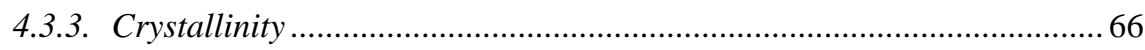

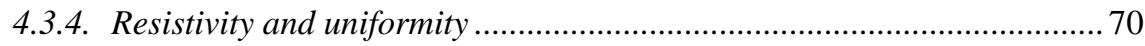

4.3.5. Step coverage on HAR substrates....................................................... 73

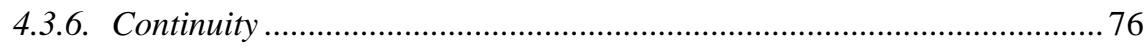

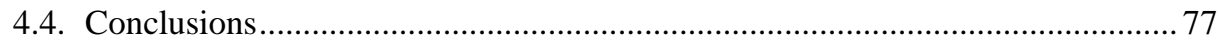

5 Effects of oxygen, nitrogen and fluorine on the formation of $\alpha$ - and $\beta$-phase $W$ by HWALD..................................................................................................................... 81

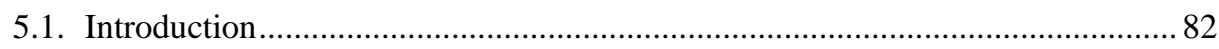


5.2. Methodology to study the influence of additional gases ................................... 82

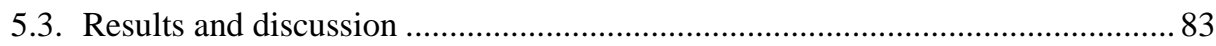

5.3.1. Influence of $\mathrm{N}_{2} \mathrm{O}$ and $\mathrm{O}_{2}$ on the HWALD W process .............................83

5.3.2. Influence of $\mathrm{H}_{2} \mathrm{O}$ vapor on the HWALD W process ................................ 87

5.3.3. Growth recovery after oxidation and its termination by nitrogen-

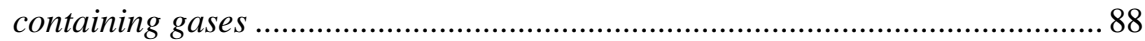

5.3.4. Influence of $W_{6}$ overdose on the HWALD W process........................... 91

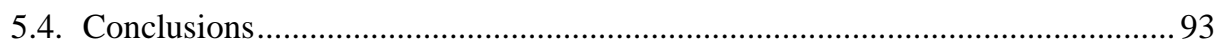

6 Inherently area-selective HWALD of W films on metal/insulator substrates ...... 95

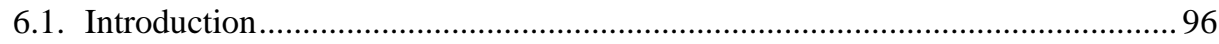

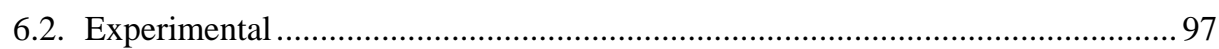

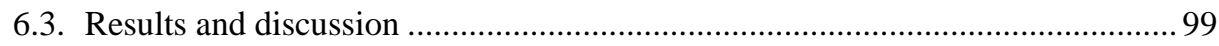

6.3.1. Nucleation of HWALD W on substrates of various materials ................ 99

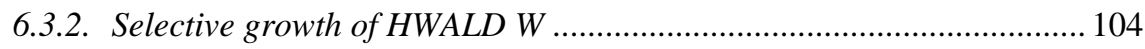

6.3.3. Nucleation of HWALD W on a-Si seed layer of various thicknesses ..... 108

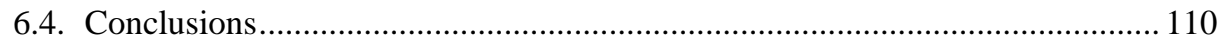

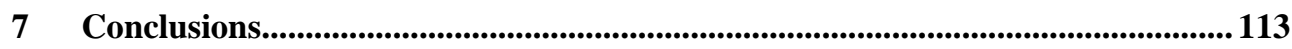

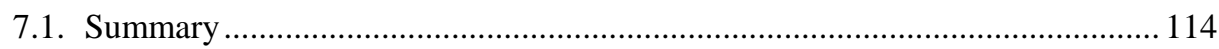

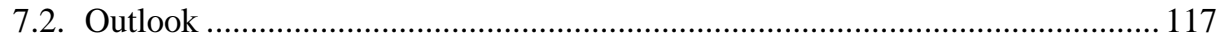

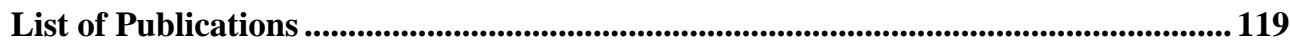

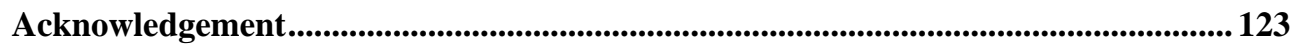





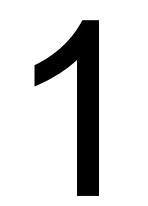

\section{Introduction}




\subsection{Motivation of the project}

Currently, shrinking dimensions of modern ultra-large-scale integration (ULSI) pose stringent demands on the control of film conformity, uniformity and thickness. Moreover, the increasingly complex structures require a uniform step coverage when fabricating nano-scale features in high-aspect-ratio and even threedimensional (3D) structures. In this light, conventional physical vapour deposition (PVD) and chemical vapour deposition (CVD) have their limitations because of their poor step coverage and insufficient control of thickness ${ }^{[1,2]}$.

In this project, metallic layers (films) are our focused materials because they play a crucial role as electrodes and interconnects in integrated circuits such as microprocessors, dynamic random-access memories, flash memories, and image sensors. Commonly applied metals include aluminum (Al), copper (Cu), titanium (Ti) and tungsten (W). Pure-metallic films are traditionally deposited by PVD, i.e. sputtering or evaporation, or by $C V D^{[2-4]}$. However, as mentioned above, memories and logic ULSIs having a three-dimensional structure are shrinking. For example, the half pitch of the $\mathrm{Cu}$ interconnects used in ULSIs, fabricated by through-siliconvia technology, are expected to be reduced to $15 \mathrm{~nm}^{[5]}$. Fin Field Effect Transistors are commonly selected for high performance and low power consumption circuits ${ }^{[6]}$. These technologies require a novel technique of metal deposition to achieve downscaled metal layers of high-aspect-ratios and even 3D features.

To this purpose, atomic layer deposition (ALD) has emerged as an important technique for depositing ultra-thin metal films. The most prominent advantage of ALD over other deposition techniques is its self-limiting reaction mechanism, the main feature of ALD, leading to an accurate thickness control and high film uniformity on arbitrarily shaped and patterned surfaces ${ }^{[7]}$. The combination of these two features is demanded for e.g. future $3 \mathrm{D}$ integration. A reduced processing temperature, natural to ALD, additionally allows the manufacturing of devices by post-processing of electronic chips. 


\subsection{Introduction to atomic layer deposition}

ALD is a technique suitable for manufacturing inorganic material layers with thickness down to a fraction of one monolayer. It is based on a sequential use of self-limiting gas-solid reactions ${ }^{[8]}$. During deposition, two reactive gases $A$ and $B$, also known as precursors, are introduced sequentially to the reactor in order to react at the substrate surface. The duration of gas introduction is normally short in the form of a pulse. Different from CVD, a reactor purge in between precursor pulses avoids the mixture of the reactants in the gas phase. Thus a standard ALD cycle can be expressed as (a) precursor A/ (b) purge/ (c) precursor B/ (d) purge. Normally, in (a) and (c) the two precursors must have self-limiting reactions on the surface, meaning the precursor can neither react nor adsorb on a surface where this surface is already covered by this precursor. In this manner, saturation will occur when introducing one precursor superfluously. Furthermore, purges in (b) and (d) need to be long enough to ensure a sufficient removal of residual precursors. As a result, each reaction cycle adds a given amount of material to the surface, referred to as the growth per cycle (GPC). To grow a desired layer thickness, the ALD cycle is repeated.

An ALD window is defined as the region where an ALD process fulfills the criterion of self-limiting reactions ${ }^{[8]}$. This window can be achieved in a certain range of experimental conditions, within which the GPC is constant (for example a substrate-temperature window). With this constant GPC, a film will have a linear growth by repeated ALD cycles. Hence, finding the window is crucial in studies of ALD.

\subsection{From thermal to radical enhanced ALD}

ALD was conventionally developed to deposit two-element materials such as oxides or nitrides. Single-element films of metals and semiconductors, with a few exceptions, are however difficult to deposit using thermal-only ALD processes ${ }^{[7]}$. A solution in this case is called radical-enhanced ALD (REALD) ${ }^{[1]}$, which normally utilizes a variety of energy-enhancement methods to generate chemically-reactive 
species (radicals). REALD is used to enable deposition of films at much lower substrate temperatures $\left(T_{s}\right)$ than thermal ALD. For example, radical-enhanced aluminum oxide $\left(\mathrm{Al}_{2} \mathrm{O}_{3}\right)$ ALD can be performed using TMA and $O$ radicals at a $T_{s}$ as low as room temperature ${ }^{[9]}$. The most common REALD variety is plasma-enhanced ALD (PEALD). Hydrogen- or nitrogen-based plasmas have been used to deposit tantalum (Ta), titanium $(\mathrm{Ti})$, ruthenium $(\mathrm{Ru})$, silicon $(\mathrm{Si})$ and germanium $(\mathrm{Ge})^{[7]}, \mathrm{Al}^{[10]}$ as well as aluminum nitride $(\mathrm{AIN})^{[11]}$ and gallium nitride $(\mathrm{GaN})^{[12]}$. With PEALD, platinum $(\mathrm{Pt})$ can be grown by oxygen $\left(\mathrm{O}_{2}\right)$ plasma ${ }^{[13]}, \mathrm{Ru}^{[14,15]}$ and cobalt $(\mathrm{Co})$ by ammonia $\left(\mathrm{NH}_{3}\right)$ plasma ${ }^{[16]}$, and $\mathrm{Al}^{[10]}$ and $\mathrm{Cu}^{[17]}$ by hydrogen $\left(\mathrm{H}_{2}\right)$ plasma.

However, some limitations make PEALD less attractive. The first is a reduced step coverage compared to thermal ALD, caused by radical recombination away from the plasma. For example, the recombination of hydrogen radicals on the walls of trenches attenuates the hydrogen radical flux in the downward direction, resulting in a non-uniform Ta film formed in trenches with an aspect ratio of 40:1 ${ }^{[18,19]}$. The second limitation is that plasmas cause damage to the wafer under treatment, in particular to metal-oxide-semiconductor (MOS) transistors. A common solution is to employ a remote plasma, by increasing distance between the plasma source and the substrate. This, however, will increase the reactor volume leading to long ALD cycle times. As the distance increases, radical recombination can further occur during their delivery to the wafer surface. Additionally, a plethora of radicals is typically created in even simple one- or two-gas plasmas, enabling numerous chemical reactions besides the desired one. Not all the reactions lead to the formation of high-quality films; certain plasma compounds can deteriorate film quality. As a result, the wafer surface is exposed to various ions, radicals and atoms, as well as ultra-violet (UV) photons ${ }^{[20]}$. This makes the composition and structure of the growing film hard to predict and control.

Apart from plasma, there are several other methods to generate radicals. There are reports about radicals created by means of a supersonic jet ${ }^{[21-23]}$. Moreover, some molecules, such as methane $\left(\mathrm{CH}_{4}\right), \mathrm{NH}_{3}$ and $\mathrm{H}_{2}$, have been found to dissociate on surfaces of transition metals ${ }^{[24-27]}$. More promisingly, the hot-wire CVD (HWCVD) has been well established using a heated metal filament, also called hot wire (HW), to dissociate molecules ${ }^{[28,29]}$. Also, this technique has been successfully applied to 4 
deposit various materials including poly- $\mathrm{Si}^{[30]}, \mathrm{Si}_{3} \mathrm{~N}_{4}{ }^{[31]}$ and metal oxides ${ }^{[32,33]}$.

Enlightened by HWCVD, in this work, we propose to utilize hot wire for generating radicals for REALD processes, instead of using a plasma. In view of catalytic activities of metals, there are many potential candidates to realize hot wires, such as $\mathrm{Pt}^{[34]}$, nickel $(\mathrm{Ni})^{[35]}$ and $\mathrm{W}^{[36]}$. In this study, tungsten (W) filament became our choice due to its long durability and low cost.

It is well-established that radicals can form upon catalytic dissociation of certain gas molecules on a hot $\mathrm{W}$ filament ${ }^{[37-40]}$. For instance, molecular hydrogen $\left(\mathrm{H}_{2}\right)^{[41-43]}$ and $\mathrm{NH}_{3}{ }^{[44]}$ can effectively decompose on a $\mathrm{W}$ filament heated up to 1500 $2000^{\circ} \mathrm{C}$. By replacing plasma by a hot wire, we aim to avoid substrate damage, limit the number of radicals formed in gas phase and thereby achieve a better control of the reactant supply. The hot-wire assisted ALD (HWALD) is a novel technique explored in only a few publications so far. The available works on HWALD concern Co and $\mathrm{Co}(\mathrm{W})$ films ${ }^{[45,46]}$, where $\mathrm{NH}_{3}$ dissociated upon a hot wire is used as a reducing agent to form these metals. Kostis et al. ${ }^{[47]}$ introduced oxygen gas to oxidize hot tungsten filament and form volatile tungsten oxides (WOx). The oxides were further transported to the substrate, resulting in $\mathrm{WO}_{x}$ deposition. Ni was reported to be deposited by cracking $\mathrm{NH}_{3}$ on a hot wire ${ }^{[48,49]}$. In this work, we aim to propose and establish a HWALD process for deposition of tungsten films.

\subsection{Application of HWALD in tungsten deposition}

In today's metallization schemes, W vias are widely used to provide interlevel contacts between metal layers due to tungsten's inertness to many chemicals, compatibility with silicon technology and low electrical resistivity ${ }^{[50,51]}$. Tungsten can conventionally be deposited by chemical vapor deposition (CVD) or by sputtering ${ }^{[52,53]}$. To meet the requirements of recent ULSI, ALD is rapidly strengthening its position as a method suitable for industrial use ${ }^{[54]}$.

Successful ALD of $\mathrm{W}$ has been reported by using tungsten hexafluoride $\left(\mathrm{WF}_{6}\right)$ and different reductants, for example, disilane ${ }^{[55-58]}$, silane ${ }^{[59,60]}$ and $\mathrm{B}_{2} \mathrm{H}_{6}{ }^{[0,61]}$. 
The reductants form an intermediate sacrificial layer (i.e. Si or boron (B), respectively), which can be turned into $W$ while reacting with $W_{6}$. However, deposition of Si or B in those cases is hardly limited to one-monolayer formation, thereby diminishing the self-limiting nature of ALD. It may additionally leave $\mathrm{Si}, \mathrm{B}$ and fluorine $(F)$ impurities inside the films, resulting in a higher-resistivity $W^{[61]}$.

In this project, we focus on the deposition of tungsten films by HWALD using sequential pulses of $\mathrm{WF}_{6}$ gas and atomic hydrogen $(\mathrm{at}-\mathrm{H})$. The latter is generated by dissociation of $\mathrm{H}_{2}$ on a hot wire, as described in the previous section. It is known from the literature that the dissociation probability of $\mathrm{H}_{2}$ rises with increasing hot-wire temperature, and can reach a maximum at around $2700{ }^{\circ} \mathrm{C}^{[62]}$. Importantly, the hot wire $(\mathrm{HW})$ itself is not a source of tungsten: the $\mathrm{W}$ vapor pressure is rather low at temperatures below $2000{ }^{\circ} \mathrm{C}^{[63]}$. Therefore the filament is not an efficient source of W. This will be further discussed in section 2.5 of Chapter 2. In the HWALD of W, at- $\mathrm{H}$ acts as a reductant to remove fluorine (F) termination of the growing film by forming HF gas, leaving pure W surface. This work explores HWALD W in view of its potential use in backend-of-line processing of future ULSI circuits.

\subsection{Outline}

In this thesis, we demonstrate the novel HWALD technique and successful realization of tungsten $(\mathrm{W})$ films of supreme properties by this technique. In Chapter 2, two deposition reactors are described. The spectroscopic ellipsometry (SE) used to in-situ monitor the film growth and the optical models for grown layers are explained. In addition, the delivery of at- $\mathrm{H}$ to the substrate is confirmed by tellurium (Te) etching experiments. In Chapter 3, results of HWALD W formed in the cold-wall reactor are presented. In that reactor, apart from HWALD, the co-existent parasitic CVD and etching of the grown films were also found and the interplay among them depended on experimental conditions. After optimizing the HWALD process by suppressing CVD and etching, high-purity $\mathrm{W}$ films were successfully formed. However, the deposited $W$ films were grown in $\beta$-phase, possessing a higher resistivity compared to $\alpha$-phase. 
In order to obtain low-resistivity W, we started to utilize the hot-wall reactor. The results are demonstrated in Chapter 4. W grown in a-phase has been successfully obtained in the hot-wall reactor. The resistivity of this $W$ is as low as $15 \mu \Omega \cdot \mathrm{cm}$. Moreover, the HWALD W can be deposited in trenches with an aspect ratio as high as 36 . To investigate factors leading to the preferential formation of either $\alpha$ - or $\beta$-phase, some additional reactive gases were introduced during the HWALD process, as described in Chapter 5. It has been found that oxidants such as $\mathrm{N}_{2} \mathrm{O}, \mathrm{O}_{2}$ and water $\left(\mathrm{H}_{2} \mathrm{O}\right)$ vapor have profound effects on GPC, probably due to surface oxidation. However, the oxidized $\mathrm{W}$ could still be reduced by at- $\mathrm{H}$, continuing the HWALD process and leaving the HWALD W of high purity and in the a-phase form. In opposite, nitrogen-containing gases, i.e., $\mathrm{N}_{2} \mathrm{O}$ and $\mathrm{NH}_{3}$, effectively terminated the growth of HWALD W. Apart from the oxidants and nitrogen-containing gases, the surplus of fluorine-containing gas appeared to be a crucial factor leading to the formation of $\beta$-phase $W$ instead of $\alpha$-phase.

In Chapter 6, we characterize and compare the nucleation and growth of HWALD W films on various substrates. As a result, an inherently area-selective HWALD W process was achieved on $\mathrm{W} / \mathrm{SiO}_{2}$ and $\mathrm{Co} / \mathrm{SiO}_{2}$ patterned surfaces. Furthermore, ultra-thin a-Si seed layers were explored in order to start HWALD of W on surfaces showing inhibited nucleation. Applying an a-Si seed layer far below $1 \mathrm{~nm}$ in thickness appeared to be sufficient to support the effective nucleation, enabling standard GPC with little to no incubation time.

\section{References}

[1] H. Kim, J. Vac. Sci. Technol. B 21, 2231 (2003).

[2] T. T. Kodas and M. J. Hampden-Smith, The chemistry of metal CVD (Wiley-VCH Verlag GmbH, Weinheim, 1994).

[3] J. D. Plummer, M. D. Deal and P. B. Griffin, Silicon VLSI technology: fundamentals, practice, and modeling (Prentice Hall, Upper Saddle River, 2000).

[4] W. Kern and J. L. Vossen, Thin film processes II, Vol. 2 (Academic Press, San Diego, 2012).

[5] H. Shimizu, K. Sakoda, T. Momose, M. Koshi and Y. Shimogaki, J. Vac. Sci. Technol. A 30, 01A144 (2012). 
[6] The International Technology Roadmap for Semiconductor, 2015 Update http://www.itrs2.net/itrs-reports.html.

[7] S. M. George, Chem. Rev. 110, 111 (2010).

[8] R. L. Puurunen, J. Appl. Phys. 97, 9 (2005).

[9] S. Heil, P. Kudlacek, E. Langereis, R. Engeln, M. van de Sanden and W. Kessels, Appl. Phys. Lett. 89, 131505 (2006).

[10] Y. J. Lee and S. W. Kang, Electrochem. Solid St. Lett. 5, C91 (2002).

[11] Y. J. Lee and S. W. Kang, Thin Solid Films 446, 227 (2004).

[12] C. Ozgit, I. Donmez, M. Alevli and N. Biyikli, J. Vac. Sci. Technol. A 30, 01A124 (2012).

[13] D. Longrie, K. Devloo-Casier, D. Deduytsche, S. van den Berghe, K. Driesen and C. Detavernier, J. Solid State Sci. Technol. 1, Q123 (2012).

[14] O.-K. Kwon, S.-H. Kwon, H.-S. Park and S.-W. Kang, J. Electrochem. Soc. 151, C753 (2004).

[15] O.-K. Kwon, S.-H. Kwon, H.-S. Park and S.-W. Kang, Electrochem. Solid St. Lett. 7, C46 (2004).

[16] H. Kim, Electrochem. Solid St. Lett. 9, G323 (2006).

[17] J. Mao, E. Eisenbraun, V. Omarjee, A. Korolev, C. Lansalot and C.

Dussarrat, ECS Trans. 33, 125 (2010).

[18] R. Grubbs and S. George, J. Vac. Sci. Technol. A 24, 486 (2006).

[19] H. Kim, C. Cabral Jr, C. Lavoie and S. Rossnagel, J. Vac. Sci. Technol. B 20, 1321 (2002).

[20] V. V. Afanas`ev, J. M. M. de Nijs and P. Balk, J. Appl. Phys. 78, 6481 (1995).

[21] P. Misra, X. Zhu, C.-Y. Hsueh and J. B. Halpern, Chem. Phys. 178, 377 (1993).

[22] H. Fu, Y. Hu and E. Bernstein, J. Chem. Phys. 125, 014310 (2006).

[23] D. W. Kohn, H. Clauberg and P. Chen, Rev. Sci. Instrum. 63, 4003 (1992).

[24] G. Papapolymerou and V. Bontozoglou, J. Mol. Catal. A: Chem. 120, 165 (1997).

[25] J. Harris and S. Andersson, Phys. Rev. Lett. 55, 1583 (1985).

[26] J. Harris, J. Simon, A. Luntz, C. Mullins and C. Rettner, Phys. Rev. Lett. 67, 652 (1991).

[27] M.-S. Liao and Q.-E. Zhang, J. Mol. Catal. A: Chem. 136, 185 (1998).

[28] H. Matsumura, H. Umemoto and A. Masuda, J. Non-Cryst. Solids 338, 19 (2004).

[29] R. Schropp, Thin Solid Films 395, 17 (2001).

[30] J. Rath, H. Meiling and R. Schropp, Sol. Energy Mater. Sol. Cells 48, 269 (1997).

[31] P. Alpuim, L. Gonçalves, E. S. Marins, T. Viseu, S. Ferdov and J. Bourée, Thin Solid Films 517, 3503 (2009).

[32] S. Mitra, K. Sridharan, J. Unnam and K. Ghosh, Thin Solid Films 516, 798 (2008).

[33] C. M. White, D. T. Gillaspie, E. Whitney, S.-H. Lee and A. C. Dillon, Thin Solid Films 517, 3596 (2009).

[34] R. E. Schropp, Thin Solid Films 451, 455 (2004). 
[35] J. Thangala, S. Vaddiraju, R. Bogale, R. Thurman, T. Powers, B. Deb and M. K. Sunkara, Small 3, 890 (2007).

[36] J. K. Holt, M. Swiatek, D. G. Goodwin and H. A. Atwater, J. Appl. Phys. 92, 4803 (2002).

[37] A. H. Mahan, A. C. Dillon, L. M. Gedvilas, D. L. Williamson and J. D. Perkins, J. Appl. Phys. 94, 2360 (2003).

[38] A. H. Mahan, J. Carapella, B. P. Nelson, R. S. Crandall and I. Balberg, J. Appl. Phys. 69, 6728 (1991).

[39] R. Toukabri, N. Alkadhi and Y. Shi, J. Phys. Chem. A 117, 7697 (2013).

[40] Y. Shi, Acc. Chem. Res. 48, 163 (2015).

[41] I. Langmuir, J. Am. Chem. Soc. 34, 860 (1912).

[42] I. Langmuir and G. M. J. Mackay, J. Am. Chem. Soc. 36, 1708 (1914).

[43] I. Langmuir, J. Am. Chem. Soc. 37, 417 (1915).

[44] H. Matsumura and H. Tachibana, Appl. Phys. Lett. 47, 833 (1985).

[45] H. Shimizu, K. Sakoda, T. Momose and Y. Shimogaki, Japanese Journal of Applied Physics 51, 05EB02 (2012).

[46] H. Shimizu, K. Sakoda, T. Momose, M. Koshi and Y. Shimogaki, Journal of Vacuum Science \& Technology A 30, 01A144 (2012).

[47] I. Kostis, M. Vasilopoulou, G. Papadimitropoulos, N. Stathopoulos, S.

Savaidis and D. Davazoglou, Surface and Coatings Technology 230, 51 (2013).

[48] G. Yuan, H. Shimizu, T. Momose and Y. Shimogaki, J. Vac. Sci. Technol. A 32, 01A104 (2014).

[49] G. Yuan, H. Shimizu, T. Momose and Y. Shimogaki, Microelectron. Eng. 120, 230 (2014).

[50] E. Lassner and W.-D. Schubert, Tungsten: Properties, chemistry, thechnology of the element, alloys, and chemical compounds (Kluwer Academic/ Plenum Publishers, New York, 1999).

[51] E. Lassner and W. D. Schubert, Tungsten: Properties, Chemistry, Technology of the Elements, Alloys, and Chemical Compounds (Springer Science \& Business Media, New York, 1999).

[52] C. H. Ting and M. Paunovic, J. Electrochem. Soc. 136, 456 (1989).

[53] S. Rossnagel, I. Noyan and C. Cabral Jr, J. Vac. Sci. Technol. B 20, 2047 (2002).

[54] M. Leskelä and M. Ritala, Thin Solid Films 409, 138 (2002).

[55] J. Klaus, S. Ferro and S. George, Thin Solid Films 360, 145 (2000).

[56] J. Elam, C. Nelson, R. Grubbs and S. George, Surf. Sci. 479, 121 (2001).

[57] J. Elam, C. Nelson, R. Grubbs and S. George, Thin Solid Films 386, 41 (2001).

[58] S. A. Van Norman, J. W. Tringe, J. D. Sain, R. Yang, J. L. Falconer and A. W. Weimer, Appl. Phys. Lett. 106, 153102 (2015).

[59] B. Kalanyan, M. D. Losego, C. J. Oldham and G. N. Parsons, Chem. Vap. Deposition 19, 161 (2013).

[60] G. Wang, Q. Xu, T. Yang, J. Xiang, J. Xu, J. Gao, C. Li, J. Li, J. Yan and D. Chen, ECS J. Solid State Sci. Technol. 3, P82 (2014).

[61] S.-H. Kim, N. Kwak, J. Kim and H. Sohn, J. Electrochem. Soc. 153, G887 (2006). 
[62] J. N. Smith Jr. and W. L. Fite, J. Chem. Phys 37, 898 (1962).

[63] R. Szwarc, E. Plante and J. Diamond, NBS J. Res. Phys. Chem. 69, 417 (1965). 


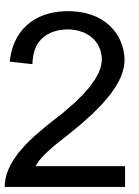

\title{
HWALD reactors: design and supply of atomic hydrogen
}

\begin{abstract}
.
This chapter descibes the hot- and cold-wall reactors used in the experiments to deposit HWALD W films. Basic characteristics of both reactors are given. We also present the optical model for spectroscopic ellipsometry to extract thickness, resistivity and optical properties of $\mathrm{W}$ films, along with the thicknesses verification by other techniques. Further, the existence of at- $\mathrm{H}$ and its delivery to the substrate in both reactors are demonstrated: we provide results of telllurium (Te) etching experiments by at- $\mathrm{H}$ pulses in the cold-wall reactor. Finally, the influence of several experimental parameters on the etch rate of $\mathrm{Te}$ is investigated for optimization of the HWALD process.
\end{abstract}




\subsection{Thin film deposition facilities}

Two differently designed HWALD reactors have been utilized in the experiments: a big-volume cold-wall reactor and a small-volume hot-wall reactor. The reactors were connected to the home-built cluster system, sharing the gas network ${ }^{[1]}$ and the loadlock with a base pressure of $10^{-7}$ mbar. The loadlock enabled wafer transfer without vacuum break, ensuring no interface deterioration. The reactors were equipped with a spectroscopic ellipsometer (SE), Woollam M-2000 of J. A. Woollam Co., Inc., combined with CompleteEASE ${ }^{\circledR}$ software. A hot wire, implementing resistive heating of a pure tungsten (W) filament, was installed using the special assembly. To bear in mind (see Section 1.4), the hot wire itself was not acting as a source of tungsten.

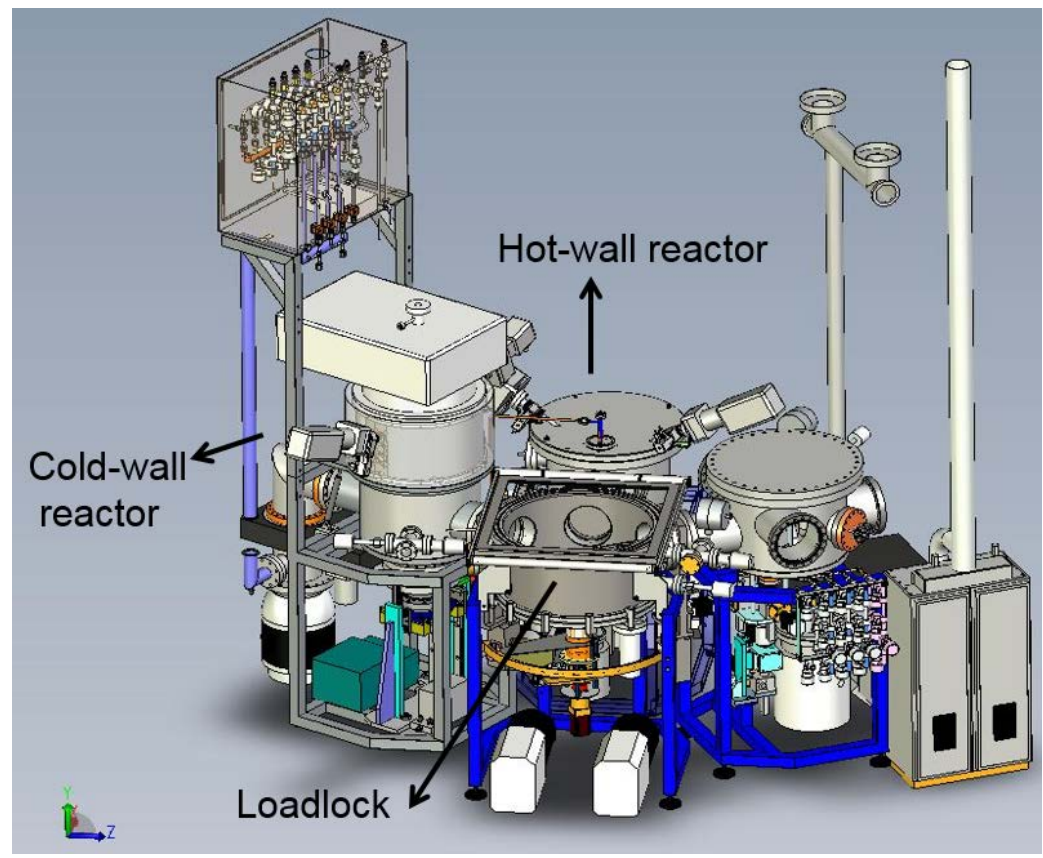

Figure 2.1. A schematic view of the cluster system. Both reactors used in this thesis are connected to the same loadlock. 


\subsubsection{Cold-wall reactor}

A schematic cross-section of the cold-wall HWALD reactor is shown in Fig. 2.2. Molecular hydrogen $\left(\mathrm{H}_{2}\right)$ carried by argon gas $(\mathrm{Ar})$ was introduced into the chamber via the hot-wire port (top). The distance between the at-H outlet and the substrate is approximately $70 \mathrm{~cm}$. WF 6 is supplied through the gas ring, situated around 10 centimeters above the substrate. The volume of this reactor is approximately 70 liters. The advantage of this design, despite a long diffusion distance required, was that the wafer could be protected from the hot-wire radiation. This reactor could be evacuated to a base pressure of $10^{-7} \mathrm{mbar}$ by a turbomolecular pump. The maximum temperature of the substrate holder was $400{ }^{\circ} \mathrm{C}$. High-speed ALD valves were used, with a time resolution of $0.1 \mathrm{~s}$.

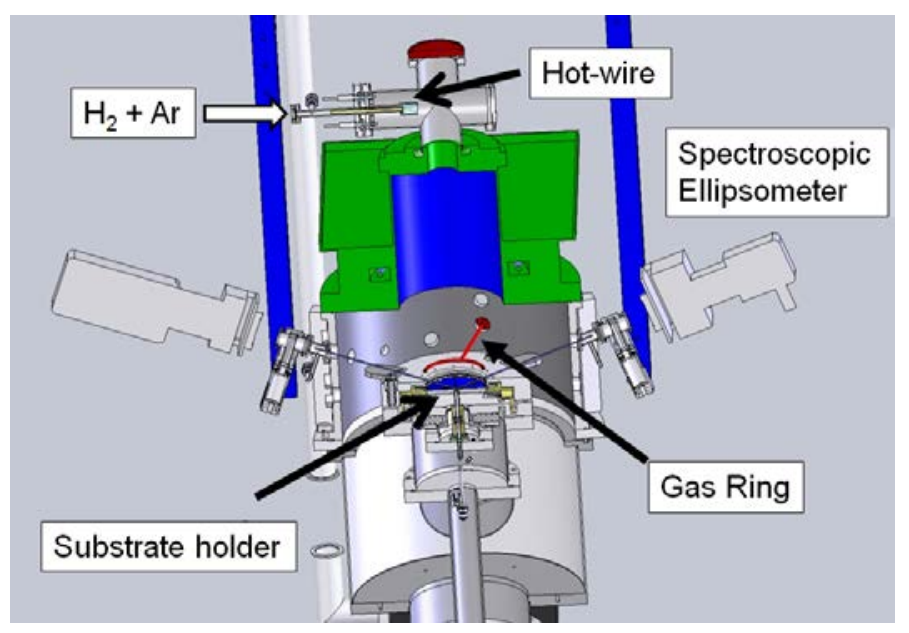

Figure 2.2. A schematic cross-sectional view of the cold-wall HWALD reactor. The spectroscopic ellipsometer is installed at a fixed angle of $73^{\circ}$. 


\subsubsection{Hot-wall reactor}

The home-built hot-wall reactor ${ }^{[1,2]}$ used for all depositions is schematically shown in Fig. 2.3. This 24-ml hot-wall inner reactor is placed inside a big (several liters) cold-wall outer reactor. In opposite to the cold-wall version, walls of the inner reactor are heated to reduce gas adsorption on them. The hot wire is installed on the side (see "hot wire" in Fig. 2.3), 2-3 cm away from the wafer. Importantly, there is no direct line-of-sight between the hot wire and the substrate. The second precursor $\left(\mathrm{WF}_{6}\right)$ is supplied via the lateral gas inlets distributed around the substrate. This reactor can be evacuated to a base pressure of $10^{-7} \mathrm{mbar}$ by a turbomolecular pump. The maximum temperature of the substrate holder can be as high as $400{ }^{\circ} \mathrm{C}$.

Different from its cold-wall counterpart, this hot-wall reactor is not equipped with ALD valves. Instead, there are by-pass lines to evacuate reactive gas when the valve in between the precursor sources and the reactor is closed. Therefore, a constant flow rate of precursors can be maintained during experiments. The opening and closing times of all the valves are programmable with a resolution of $0.1 \mathrm{~s}$.

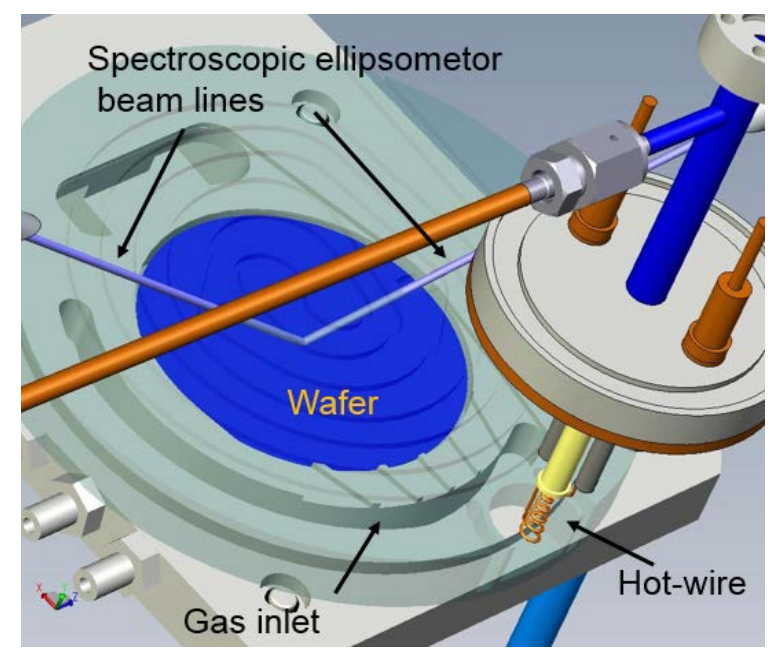

Figure 2.3. Schematic drawing of the inner hot-wall reactor. 


\subsection{Hot-wire temperature calibration}

In our experiment, the hot-wire radiative temperature was controlled by applying a voltage across it. The hot-wire temperature at around $1500{ }^{\circ} \mathrm{C}$ was first measured by a pyrometer assuming the same emissivity of $\mathrm{W}$ of the hot wire and $\mathrm{W}$ of the pyrometer filament. This point at $1500^{\circ} \mathrm{C}$ was further used for the temperature calibration. Fig. 2.4 (a) shows the hot-wire temperature as a function of applied power. The other points besides $1500^{\circ} \mathrm{C}$ in this figure were obtained on basis of the known hot-wire geometry and temperature coefficient of resistance (TCR) of tungsten ${ }^{[3]}$, where the hot-wire resistance was measured at each applied voltage and current. The film deposition experiments were conducted in the power range of 138 to $336 \mathrm{~W}$, corresponding to the temperature range of 1500 to $1950^{\circ} \mathrm{C}$. Fig. 2.4 (b) presents two $I-V$ curves measured for the hot wire on two different days. The good overlapping verifies a stable performance of this hot wire and indicates the reproducibility of the same hot-wire temperature when applying the same voltage. It is noteworthy that the hot wire exhibited a good stability and reproducibility of the calibration curve after hundreds of hours operation.

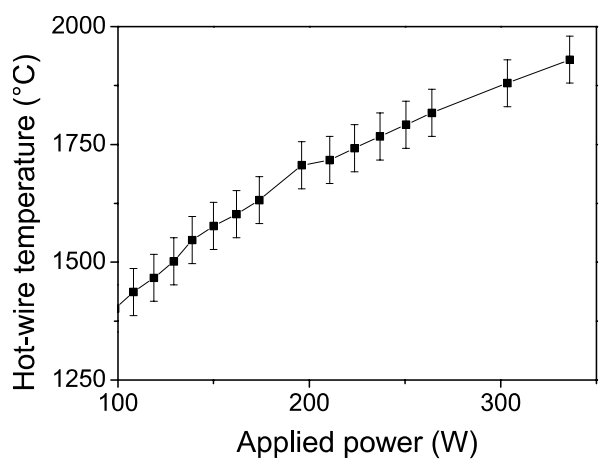

(a)

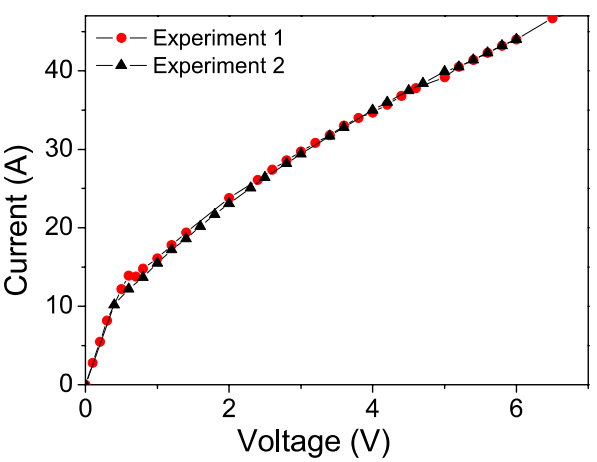

(b)

Figure 2.4. (a) A curve presenting the relationship between hot-wire temperature (extracted from the resistance/TCR values while calibrating one point at $1500{ }^{\circ} \mathrm{C}$ ) and applied power. (b) Stability of the tungsten filament confirmed by the two overlapping curves on two different days. 


\subsection{Spectroscopic ellipsometry}

Spectroscopic ellipsometry (SE) is a non-destructive optical technique that has been widely used for studying various deposition and etching processes ${ }^{[4-6]}$. It measures a change in polarization as light reflects from the wafer surface after passing through the film(s). The polarization change is represented as an amplitude ratio, i.e. Psi $(\Psi)$, and the phase difference, i.e. Delta $(\Delta)$. Based on the polarization change, the complex dielectric function of the film(s) can be extracted, providing wavelength-dependent values of the refractive index $(n)$ and the extinction coefficient $(k)$. The measured polarization change depends on the optical properties and the thicknesses of individual materials present on the wafer. Thus, ellipsometry is primarily used to determine film thickness and optical constants. However, it can be also applied to characterize many other properties of measured materials, such as crystallinity, see Fig. 4.7, or resistivity, see Fig. 4.11 in Chapter 4. Moreover, the substrate temperature $\left(T_{s}\right)$ could be measured by SE using the known temperature dependence of optical constants of certain materials, such as a Si (100) wafer. Fig. 2.5 compares the readings of $T_{s}$ by a thermocouple and SE. All temperature values were recorded after the temperature became stable according to SE. It can be seen from Fig. 2.5 that there was a slight temperature difference of maximum $30^{\circ} \mathrm{C}$ between the two methods.

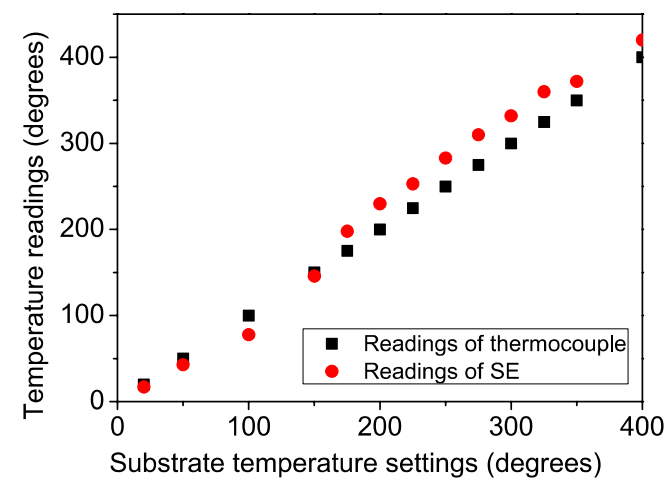

Figure 2.5. A comparison of the substrate temperature measured by a thermocouple and SE. 
In this thesis, we focus on thickness and electrical properties of W measured by SE. Electrical resistivity can be extracted from the dielectric functions by analyzing the Drude term ${ }^{[7,8]}$. The in-situ SE enables thickness monitoring in real time during deposition, thus providing a close eye to the process of ALD. It appears from both experiments and simulations that a W film thinner than $30 \mathrm{~nm}$ is sufficiently transparent for SE measurements.

All in-situ SE measurements shown in this thesis were obtained by using a Woollam M2000 spectroscopic ellipsometer, operating in a wavelength range between 245 and $1688 \mathrm{~nm}$ with a resolution of $1.6 \mathrm{~nm}$, in combination with CompleteEASE $^{\circledR}$ modeling software.The measurement data were acquired throughout the growth process every 2.5 seconds.

\subsubsection{Optical model used for SE}

The optical SE model, used to extract thickness and optical constants of W layers, is shown in Table 2.1. In this model, the required optical constants of the $\mathrm{Si}$ substrate, $\mathrm{SiO}_{2}$ and amorphous $\mathrm{Si}(\mathrm{a}-\mathrm{Si})$ were provided by the software database; the thicknesses were fitted by SE. The surface roughness was obtained by the Bruggeman effective medium approximation $(E M A)^{[8]}$, comprising $50 \%$ of voids and $50 \%$ of the corresponding material.

As the optical constants of thin HWALD W were unknown, its dielectric functions were parameterized by Drude-Lorentz mode ${ }^{[9]}$ with a number of fitting parameters. To be more specific, the dielectric functions were first constructed, assuming a number of Lorentz oscillators, and then fitted to optical properties obtained by SE. The $\mathrm{W}$ seed layers were modelled by introducing 6 Lorentz oscillators ${ }^{[10]}$. However, the dielectric functions of HWALD W layers consisted of only 2 Lorentz oscillators and one Drude term ${ }^{[9,11]}$. The Drude term describes the intraband absorption of conduction electrons whereas the interband transitions are characterized by Lorentz oscillators. The layer's conductivity can be extracted from 
Table 2.1 Layer stack, included in the optical SE model to extract thickness of the grown $\mathrm{W}$.

\begin{tabular}{ccc}
\hline \multicolumn{1}{c}{ Layer } & Material chosen in the model & Fitting parameters \\
\hline Roughness & Bruggeman EMA & Thickness \\
Capping layer & a-Si[ $^{[12]}$ & Thickness \\
ALD W layer & Parameterized & Thickness, parameters of Lorentz oscillators and \\
W seed layer & Parameterized & Thickness, parameters of Lorentz oscillators and \\
SiO & SiO $_{2}{ }^{[13]}$ & Drude term \\
Si substrate & Si substrate $^{[14]}$ & Thickness \\
\hline
\end{tabular}

the Drude term using the CompleteEase ${ }^{\circledR}$ software.

\subsubsection{Thickness verification}

To validate the model shown in Table 2.1, for selected samples the thickness of each layer measured by SE was verified by X-ray reflectometry (XRR) and highresolution scanning electron microscopy (HR-SEM).

Fig. 2.6 shows cross-sectional HR-SEM images of a HWALD tungsten sample with an a-Si capping layer of approximately $5 \mathrm{~nm}$. Thicknesses of the $\mathrm{W}$ seed layer and HWALD W layer are roughly $3 \mathrm{~nm}$ and $13 \mathrm{~nm}$ (by SE), respectively. Fig. 2.6 (a) presents the normal InLens image where the a-Si capping layer cannot be distinguished; the total thickness of all sub-layers (approx. $20 \mathrm{~nm}$ by SE) is in agreement with the value of $17 \mathrm{~nm}$ obtained by HR-SEM. The energy selective backscattered (ESB) image in Fig. 2.6 (b) exhibits a better contrast between the aSi and the $\mathrm{W}$ layer underneath, giving a total thickness of the two tungsten layers (bright-grey) of approx. $12 \mathrm{~nm}$. Furthermore, Fig. 2.6 (a) indicates a remarkable surface roughness (see further Section 3.4.3). Considering the roughness of a few $\mathrm{nm}$ and different measurement positions on the wafer for SE and HR-SEM, the thickness determined by SE is in good agreement with that measured by HR-SEM. 


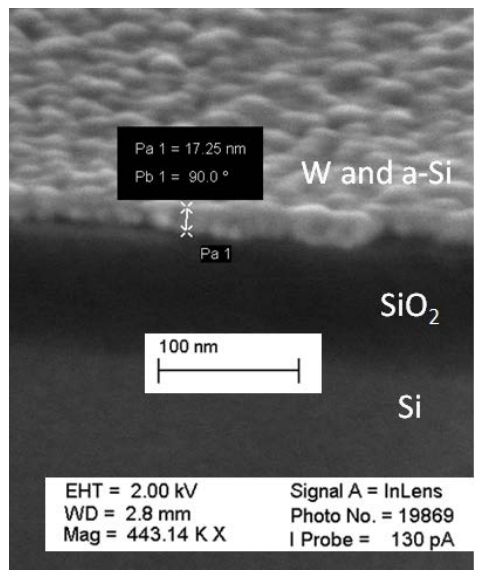

(a)

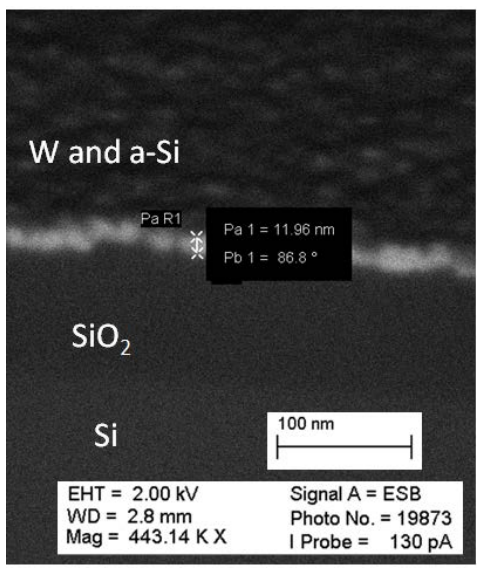

(b)

Figure 2.6. Cross-sectional HR-SEM images of a HWALD tungsten film. The tungsten layer is covered by an approximately $5 \mathrm{~nm}$ thick a-Si layer. Image (a) is the standard Inlens detection, showing the total thickness of all tungsten and a-Si sub-layers of approximately $17 \mathrm{~nm}$. Image (b) is the result of Energy Selective Backscattered detection, where approximately $12 \mathrm{~nm}$ thick W layers (bright-grey) can be visualized. $\mathrm{Pa}$ is the measured thickness (i.e. length of the $\uparrow$-line); $\mathrm{Pb}$ is the angle between the $\uparrow$-line and the substrate surface.

Table 2.2. A comparison of thicknesses measured by SE and XRR at the center of the wafer.

\begin{tabular}{ccc}
\hline \hline Sample & $\begin{array}{c}\text { Thickness by in-situ SE } \\
(\mathrm{nm})\end{array}$ & Thickness by XRR (nm) \\
\hline 1 & 10.2 & 9.7 \\
2 & 24.6 & 20.2 \\
3 & 13.9 & 11.2 \\
\hline \hline
\end{tabular}

Table 2.2 compares the SE and XRR thicknesses of three different samples. The thicknesses measured by XRR are on average $20 \%$ smaller than those obtained by SE. To note, the SE data are measured in the center of the wafer, sometimes without having a-Si capping layer on $\mathrm{W}$, whereas the XRR measurements were always done on the wafer with the capping layer, and on an area adjacent to the center of the wafer. Both differences may have caused the small discrepancy in thickness. We conclude from Table 2.2 Fig. 2.5 and Fig. 2.6 that thicknesses 
measured by SE, HIM, HR-SEM and XRR are in good agreement. This confirms the validity of SE for measuring $W$ films within their transparency range, i.e. up to $30 \mathrm{~nm}$.

Importantly, the sub-nanometer thickness changes such as shown for example in Fig. 6.1 of Chapter 6 fall beyond the measurement accuracy of SE. These changes are in other words hardly physical and are only shown to indicate no measurable variation of the thickness during the corresponding experiments. The larger but still few-nm thickness changes (see Figures 6.2 and 6.3) solely indicate a qualitative trend (i.e., increase, decrease or hardly any change) in thickness behavior and do not provide quantitative information. The sub-monolayer numbers given in Table 6.1 can at best be interpreted as the average thickness over the $\mathrm{mm}$-scale area probed by SE; this area features discrete nm-scale film islands on an otherwise uncovered surface.

A properly-tuned SE model still allows for a reliable monitoring of individual ALD or etching cycles, as demonstrated for example in Fig. 2.11. However, the within-cycle variations seen in this and similar figures could reflect the changes of optical properties of the surface upon exposure to different reactants and would not necessarily correspond to the actual (quantitative) thickness variations. To note, the net thickness increase (or decrease) after each cycle should still correspond to the actual film growth, thereby indicating the growth rate per cycle, provided the growth curve has been verified by other (ex-situ) techniques for each new material under study.

\subsection{Delivery of at-H}

Although at- $\mathrm{H}$ has to make a 90-degree turn in order to reach the substrate in both reactors, there is still an appreciable flux of at- $\mathrm{H}$ to the wafer surface in the hot-wall reactor, as earlier confirmed by tellurium (Te) etching experiments ${ }^{[1]}$. Te reacts with at- $\mathrm{H}$ at room temperature to form volatile hydrogen telluride $\left(\mathrm{H}_{2} \mathrm{Te}\right)^{[15]}$; however, the reaction between Te and molecular hydrogen $\left(\mathrm{H}_{2}\right)$ does not occur. 
Therefore, the observation of etching of a Te film in hydrogen ambient at room temperature can confirm the existence of at- $\mathrm{H}$ at Te surface ${ }^{[1]}$.

To verify the existence of at- $\mathrm{H}$ and its efficient delivery over $70 \mathrm{~cm}$ from the source to the substrate in the cold-wall reactor, Te etching experiments were carried out before starting the work on $\mathrm{W}$ film deposition in this reactor. The optical model for a layer of Te on Si has been established and verified in our previous work ${ }^{[1]}$ where kinetics of Te etching was monitored by SE in real-time.

\subsubsection{Te etching by at-H pulses in the cold-wall reactor}

Our previous work, using the same hot-wire source installed in the hot-wall reactor, has demonstrated the high etch rate of $\mathrm{Te}$ by at- $\mathrm{H}$, greatly depending on the hot-wire temperature ${ }^{[1]}$. To enable HWALD, well-defined pulses of at- $\mathrm{H}$ must be provided instead of a continuous flow. We therefore confirmed the ability to reliably supply at-H in pulses for HWALD in the following experiments (see Fig. 2.7). In regime (1), the Te film could not be etched with the hot wire off while exposed to $\mathrm{H}_{2}$ flow (as expected). In regime (3), with hot wire on while exposed to argon or nitrogen, the Te film could not be etched either. The three regimes indicated in Fig. 2.7 manifest that only the combination of a switched-on hot wire with $\mathrm{H}_{2}$ flow along the hot wire source causes etching of the Te film. It can be seen that Te etching occurs by each pulse of at- $\mathrm{H}$ of $0.1 \mathrm{~s}$; the etching quickly diminishes and stops during a purge of $30 \mathrm{~s}$ with Ar. As the figure further indicates, there is no delay between the injection of $\mathrm{H}_{2}$ and the on-set of etching; however etching tends to continue for another $8 \mathrm{~s}$ after the $0.1 \mathrm{~s}$ pulse of hydrogen. This is attributed to the residence time of at- $\mathrm{H}$ in the reaction chamber. In conclusion, etching of Te films confirms not only the efficient delivery of at- $\mathrm{H}$ to the substrate but also its sufficiently long lifetime in the reactor. 


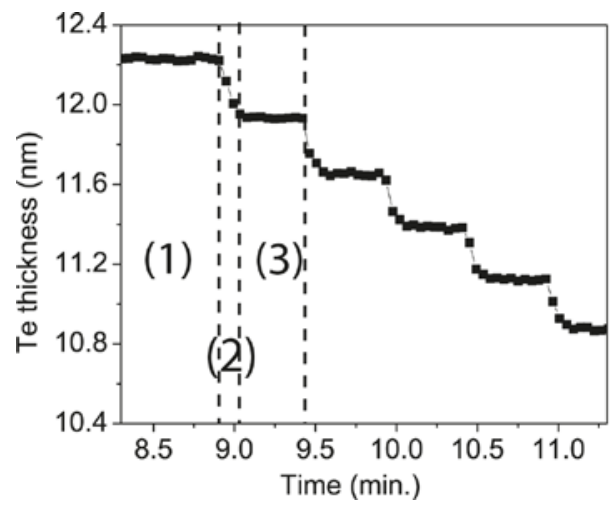

Figure. 2.7. Etching a Te film by sequential $0.1 \mathrm{~s}$ pulses of at-H followed by $30 \mathrm{~s}$ purge. Shown is the thickness of remaining Te on a silicon wafer as measured by SE. Conditions: room $T_{s}$, process pressure of $0.003 \mathrm{mbar}, \mathrm{H}_{2}$ flow rate of $100 \mathrm{sccm}$ and a carrier gas (Ar) flow rate of $50 \mathrm{sccm}$. Three regimes are identified: (1) introducing molecular hydrogen $\left(\mathrm{H}_{2}\right)$, hot wire off; (2) introducing $\mathrm{H}_{2}$ via the hot wire kept at $1750^{\circ} \mathrm{C}$; (3) Ar flowing through the hot wire at $1750^{\circ} \mathrm{C}$.

In this tellurium etching experiment, each 0.1 s pulse of hydrogen could etch approximately $0.3 \mathrm{~nm}$ of Te. Before calculating the dissociation efficiency of $\mathrm{H}_{2}$, following assumptions are made: (i) all $\mathrm{H}_{2}$ molecules will dissociate on the hot wire, (ii) all generated at- $\mathrm{H}$ could reach the surface to etch $\mathrm{Te}$, (iii) no re-deposition of $\mathrm{Te}$ occurred and (iv) etching was uniform and conformal across the wafer. With a $\mathrm{H}_{2}$ flow of $100 \mathrm{sccm}$, the rate of $\mathrm{H}_{2}$ molecules coming to the filament was (1 sccm gives $2.7 \times 10^{18} \mathrm{H}_{2}$ molecules $/ \mathrm{min}$ ) $2.7 \times 10^{20} \mathrm{molecules} / \mathrm{min}$. The pulse time was $0.1 \mathrm{~s}$, thus the number of molecules introduced in each cycle was around $\mathrm{F}=4.5 \times 10^{17}$. The number of Te atoms per $\mathrm{nm}$ of film thickness per $\mathrm{cm}^{2}$ is $1.5 \times 10^{15}$ [16]. As two $\mathrm{H}$ atoms are needed to form one $\mathrm{H}_{2} \mathrm{Te}$ molecule and thus etch one Te atom, $3.1 \times 10^{15}$ $\mathrm{H}$ atoms were required to etch $1 \mathrm{~nm}$ of Te film per $1 \mathrm{~cm}^{2}$ of surface area. In each pulse around $0.3 \mathrm{~nm} \mathrm{Te} / \mathrm{cm}^{2}$ was etched, requiring $9.8 \times 10^{14} \mathrm{H}$ atoms $/ \mathrm{cm}^{2}$. As the wafer area was around $81 \mathrm{~cm}^{2}$, the required number of hydrogen atoms to uniformly etch the film was $f=7.9 \times 10^{16}$. Hence a dissociation efficiency of $\mathrm{H}_{2}$ on the filament surface can be roughly estimated at

$$
P_{\text {dis }}=(1 / 2 f) / F=0.0884=8.84 \% \text {. }
$$


A more accurate estimation requires chemical modeling of the etching reactions including knowledge of the sticking probability of at- $\mathrm{H}$ to the surface, the actual gas dynamics, reaction rate constants, and also taking the decomposition of the formed $\mathrm{TeH}_{2}$ (i.e. re-deposition) into account. Unfortunately, several unknown parameters of this process make it rather difficult to estimate the amount of at-H produced. In terms of this simple model, $9.8 \times 10^{14} \mathrm{H}$ atoms $/ \mathrm{cm}^{2}$ are needed (assuming $100 \%$ participation in the reactions, sticking probability 1 , etc.) to maintain the experimental etch rate. The actually generated amount of at- $\mathrm{H}$ could be higher (e.g., in case of a lower sticking probability) or lower (e.g., for a non-uniform etching with the etch front propagating gradually in the direction of flow).

\subsubsection{Factors influencing on Te etch rate}

The total process pressure is a crucial parameter affecting the etch rate. A higher process pressure indicates more species in the reactor and thus a higher chance for recombination of at- $\mathrm{H}$ in the gas phase. This combination is a three-body process $^{[17]}$, in other words it requires three particles to collide at the same time. Any

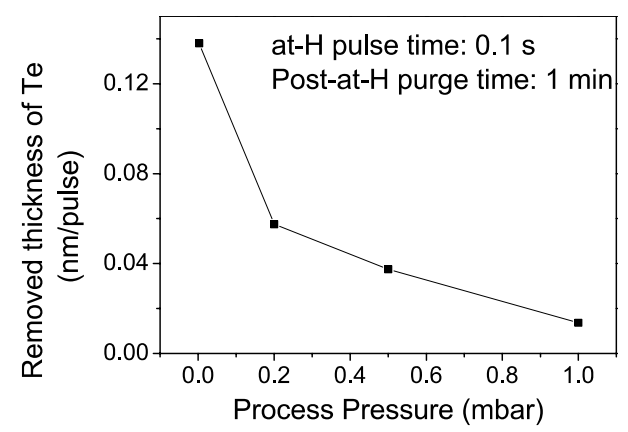

Figure 2.8. Influence of the total process pressure on the removed thickness of Te per a-H pulse. Conditions: room $T_{s}, \mathrm{H}_{2}$ flow rate of $100 \mathrm{sccm}$ and a carrier gas (Ar) flow rate of $50 \mathrm{sccm}$. The hot-wire temperature was kept at $1550^{\circ} \mathrm{C}$. 
surface or species inside the reactor can act as a third particle (body). As a result, the etch rate was severely suppressed with an increasing process pressure, confirmed in Fig. 2.8. Especially when the process pressure reached 1 mbar, etching was nearly terminated due to very limited at- $\mathrm{H}$ reaching the Te surface.

Flow rates of the carrier gas (Ar) can affect the partial pressure of at- $\mathrm{H}$ and thus the etch rate. Fig. 2.9 shows how the removed thickness of Te/pulse (a measure of the etch rate) reduced when a higher flow rate of Ar from the HW port was adopted. This was not only due to the dilution of at- $\mathrm{H}$, but also the consequence of a higher probability of at- $\mathrm{H}$ recombination. Despite the negative effects on etch rate, a suitable dose of Ar was necessary to ensure an efficient purge. Similar effects of the Ar from the gas ring were expected.

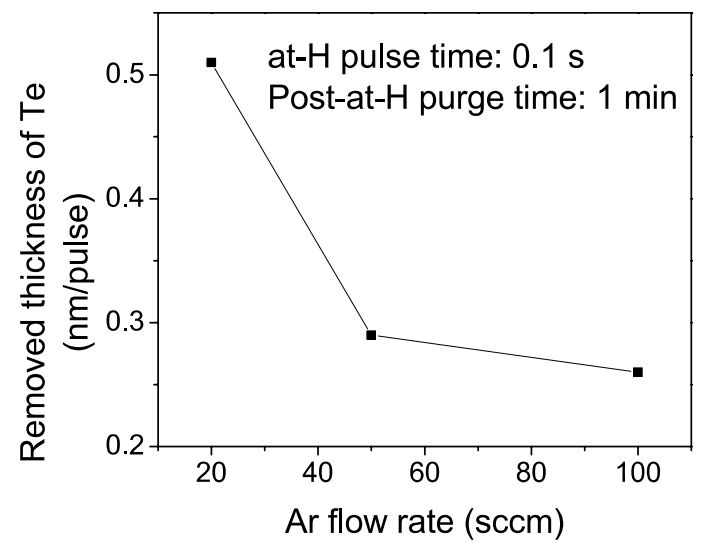

Figure 2.9. Influence of Ar flow rate on the removed thickness of Te per a-H pulse. Conditions: room $T_{s}$, process pressure of 0.003 mbar, $\mathrm{H}_{2}$ flow rate of $100 \mathrm{sccm}$ and the hot-wire temperature was kept at $1750^{\circ} \mathrm{C}$.

\subsubsection{Back-stream diffusion}

In reality, except the flows of precursors coming from either hot-wire port or gas ring to the pump, there is also diffusion of precursors. It is possible that a precursor injected from the gas ring can diffuse upwards to the hot wire, a process 24 
called back-stream diffusion here. To investigate the existence of back-stream diffusion, $\mathrm{H}_{2}$ was introduced from the gas ring situated $10 \mathrm{~cm}$ above the substrate. The occurrence of $\mathrm{H}_{2}$ diffusion upwards to the filament, the formation of at- $\mathrm{H}$ and its subsequent transportation downwards to the substrate would result in Te etching. Fig. 2.10 confirms the existence of back-stream diffusion, by showing the etch rate as a function of the total process pressure and the at- $\mathrm{H}$ pulse time. Moreover, increasing the process pressure suppressed the etch rates. In comparison, at the lowest pressure in Fig 2.10, the same $\mathrm{H}_{2}$ flow introduced from top of the reactor resulted in an etch rate of $0.6 \mathrm{~nm} /$ pulse, whereas the etch rate by back-stream diffusion was $0.0375 \mathrm{~nm} /$ pulse (see the circled point). It indicates that, under the same experimental conditions, the contribution of back-stream diffusion to etching was less than $10 \%$ compared to the forward-stream $\mathrm{H}_{2}$ flow. Minimizing the backstream diffusion is required for the optimization of HWALD experimental conditions; this will be considered later in this thesis.

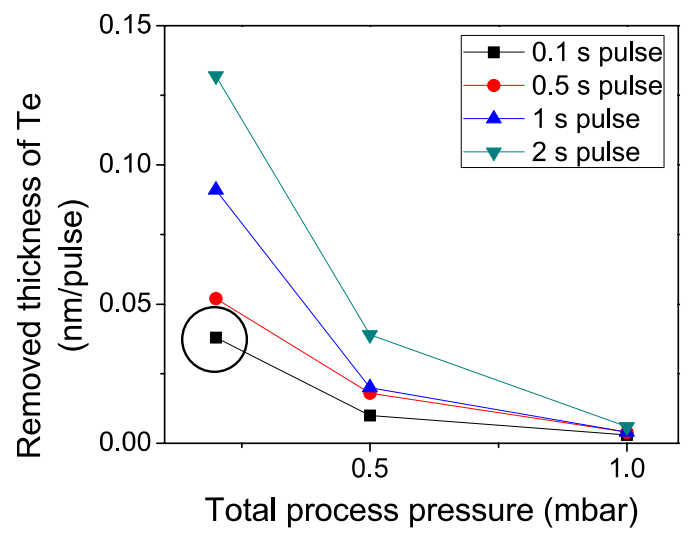

Figure 2.10. Influences of total process pressure and at- $\mathrm{H}$ pulse time on the removed thickness of Te per a-H pulse. Conditions: room $T_{s}, \mathrm{H}_{2}$ flow rate of $100 \mathrm{sccm}$, post-at- $\mathrm{H}$ purge of $1 \mathrm{~min}$ and the hot-wire temperature was kept at $1750^{\circ} \mathrm{C}$. 


\subsection{Hot wire is not a source for $\mathbf{W}$ deposition}

To deposit $\mathrm{W}$ with assistance of a $\mathrm{W}$ filament, it is very important that the hot wire itself is not a source of tungsten. Since the $W$ vapor pressure is rather low at temperatures below $2000^{\circ} \mathrm{C}^{[18]}$, evaporation of $\mathrm{W}$ is negligible. A demonstration of HWALD of $W$ in the hot-wall reactor is presented in Fig. 2.11, where the hot wire was kept at $1750{ }^{\circ} \mathrm{C}$. In regimes (1) and (2), either $\mathrm{Ar}$ or $\mathrm{Ar} / \mathrm{H}_{2}$ mixture was introduced via the hot wire, showing no detectable growth of W. In regime (3), while exposed to subsequent $\mathrm{H}_{2}$ and $\mathrm{WF}_{6}$ pulses, $W$ started to grow in an ALD manner. The three regimes indicated in Fig. 2.11 manifest that the $W$ filament itself is not a source of $W$ for deposition.

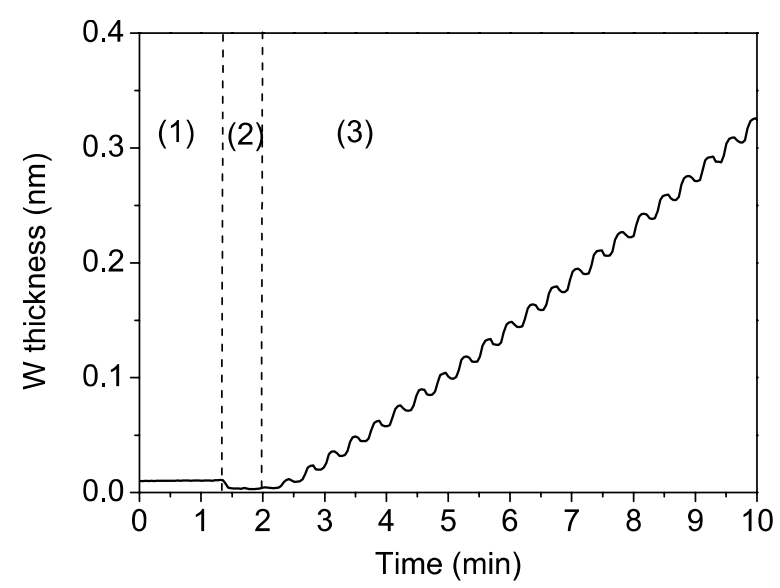

Figure. 2.11. A demonstration of $W$ deposition by HWALD. Shown is the thickness of deposited $W$ on $W$ surface measured by SE. Conditions: $T_{S}$ of $325^{\circ} \mathrm{C}$, HW temperature of $1750{ }^{\circ} \mathrm{C}$, process pressure of 0.05 mbar, $\mathrm{H}_{2}$ flow rate of $50 \mathrm{sccm}$ and a carrier gas (Ar) flow rate of $50 \mathrm{sccm}$. Three regimes are identified: (1) Ar flowing along the hot wire; (2) introducing $\mathrm{H}_{2}$ via the hot wire without introducing $W \mathrm{~F}_{6}$; (3) introducing ALD pulses of $\mathrm{H}_{2}$ (via the $\mathrm{HW}$ ) and $\mathrm{WF}_{6}$. 


\subsection{Conclusions}

This chapter describes the hot- and cold-wall reactors which will be used in the next experiments to grow HWALD W. The film thicknesses in-situ measured by spectroscopic ellipsometer have been verified by other ex-situ techniques. The optical models have been established and validated. This work further confirmed the existence of at- $\mathrm{H}$ and its delivery to the substrate in the cold-wall reactor under various experimental conditions. And here we also provide results of Te etching by at- $\mathrm{H}$ pulses in the cold-wall reactor. Despite a big volume and a long distance, at- $\mathrm{H}$ can transfer to the substrate surface and sustain a reasonable etch rate of Te. As demonstrated, the total process pressure, Ar flow rates and other parameters can affect etching and also influence the back-stream diffision of hydrogen.

\section{References}

[1] H. Van Bui, A. Y. Kovalgin, A.A.I. Aarnink and R.A.M. Wolters, J. Solid State Sci. Technol. 2, P149 (2013).

[2] S. Bystrova, A. Aarnink, J. Holleman and R.A.M. Wolters, J. Electrochem. Soc. 152, G522 (2005).

[3] P. Desai, T. Chu, H. M. James and C. Ho, J. Phys. Chem. Ref. Data 13, 1069 (1984).

[4] S. Heil, J. van Hemmen, C. Hodson, N. Singh, J. Klootwijk, F. Roozeboom, M. van de Sanden and W. Kessels, J. Vac. Sci. Technol. A 25, 1357 (2007).

[5] S. Heil, J. van Hemmen, M. van de Sanden and W. Kessels, J. Appl. Phys. 103, 103302 (2008).

[6] E. Langereis, S. Heil, H. Knoops, W. Keuning, M. Van de Sanden and W. Kessels, J. Phys. D: Appl. Phys. 42, 073001 (2009).

[7] H. Fujiwara, Spectroscopic ellipsometry: principles and applications (John Wiley \& Sons, New York, 2007).

[8] H. Tompkins and E. A. Irene, Handbook of ellipsometry (William Andrew, New York, 2005).

[9] F. Wooten, Optical Properties of Solids (Academic Press, New York, 1972).

[10] P. W. Milloni and J. H. Eberly, Lasers (John Wiley and Sons, 1988).

[11] P. Patsalas and S. Logothetidis, J. Appl. Phys. 93, 989 (2003). 
[12] E. D. Palik, Handbook of Optical Constants of Solids (Academic Press, 1997).

[13] C. M. Hezinger, B. D. Jonhs, W. A. McGahan, J. A.Woollam and W. Paulson, J. Appl. Phys. 83, 3323 (1998).

[14] G. Jellidon and F. Modine, Phys. Rev. B 27, 7466 (1983).

[15] D. A. Outka, Surf. Sci. 235, L311 (1990).

[16] M. K. Slattery, Physical Review 25, 333 (1925).

[17] H. Wise and C. M. Ablow, J. Chem. Phys. 35, 10 (1961).

[18] R. Szwarc, E. Plante and J. Diamond, NBS J. Res. Phys. Chem. 69, 417 (1965). 


\title{
High resistivity $\beta$-phase \\ HWALD W grown in a cold-wall \\ reactor
}

\begin{abstract}
.
In this chapter, tungsten films were deposited in the cold-wall reactor by HWALD. The real-time SE monitoring revealed the co-existence of three processes: CVD, etching and ALD of the $W$ film. $W F_{6}$ could back-stream diffuse to the hot-wire, resulting in $W F_{6}$ decomposition and generation of a flux of fluorine $(F)$. The latter caused etching of the grown W film and the filament, and provided extra tungsten supply, which might cause CVD. By controlling the dose of $\mathrm{WF}_{6}$ and process pressure, the etching had been minimized. Further, we compared samples with tungsten grown by either HWALD or chemical vapor deposition (CVD) in terms of growth kinetics and properties. For CVD, the samples were made in a mixture of $W_{6}$ and molecular or atomic hydrogen. Resistivity of the CVD W was around 20 $\mu \Omega \cdot \mathrm{cm}$, whereas it was as high as $100 \mu \Omega \cdot \mathrm{cm}$ for the HWALD films. X-ray diffraction (XRD) reveals that the HWALD W was crystallized as $\beta-W$, whereas both CVD films were in the $\alpha-$ W phase.
\end{abstract}

This chapter is based on the publications:

Mengdi Yang, Antonious A.I. Aarnink, Alexey Y. Kovalgin, Rob A.M. Wolters and Jurriaan Schmitz, "Hot-wire assisted ALD of tungsten films: In-situ study of the interplay between CVD, etching and ALD modes”, Phys. Status Solidi A, 212, 1607 (2015).

Mengdi Yang, Antonious A.I. Aarnink, Alexey Y. Kovalgin, Dirk J. Gravesteijn, Rob A.M. Wolters and Jurriaan Schmitz, "A Comparison of Tungsten Films Grown by CVD and Hot-wire Assisted ALD in a cold-wall reactor”, J. Vac. Sci. Technol. A, 34, 01A129 (2016). 


\subsection{Introduction}

In this chapter, results of tungsten formed by HWALD using sequential WF 6 and $\mathrm{H}_{2}$ in the cold-wall reactor are presented. During optimization of the HWALD window, an interplay among CVD, etching, and ALD modes was found and investigated. The interplay is highly dependent on deposition conditions. By optimizing these conditions, the HWALD mode can be successfully enabled. Film properties, such as resistivity, thickness, roughness, density, elemental composition and crystal structure have been evaluated by means of four-point probe (FPP), atomic force microscope (AFM), X-ray diffraction (XRD) and reflection (XRR), X-ray photoelectron spectroscopy (XPS), high resolution transmission electron microscopy (HR-TEM) and HR-SEM. Further, we compared three deposition methods of W: (i) CVD by using $\mathrm{WF}_{6}$ and molecular hydrogen $\left(\mathrm{H}_{2}-\mathrm{CVD}\right.$ ), (ii) $\mathrm{CVD}$ by $\mathrm{WF}_{6}$ and atomic hydrogen (at-H-CVD) and (iii) HWALD.

\subsection{Experimental}

\subsubsection{Deposition}

In this experiment, tungsten films were deposited on a 100-nm-thick silicon oxide $\left(\mathrm{SiO}_{2}\right)$ thermally grown on p-type $\mathrm{Si}(100)$ substrate. Prior to deposition, the wafers were cleaned in fuming (99\%) $\mathrm{HNO}_{3}$ and boiling $69 \% \mathrm{HNO}_{3}$ to remove organic and metallic contaminations, respectively. Finally, the substrate was immersed into a $0.3 \% \mathrm{HF}$ solution for $3 \mathrm{~min}$. As the tungsten nucleation is very poor on $\mathrm{SiO}_{2}$ and $\mathrm{Si}_{3} \mathrm{~N}_{4}{ }^{[1]}$, a seed layer is required ${ }^{[2]}$. Formation of this seed layer consisted of (i) CVD of a thin ( $<10 \mathrm{~nm}$ ) layer of amorphous $\mathrm{Si}(\mathrm{a}-\mathrm{Si})$ from trisilane $\left(\mathrm{Si}_{3} \mathrm{H}_{8}\right)$; and (ii) converting the a-Si into $\mathrm{W}$ by reacting with $\mathrm{WF}_{6}$. The whole process of forming the seed layer was performed in the hot-wall reactor, and then the wafer was transferred to the cold-wall reactor without vacuum break.

To be more specific, a $\mathrm{Si}_{3} \mathrm{H}_{8}$ flow of $10 \mathrm{sccm}$ was supplied. The precursor dissociated on the $\mathrm{SiO}_{2}$ surfaces at a substrate temperature $\left(T_{\mathrm{s}}\right)$ of $325{ }^{\circ} \mathrm{C}$ and a 
pressure of 10 mbar, forming a layer of amorphous silicon (a-Si) of approximately $5 \mathrm{~nm}$. The thickness of a-Si was monitored in-situ by SE. Next, the reactor was pumped down to a pressure of 1 mbar followed by introducing WF6 $(10 \mathrm{sccm})$ to convert the a-Si into W. Further, the reactor was flushed by $\mathrm{N}_{2}$ for $10 \mathrm{~min}$ and evacuated back to $10^{-7}$ mbar, followed by the wafer transfer to the cold-wall reactor, to continue with the HWALD process.

The HWALD of $\mathrm{W}$ films was carried out using sequential pulses of $\mathrm{WF}_{6}$ and at- $\mathrm{H}$ at substrate temperatures ranging between 200 and $325{ }^{\circ} \mathrm{C}$, and process pressures of $0.001-1$ mbar. The hot-wire temperature was varied between 1800 to $1900{ }^{\circ} \mathrm{C}$. For ex-situ (electrical) characterization, it is important to prevent oxidation of the grown $\mathrm{W}$ film during its exposure to air. The wafer was therefore transferred back to the hot-wall reactor after the HWALD process, where a $10 \mathrm{~nm}$ capping layer of a-Si was deposited (employing the same deposition method as used for the a-Si seed layer) on top of $\mathrm{W}$, completing the process.

\subsubsection{Film characterization}

The film thickness was measured in real-time during the deposition using the in-situ spectroscopic ellipsometer described in Chapter 2. The measurements were taken every $2.5 \mathrm{~s}$. Due to the opacity of thicker W layers, only the films with thickness up to $30 \mathrm{~nm}$ could be measured by SE. The film thickness was verified by high-resolution scanning electron microscopy (HR-SEM) and XRR, shown earlier in Chapter 2. Additionally, optical properties of the films were also obtained by SE.

The elemental composition of the as-grown film was obtained by XPS. A PANalytical X'PERT MPD diffractometer was utilized for XRD and XRR measurements. XRD and XRR patterns of the samples were recorded in the region of $2 \theta=30-90^{\circ}$ using $\mathrm{Cu}$ Ka radiation, with a PANalytical PIXcel1D detector. The film resistivity was examined by an automatic four-point probe stage of Polytec. The film surface morphology was characterized by a Bruker Fastscan/ICON model AFM. 
Further, HR-TEM and energy filtered TEM (EFTEM) were utilized to characterize grown films.

\subsection{In-situ study of the interplay between CVD, etching and ALD modes}

\subsubsection{The existence of CVD and etching modes}

According to literature, the thermal dissociation of WF 6 (in gas phase) starts at $750{ }^{\circ} \mathrm{C}^{[3,4]}$. Although the gas ring was installed at a distance of $70 \mathrm{~cm}$ below the hot wire, the operating conditions (pressure, gas flows) could greatly influence the upward diffusion of $\mathrm{WF}_{6}$ to the hot wire. As a consequence, this $\mathrm{WF}_{6}$ may dissociate at the hot wire, likely generating tungsten subfluorides $\left(W F_{x}\right)$ and fluorine-containing species (atomic fluorine and fluorine $)^{[5-8]}$. As the dissociation of WF 6 occurs in equilibrium, any increase of concentration of $\mathrm{WF}_{6}$ will enhance the generation of fluorine-containing species. It is reported that the lifetime of atomic fluorine in a (plasma) reactor can be quite long ${ }^{[9]}$. Additionally, both WFx and fluorine-containing species can adsorb on the (cold) reactor walls ${ }^{[10,11]}$. This provides a background supply of $\mathrm{WF}_{6}$ and fluorine-containing species to the gas phase over the deposition cycles. Fluorine-containing species, generated from $\mathrm{WF}_{6}$ dissociation upon the hot wire, can contribute to etching the hot wire and regeneration of volatile tungsten precursor(s) (likely tungsten fluorides). When mixed with at- $\mathrm{H}$, these precursors may contribute to a CVD mode at substrate level. The experiments shown in Fig. 3.1 confirm the existence of a CVD mode. For example a 1-min exposure to $\mathrm{WF}_{6}$ gas followed by a 2-min purge and subsequent at- $\mathrm{H}$ exposure reveals a continuous growth of W film up to $2.5 \mathrm{~nm}$ in thickness (filament temperature of $1910{ }^{\circ} \mathrm{C}$ ). This occurs during the entire (up to $25 \mathrm{~min}$ ) exposure to at- $\mathrm{H}$ only, likely due to CVD. 


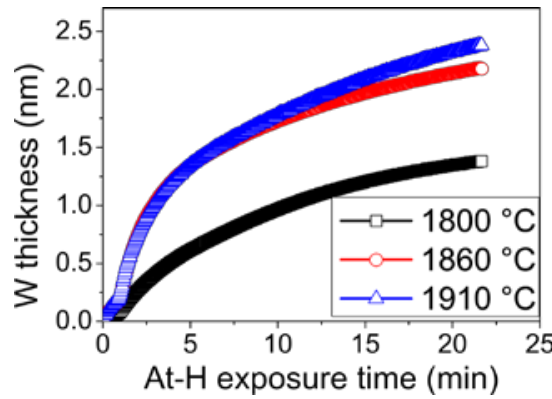

(a)

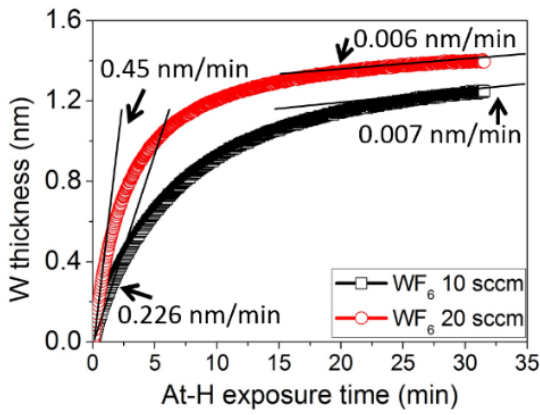

(c)

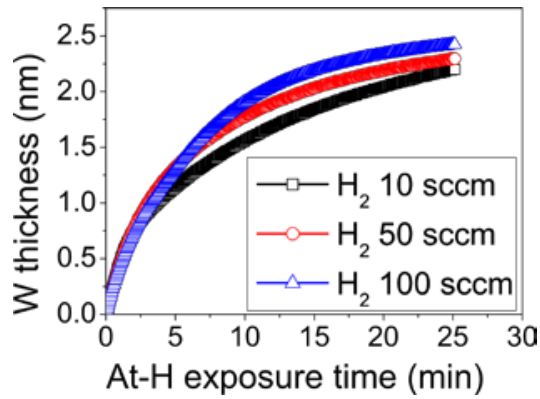

(b)

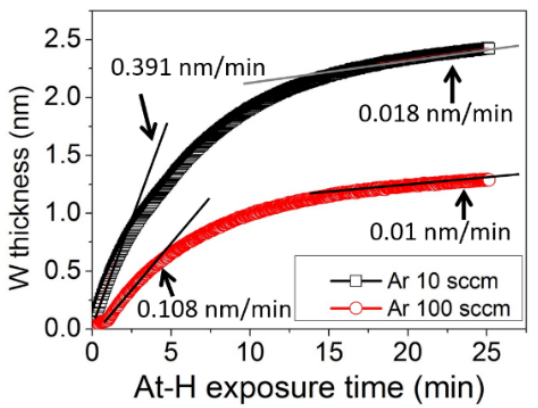

(d)

Figure 3.1. Film growth (obtained by in-situ SE) versus different deposition parameters. All long-time exposures to at- $\mathrm{H}$ were performed after a 1-min exposure to $\mathrm{WF}_{6}$ gas followed by a 2-min purge. Standard parameter values: $0.01 \mathrm{mbar}$ of pressure, $325^{\circ} \mathrm{C}$ of $T_{s}, 1860^{\circ} \mathrm{C}$ of hot-wire temperature, $100 \mathrm{sccm}$ of $\mathrm{H}_{2}$, $10 \mathrm{sccm}$ of $\mathrm{WF}_{6}, 100 \mathrm{sccm}$ of $\mathrm{H}_{2}$-carrier gas (Ar), and $50 \mathrm{sccm} \mathrm{WF}_{6}$-carrier gas (Ar). Each graph shows the influence of one parameter only while keeping the standard values for all other parameters. The Figure shows the influence of: (a) hot-wire temperature, (b) $\mathrm{H}_{2}$ flow rate, (c) $\mathrm{WF}_{6}$ flow rate, and (d) $\mathrm{H}_{2}$-carrier-gas (Ar) flow rate.

Figures 3.1 (a-d) show the CVD growth under different conditions, while $T_{s}$ and total pressure were fixed at $325^{\circ} \mathrm{C}$ and 0.01 mbar. Firstly, in Fig. 3.1 (a) the growth rate increases with hot-wire temperature due to the improved dissociation efficiency of $\mathrm{H}_{2}{ }^{[12]}$, resulting in a higher at- $\mathrm{H}$ flux. However, the difference between $1860^{\circ} \mathrm{C}$ and $1910^{\circ} \mathrm{C}$ is small, probably due to the limited reactant supply (i.e. volatile tungsten precursors). From Fig. 3.1 (b) it can be seen that there is no significant impact of the $\mathrm{H}_{2}$ gas flow rate on CVD growth rate, likely pointing to a comparable amount of at- $\mathrm{H}$ reaching the substrate surface in these cases. However, our experiments (not shown) indicate that the upstream diffusion of $\mathrm{WF}_{6}$ can be suppressed by a higher hot-wire gas flow from top to the reactor bottom. So, to 
minimize CVD, the flow rate of $\mathrm{H}_{2}$ is determined to be $100 \mathrm{sccm}$ (the maximum flow rate in our case). From Fig. 3.1 (c), a higher flow of the initial $\mathrm{WF}_{6}$ enhances the growth rate. It is noticeable that the growth rate in the first 5 min doubles when the $W F_{6}$ flow rate becomes two times larger, implying that the initial 0-to-10-min growth is mainly influenced by the $\mathrm{WF}_{6}$ injected from the gas ring. On the contrary, growth rates for times exceeding approximately $20 \mathrm{~min}$ are almost the same despite the different $\mathrm{WF}_{6}$ flow rates. Analyzing the curves (values and shapes), one can conclude that the growth rates after an exposure of around 20 min follow the kinetics of desorption of the reactants that adsorbed on the cold walls during the preceding $W_{6}$ pulse(s). In Fig. 3.1 (d), it is shown that the flow rate of $\mathrm{H}_{2}$-carrier gas (Ar) has a significant effect on the CVD growth rate. Apparently, a higher downward flow rate could (i) suppress the upward diffusion of the reactants, thereby decreasing their interaction with the hot wire, (ii) decrease the partial pressures of reactants and thus suppress the related CVD mode, and (iii) shorten the delivery time of at- $\mathrm{H}$ to the substrate. As a matter of fact, a 10-times higher Ar flow decreases the growth rate approximately 2 to 4 times, depending on the time of exposure to at- $\mathrm{H}$.

To examine the film grown by the CVD process shown in Fig. 3.1, X-ray photoelectron spectroscopy (XPS) was used to obtain the elemental composition of the selected $W$ film. This film was grown at 0.01 mbar with the following cycle sequence: $2.5 \mathrm{~min} \mathrm{WF}_{6} / 2 \mathrm{~min}$ purge/ $10 \mathrm{~min}$ at- $\mathrm{H} / 2$ min purge. Flow rates of $\mathrm{WF}_{6}$ and $\mathrm{H}_{2}$ were 5 and $100 \mathrm{sccm}$, respectively. The hot-wire temperature was $1750^{\circ} \mathrm{C}$, and the substrate temperature was $325^{\circ} \mathrm{C}$, Ar-carrier-gas flow rates for $\mathrm{WF}_{6}$ and $\mathrm{H}_{2}$ were 50 and $100 \mathrm{sccm}$, respectively. One should note the remarkably low concentrations (i.e. at detection limits) of all impurities and the concentration of tungsten at $92-98$ at\%. It is quite clear that the continuous deposition of $\mathrm{W}$ films up to $2.5 \mathrm{~nm}$ is evidence of a permanent source of tungsten in the gas phase, most probably in the form of $\mathrm{WF}_{6}$. As mentioned above, this source is expected due to evaporation of reactants from the reactor cold walls. 


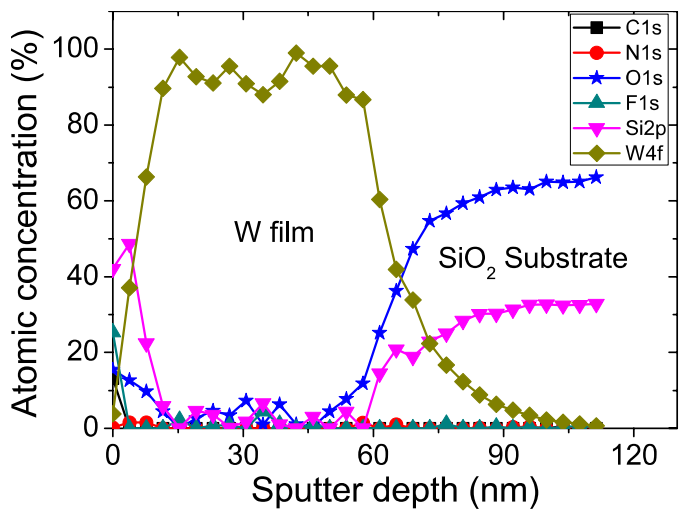

Figure 3.2. XPS-profile of the film grown at 0.01 mbar with the following cycle sequence: $2.5 \mathrm{~min} \mathrm{WF}_{6} /$ 2 min purge/ 10 min at-H/ 2 min purge. Flow rates of $\mathrm{WF}_{6}$ and $\mathrm{H}_{2}$ were 5 and $100 \mathrm{sccm}$, respectively. Other conditions: hot-wire temperature of $1750{ }^{\circ} \mathrm{C}, T_{s}$ of $325^{\circ} \mathrm{C}$, Ar-carrier-gas flows for $\mathrm{WF}_{6}$ and $\mathrm{H}_{2}$ of 50 and $100 \mathrm{sccm}$, respectively. The Si signal at the beginning is from the a-Si capping layer.

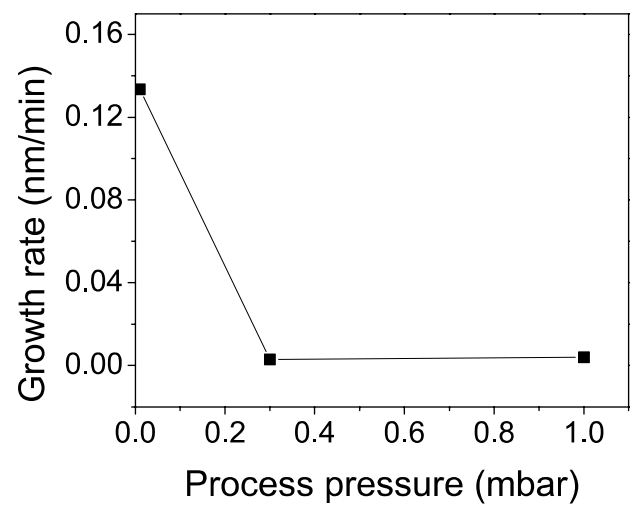

Figure 3.3. CVD growth rate versus process pressure during a $1 \mathrm{~min}$ exposure to at- $\mathrm{H}$, after a 1-min exposure to $\mathrm{WF}_{6}$ gas followed by a 2-min purge. Conditions: $T_{s}$ of $325^{\circ} \mathrm{C}$, hot-wire temperature of $1750{ }^{\circ} \mathrm{C}$, $\mathrm{H}_{2}$ of $100 \mathrm{sccm}, \mathrm{WF}_{6}$ of $2 \mathrm{sccm}, \mathrm{H}_{2}$-carrier gas (Ar) of $100 \mathrm{sccm}$, and $\mathrm{WF}_{6}$-carrier gas of $50 \mathrm{sccm}$ (Ar).

The impact of the total gas pressure on the growth rate was additionally studied, see Fig. 3.3. On one hand, a higher pressure is expected to increase the recombination of at- $\mathrm{H}^{[13]}$ and to suppress the upward diffusion. On the other hand, a higher (partial) pressure of $\mathrm{WF}_{6}$ will shift the equilibrium towards generating more fluorine. Consequently, a suppression of the CVD mode and the growth can be 
expected. This is confirmed in Fig. 3.3: a pressure of 0.3 mbar sufficiently decreases the CVD growth.

To conclude, the $\mathrm{H}_{2}$ and top-carrier-gas flow rates were chosen both at $100 \mathrm{sccm}$ (maximum values), in combination with high enough process pressure, to minimize the possible CVD mode. Moreover, the $\mathrm{WF}_{6}$ pulse should be kept short, to limit the unwanted supply of reactants enhancing CVD. This can be achieved by limiting $W_{6}$ pulse time and flow rate.

\subsubsection{Etching mode of deposited $W$ films}

Fluorine, generated by the decomposition of $\mathrm{WF}_{6}$ on the hot wire, will diffuse downwards and etch the deposited $\mathrm{W}$ film. This effect was more pronounced at high WF$_{6}$ pressures, due to the mentioned shift of equilibrium. The interplay between growth and etching modes is presented in Fig. 3.4. The high sensitivity of in-situ SE allows study of the separate ALD cycles $(0.1 \mathrm{~s}$ at- $\mathrm{H}, 60 \mathrm{~s}$ purge, $0.1 \mathrm{~s}$ WF 6 , and $60 \mathrm{~s}$

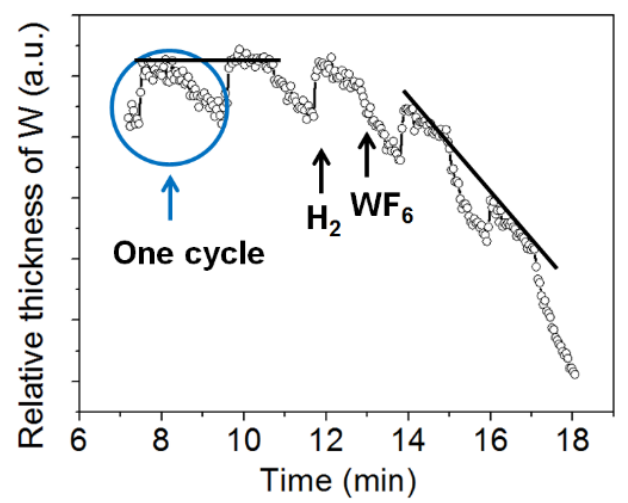

Figure 3.4. In-situ monitoring of individual pulses by SE. Black lines indicate the slopes. The black arrows show the admittance of the corresponding gas pulses to the reactor. One cycle consisted of $0.1 \mathrm{~s}$ at- $\mathrm{H}$ exposure, $60 \mathrm{~s}$ purge, $0.1 \mathrm{~s} \mathrm{WF_{6 }}$ exposure, and $60 \mathrm{~s}$ purge. Conditions: pressure of $1 \mathrm{mbar}, T_{\mathrm{s}}$ of $325^{\circ} \mathrm{C}$, hot-wire temperature of $1750{ }^{\circ} \mathrm{C}, 100 \mathrm{sccm}$ Ar carrier gas of $\mathrm{H}_{2}, 50 \mathrm{sccm}$ Ar carrier gas of $\mathrm{WF}_{6}$, and $100 \mathrm{sccm} \mathrm{H}_{2}$ flow and $10 \mathrm{sccm} \mathrm{WF}_{6}$ flow. Due to the short pulse times of at- $\mathrm{H}$ and $\mathrm{WF}_{6}$, the last two flow rates cannot be accurately measured. 
purge). Pulses of at- $\mathrm{H}$ and $\mathrm{WF}_{6}$ are indicated. One can clearly see a gradually increasing decay of the thickness after introducing every next WF 6 pulse, i.e. etching. In the first two cycles starting from $0.23 \mathrm{~nm}$ at 7 minutes, the growth rate $\left(\mathrm{H}_{2}\right.$ pulse) is approximately equal to the etch rate $\left(\mathrm{WF}_{6}\right.$ pulse), resulting in near-zero net growth of the film. From the third cycle, etching starts to increasingly dominate, leading to the net decline of the film thickness. This behavior, typical and reproducible for given conditions, can be explained by a gradual increase of fluorine concentration in the reactor due to the preceding $\mathrm{WF}_{6}$ pulses. This highlights the importance of limiting the $\mathrm{WF}_{6}$ dose during each pulse, in order to minimize etching.

The influence of substrate temperature $\left(T_{s}\right)$ and total gas pressure on the net growth is shown in Fig. 3.5, which further illustrates the interplay between deposition and etching. It is obvious that etching is enhanced by a higher pressure resulting in a lower growth rate. Furthermore, etching becomes dominant at a lower temperature if the pressure is higher. Considering etching and deposition as two parallel reactions, an increase in $T_{s}$ results in a higher etch rate rather than a higher growth rate, we conclude that etching has a stronger dependence on $T_{s}$ compared to deposition. In order to achieve a higher growth rate, $315^{\circ} \mathrm{C}$ was determined to be the $T_{s}$ for the following ALD experiments.

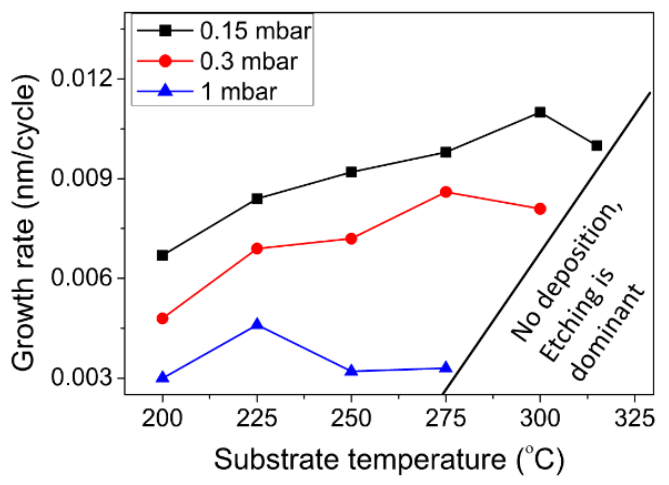

Figure 3.5. Influence of total pressure and substrate temperature on net growth. The cycle sequence: $10 \mathrm{~s} \mathrm{H}_{2}(100 \mathrm{sccm}) / 30 \mathrm{~s} \mathrm{Ar}$ (purge)/ $0.1 \mathrm{~s} \mathrm{WF}_{6}(2 \mathrm{sccm}) / 30 \mathrm{~s} \mathrm{Ar}$ (purge). Other conditions: Ar-carrier gas flow rate of $100 \mathrm{sccm}$ and $50 \mathrm{sccm}$ for $\mathrm{H}_{2}$ and $\mathrm{WF}_{6}$, respectively; hot-wire temperature of $1750{ }^{\circ} \mathrm{C}$. Due to the short pulse time of $\mathrm{WF}_{6}$, its actual flow rate cannot be accurately measured. 
Pressure is clearly a crucial parameter in the interplay between deposition and etching. Furthermore, the net-deposition can be affected by both CVD and ALD, as both processes can contribute. For a CVD mode, lowering the total pressure is favorable as $\mathrm{WF}_{6}$ can easier diffuse upwards to the hot hot-wire and decompose there. Therefore, at a higher pressure, lesser contribution from CVD may be expected. However, increasing the pressure will enhance simultaneous etching of the deposited film. Therefore, an optimum pressure must be found to achieve a balance (net-zero effect) between CVD and etching. In the corresponding experiment, $\mathrm{WF}_{6}$ and at- $\mathrm{H}$ were mixed in the gas phase to ensure CVD mode and no ALD, aiming to observe the interplay of CVD and etching. From Fig. 3.6, the maximum (net) CVD growth is observed at the lowest pressure of $0.01 \mathrm{mbar}$, and growth rate decreases to $0.008 \mathrm{~nm} / \mathrm{min}$ at $0.1 \mathrm{mbar}$. At $0.2 \mathrm{mbar}$, the net growth is already negative, meaning dominant etching. Therefore, a pressure between 0.1 and 0.2 mbar was selected to provide a balance between CVD mode and etching.

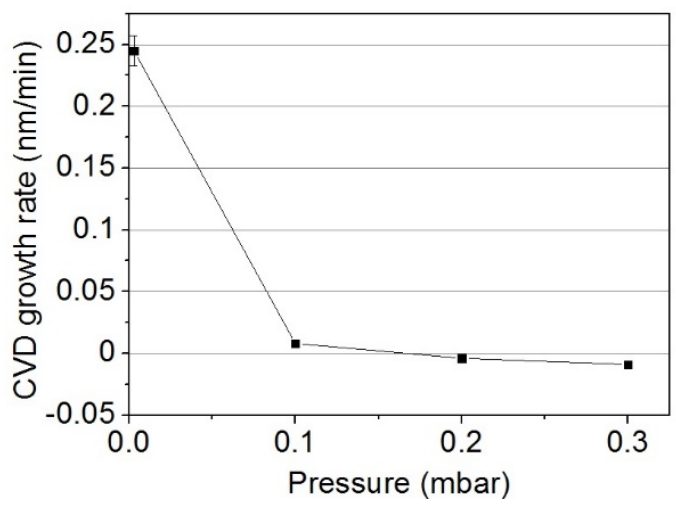

Figure 3.6. Influence of process pressure on the CVD growth rate when at- $\mathrm{H}$ and $\mathrm{WF}_{6}$ were mixed. Conditions: $100 \mathrm{sccm}$ of $\mathrm{H}_{2}, 2 \mathrm{sccm}$ of $\mathrm{WF}_{6}, 100 \mathrm{sccm}$ of $\mathrm{H}_{2}$-carrier gas (Ar), and 50 sccm WF -carrier gas (Ar), hot-wire temperature of $1750{ }^{\circ} \mathrm{C}$ and $T_{s}$ of $315^{\circ} \mathrm{C}$. 


\subsubsection{Optimization towards the dominant HWALD process}

For an ideal ALD process, similar to CVD, the growth rate per cycle (GPC) can be very slow at the initial stage, due to nucleation. GPC is expected to settle to a constant value (i.e. reaching a linear-growth regime) when the surface has been fully covered by the ALD layer ${ }^{[14]}$. In this regime, GPC is expected to be independent of experimental parameters (a so-called ALD window) ${ }^{[15]}$. To determine the ALD window in our work, the at- $\mathrm{H}$ pulse time, hot-wire temperature and the post at- $\mathrm{H}$ purge time were varied. The $\mathrm{WF}_{6}$ pulse time and the total pressure were fixed at $0.1 \mathrm{~s}$ and $0.15 \mathrm{mbar}$, as discussed above, to provide optimal conditions for the HWALD.

In Fig. 3.7 (a-c) the GPC as a function of $\mathrm{H}_{2}$ pulse time (a), filament temperature (b) and purge time (c) is shown. From these figures, an at- $\mathrm{H}$ pulse time of $10 \mathrm{~s}$, a hot-wire temperature of $1750{ }^{\circ} \mathrm{C}$, and a post at- $\mathrm{H}$ purge time of $20 \mathrm{~s}$ can be chosen to maintain an ALD mode. These parameters ensure a relatively parameter-independent GPC. The at-H pulse time shorter than $10 \mathrm{~s}$ led to nonsaturating surface reactions, whereas exposures longer than 20 s enhanced a CVD mode. The purge times shorter than $20 \mathrm{~s}$ also enhanced CVD and thereby increased

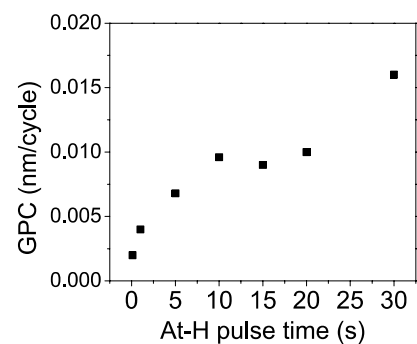

(a)

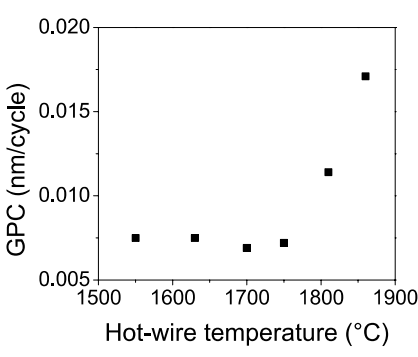

(b)

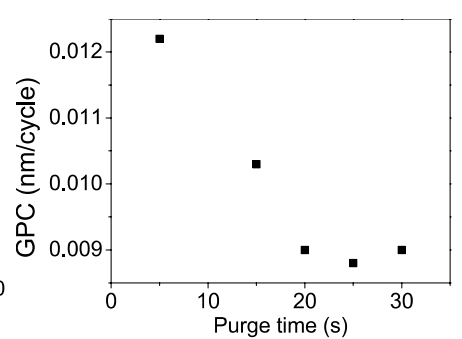

(c)

Figure 3.7. Determining HWALD windows. Influence of: (a) at- $\mathrm{H}$ pulse time, (b) hot-wire temperature and (c) post at- $\mathrm{H}$ purge time. Standard parameter values: pressure of $0.15 \mathrm{mbar}, T_{s}$ of $315{ }^{\circ} \mathrm{C}$, hot-wire temperature of $1750{ }^{\circ} \mathrm{C}, \mathrm{H}_{2}$ of $100 \mathrm{sccm}, \mathrm{WF}_{6}$ of $2 \mathrm{sccm}, \mathrm{H}_{2}$-carrier gas (Ar) of $100 \mathrm{sccm}$, and $50 \mathrm{sccm}$ $\mathrm{WF}_{6}$-carrier gas $(\mathrm{Ar})$. Each graph shows the influence of one parameter only while keeping the standard values for all other parameters. Due to the short pulse time of $\mathrm{WF}_{6}$, its actual flow rate cannot be accurately measured. 
GPC. Hot-wire temperatures exceeding $1750^{\circ} \mathrm{C}$ negatively affected the ALD window probably due to the enhancement of gas-phase reactions, again shifting the process towards CVD and increasing the GPC. The pulse time of $\mathrm{WF}_{6}$ was limited at $0.1 \mathrm{~s}$, to minimize the role of the permanent background reactants contributing to CVD and etching, as discussed in the previous sections. The post $\mathrm{WF}_{6}$ purge time was fixed at $30 \mathrm{~s}$; shorter times resulted again in net etching.

\subsubsection{Successful HWALD W}

Based on the results above, the parameters of HWALD W were determined:

$\checkmark$ One ALD cycle consisted of $10 \mathrm{~s} \mathrm{H}_{2}(100 \mathrm{sccm}) / 20 \mathrm{~s} \mathrm{Ar}$ (purge)/0.1 s WF 6 (2 sccm)/30 s Ar (purge);

$\checkmark$ Ar-carrier gas flow rate of $100 \mathrm{sccm}$ and $50 \mathrm{sccm}$ for $\mathrm{H}_{2}$ and $\mathrm{WF}_{6}$, respectively;

$\checkmark$ Hot-wire temperature of $1750^{\circ} \mathrm{C}$;

$\checkmark \quad$ The process pressure of $0.15 \mathrm{mbar}$ and substrate temperature of $315^{\circ} \mathrm{C}$.

Fig. 3.8 depicts the linear growth regime between 280 and 420 cycles under the HWALD conditions listed above. The inset shows the SE recorded points for a number of cycles. The time resolution of SE was $2.5 \mathrm{~s}$, so the recorded points in every cycle were sufficient to delineate the growth. The one-cycle variations in the inset reflect the changes of optical properties of the surface upon exposure to different reactants. In other words, these would not necessarily be the actual thickness variations. However, the net thickness increase after each cycle should correspond to the actual film growth, as validity of the SE model had been verified by other techniques (see Chapter 2). 


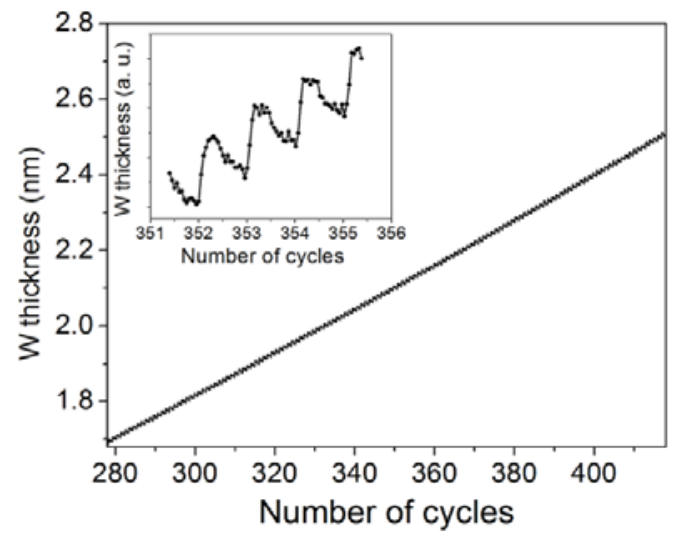

Figure 3.8. In-situ monitoring of HWALD growth in the linear regime by SE; the inset shows stepwise growth for individual cycles. Conditions: one ALD cycle consisted of $10 \mathrm{~s} \mathrm{H}_{2}(100 \mathrm{sccm}) / 20 \mathrm{~s} \mathrm{Ar}$ (purge)/0.1 s WF 6 (2 sccm)/30 s Ar (purge). Other conditions: Ar-carrier gas flow rate of $100 \mathrm{sccm}$ and $50 \mathrm{sccm}$ for $\mathrm{H}_{2}$ and $\mathrm{WF}_{6}$, respectively; hot-wire temperature of $1750{ }^{\circ} \mathrm{C}$; process pressure of $0.15 \mathrm{mbar}$ and $T_{s}$ of $315^{\circ} \mathrm{C}$. Due to the short pulse time of $\mathrm{WF}_{6}$, its actual flow rate cannot be accurately measured.

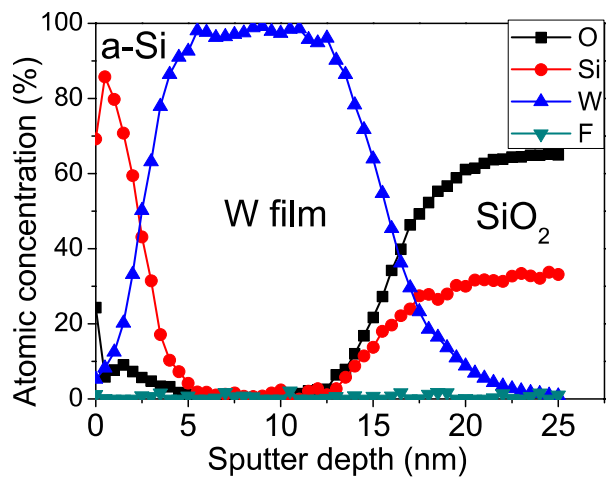

Figure 3.9. XPS depth profile of a 15-nm thick HWALD W film resulted in high-purity W. One ALD cycle consisted of $10 \mathrm{~s} \mathrm{H}_{2}(100 \mathrm{sccm}) / 20 \mathrm{~s} \mathrm{Ar}$ (purge) $/ 0.1 \mathrm{~s} \mathrm{WF}_{6}(2 \mathrm{sccm}) / 30 \mathrm{~s} \mathrm{Ar}$ (purge). Other conditions: Arcarrier gas flow rate of $100 \mathrm{sccm}$ and of $50 \mathrm{sccm}$ for $\mathrm{H}_{2}$ and $\mathrm{WF}_{6}$, respectively; hot-wire temperature of $1750{ }^{\circ} \mathrm{C}$; process pressure of 0.15 mbar and $T_{s}$ of $315^{\circ} \mathrm{C}$. Due to the short pulse time of $\mathrm{WF}_{6}$, its actual flow rate cannot be accurately measured. 
In Fig. 3.9, an XPS depth profile is shown of a $15 \mathrm{~nm}$ HWALD W film grown under the optimized conditions. As mentioned in the Section 3.2.1, the top-5-nm film corresponds to the a-Si capping layer. The SE measurements reveal a thickness of $12.6 \mathrm{~nm}$ of the actual HWALD W layer grown on top of 2.3-nm-thick W seed layer. The total thickness of $15 \mathrm{~nm}$ is in agreement with the estimate from the XPS sputter depth using the average sputter rates. Remarkably, the concentration of $\mathrm{W}$ approaches 99 at\%.

In Fig. 3.10 (a), a depth profile of the O1s-peak signal is demonstrated. Oxygen was observed at the surface and rapidly disappeared in the capping layer. It is noticeable that the O1s peak, present at the $\mathrm{W}-\mathrm{SiO}_{2}$ interface, corresponds to both $\mathrm{Si}-\mathrm{O}$ and $\mathrm{W}-\mathrm{O}$ bonding. In other words, at the $\mathrm{W}-\mathrm{SiO}_{2}$ interface an O-to-W bond signal is clearly present. Likewise, the W4f peak of tungsten with a binding energy of $32.1 \mathrm{eV}$, corresponding to bond of W-to-O of $\mathrm{SiO}_{2}$, can be noticed (Fig. 3.10 (b)). This implies a reaction between $\mathrm{W}$ of the film and $\mathrm{O}$ of $\mathrm{SiO}_{2}$ at the interface.

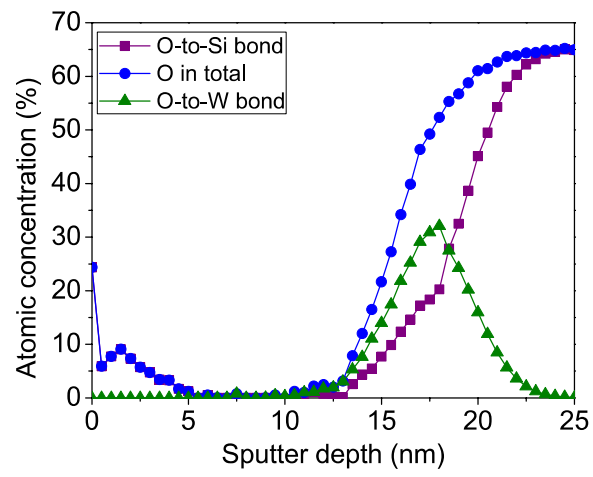

(a)

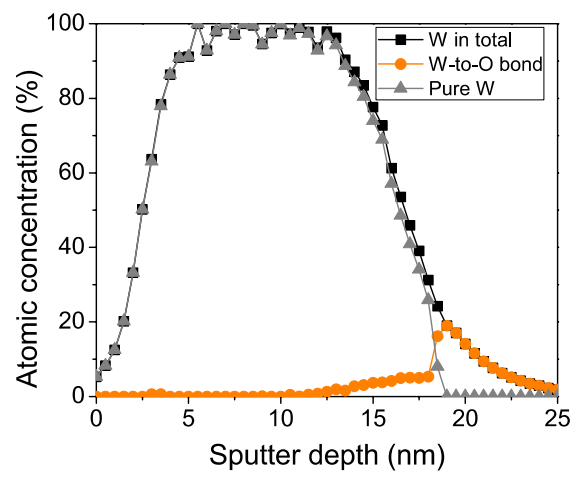

(b)

Figure 3.10. (a) The depth profile of the O1s signal. An oxygen signal is present in the top capping layer and the $\mathrm{SiO}_{2}$ substrate. A clear signal of O-to-W bond was observed at the $\mathrm{W}-\mathrm{SiO}_{2}$ interface. (b) The depth profile of the $\mathrm{W} 4 \mathrm{f}$ signal. At the $\mathrm{W}-\mathrm{SiO}_{2}$ interface, some tungsten oxidation occurred. 


\subsubsection{Conclusion}

This section studied the HWALD W by sequential pulses of $\mathrm{WF}_{6}$ and at- $\mathrm{H}$ precursors in a cold-wall reactor. We demonstrated the co-existence of CVD, etching and ALD modes and investigated the influence of process parameters on each mode. This allowed to independently enhance a selected mode and suppress the others. A higher gas pressure strengthened etching whereas a lower pressure could enhance CVD. By selecting the proper process pressure, $T_{s}$, hot-wire temperature, precursor pulse times and purge times, optimal conditions were found to maintain the ALD mode. Under these chosen conditions, HWALD W films were deposited with a W purity approaching 99 at\%.

\subsection{A Comparison of Tungsten Films Grown by CVD and HWALD}

\subsubsection{Deposition of tungsten by three methods}

One selected HWALD W film was compared with those deposited by $\mathrm{H}_{2}-$ CVD or at-H-CVD methodes. The HWALD W sample was deposited by HWALD cycles under conditions determined in Section 3.3. Two CVD modes were conducted here:

- Continuous $\mathrm{WF}_{6}$ and $\mathrm{H}_{2}$ were mixed in the gas phase to form $\mathbf{H}_{2}-\mathbf{C V D}$ W with the hot-wire off all the time;

- Continuous $\mathrm{WF}_{6}$ and at- $\mathrm{H}$ were mixed in the gas phase to form at- $\mathrm{H}$ CVD W, where at- $\mathrm{H}$ was generated by cracking molecular $\mathrm{H}_{2}$ upon the heated hot-wire.

Details of the process conditions are listed in Table 3.1. Importantly, $\mathrm{H}_{2}-\mathrm{CVD}$ W was deposited at $325^{\circ} \mathrm{C}$ as no deposition was observed at $315^{\circ} \mathrm{C}$ and 0.15 mbar. 
It was found that, at a pressure higher than 0.15 mbar, etching of the deposited tungsten by fluorine dominated rather than CVD, presumably due to the dissociation of $\mathrm{WF}_{6}$ upon the hot-wire, resulting in the enhanced formation of fluorine ${ }^{[16]}$, as discussed in Section 3.3.2. Concerning the at-H-CVD, it only took place at a pressure much lower than 0.15 mbar. Therefore, a pressure of 0.003 mbar was chosen.

Table 3.1. Deposition conditions for samples made by three different methods. The film thickness was measured by in-situ SE.

\begin{tabular}{cccccc}
\hline $\begin{array}{c}\text { Deposition } \\
\text { method }\end{array}$ & $\begin{array}{c}\text { Process } \\
\text { Pressure } \\
(\mathrm{mbar})\end{array}$ & $\begin{array}{c}\text { Substrate } \\
\text { temperature } \\
\left({ }^{\circ} \mathrm{C}\right)\end{array}$ & $\begin{array}{c}\text { Hot-wire } \\
\text { temperature } \\
\left({ }^{\circ} \mathrm{C}\right)\end{array}$ & $\begin{array}{c}\text { Gas flow rate } \\
\mathrm{H}_{2} / \mathrm{WF}_{6}(\mathrm{sccm})\end{array}$ & Growth rate $^{*}$ \\
\hline $\mathrm{H}_{2}$-CVD W & 0.15 & 325 & 25 & $100 / 2$ & $1.430 \mathrm{~nm} / \mathrm{min}$ \\
At-H-CVD W & 0.003 & 315 & 1750 & $100 / 2$ & $0.104 \mathrm{~nm} / \mathrm{min}$ \\
HWALD W & 0.15 & 315 & 1750 & $100 / 2$ & $0.006 \mathrm{~nm} / \mathrm{cycle}$ \\
\hline \hline
\end{tabular}

* Growth rate was measured by SE at the center of the wafer.

\subsubsection{Resistivity and density}

The resistivity results are shown in Table 3.2. The lowest resistivity was obtained with $\mathrm{H}_{2}-\mathrm{CVD} \mathrm{W}$; however, the reader is reminded that this W layer was deposited at a slightly higher $T_{s}$ (Table 3.1). In the literature, the lowest resistivity obtained by CVD with $\mathrm{WF}_{6}$ and $\mathrm{H}_{2}$ varies between 8 and $18 \mu \Omega \cdot \mathrm{cm}{ }^{[17]}$. However, in those reports the deposition temperature was above $400{ }^{\circ} \mathrm{C}$. The resistivity of at- $\mathrm{H}-$ CVD W was slightly higher but still comparable taking the slightly lower growth temperature into account (Tables 3.1 and 3.2). 
Table 3.2. Density (from XRR), resistivity (by FPP) and thickness (by SE) values of W films deposited by three different methods. All measurements were taken at the center of the wafer.

\begin{tabular}{cccc}
\hline \hline Sample & $\begin{array}{c}\text { Density } \\
\left(\mathrm{g} / \mathrm{cm}^{3}\right)\end{array}$ & $\begin{array}{c}\text { Resistivity } \\
(\mu \Omega \cdot \mathrm{cm})\end{array}$ & $\begin{array}{c}\text { Thickness by in- } \\
\text { situ SE }(\mathrm{nm})\end{array}$ \\
\hline $\mathrm{H}_{2}$ CVD W & 18.75 & 20 & 10.2 \\
At-H-CVD W & 19.19 & 28 & 24.6 \\
HWALD W & 17.15 & 100 & 13.9 \\
\hline \hline
\end{tabular}

The density of the tungsten films was obtained by XRR measurements. As $W$ deposition and the seed layer formation were two different processes, densities and thicknesses of these two layers were fitted separately. The obtained density of the $\mathrm{W}$ seed layer was around $17.3 \mathrm{~g} / \mathrm{cm}^{3}$. The density of bulk tungsten ranges from 15.8 to $19.25 \mathrm{~g} / \mathrm{cm}^{3}$, depending on its crystal phase ${ }^{[17,18]}$, while most industrially manufactured a-phase $W$ exhibits the highest density of $19.25 \mathrm{~g} / \mathrm{cm}^{3}$. W films realized by at-H-CVD possessed the highest density, close to that of $\alpha-W^{[17]}$. The density of $\mathrm{H}_{2}$-CVD W was $2.3 \%$ lower. HWALD W exhibited the lowest density and the highest resistivity. The possible reasons for this will be discussed in Section 3.4.4.

\subsubsection{Surface roughness}

Surface roughness has great effects on phisical properties of thin films. For applicatin of thin metal film in microelectronics, its influence on resistivity is important. An inhomogenuous and rough surface can enhance electron scattering from the boundaries, reducing electrical conductivity ${ }^{[19,20]}$. Thus, a smooth surface is more preferred.

To evaluate surface roughness of HWALD W, the roughness of the substrate, the seed layer and the capping layer need to be measured because they also 
contribute to the resulting film roughness. It is known that a thicker a-Si seed layer will lead to a rougher surface of $\mathrm{W}$ after the reaction between $\mathrm{WF}_{6}$ and $\mathrm{a}-\mathrm{Si}^{[21]}$. In order to estimate the roughness of the surface before the depositions, a $\mathrm{SiO}_{2}$ substrate, a 5-nm a-Si layer, and a W seed layer obtained after converting the a-Si into the $W$ were measured by AFM (Fig. 3.11). Further, the roughness evolution after the subsequent deposition of $W$ films was measured by AFM (Fig. 3.12). As the measurements have been done in air, one should realize that such thin layers will (partially) be oxidized; although this may slightly affect the roughness, still comparisons between different depositions are possible.

Fig. 3.11 shows a smooth surface of a HF-treated $\mathrm{SiO}_{2}$ substrate $(\mathrm{RMS}=0.25 \mathrm{~nm})$, a-Si layer $(\mathrm{RMS}=0.018 \mathrm{~nm})$ and a rougher $\mathrm{W}$ seed layer $(\mathrm{RMS}=1.67 \mathrm{~nm})$. In Fig. 3.12, the AFM images of the three $\mathrm{W}$ depositions are presented. It can been seen that at-H-CVD provided the smoothest film. $\mathrm{The}_{2}-\mathrm{CVD}$ film exhibits a rougher surface, probably due to the higher $T_{s}$. The roughness profiles of $\mathrm{H}_{2}$-CVD W and HWALD W both exhibit sharp height variations with peak-valley difference reaching $20 \mathrm{~nm}$. In contrast, the profile of at-H-CVD W shows a much smaller difference. As the at-H-CVD film is approximately twice as thick as the other two films, its relative roughness is even lower. While further analyzing Fig. 3.12, it can be concluded that $\mathrm{H}_{2}-\mathrm{CVD}$ W exhibits the smallest correlation length and at- $\mathrm{H}$ CVD W has the biggest. This can be related to (i) a difference in the nucleation site density and (2) either vertically- or laterally-dominant growth. Atomic hydrogen obviously plays a crucial role in the growth mechanism, smoothing the film surface for at-H-CVD. 
(a)
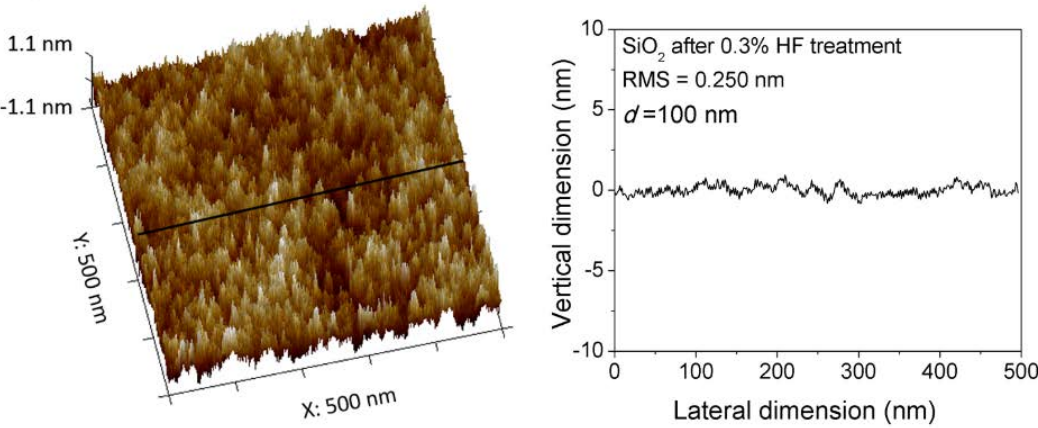

(b)
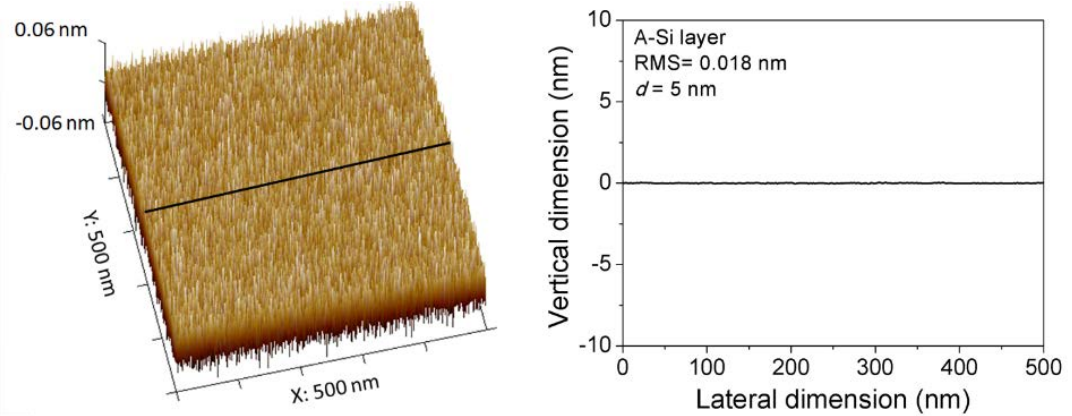

(c)
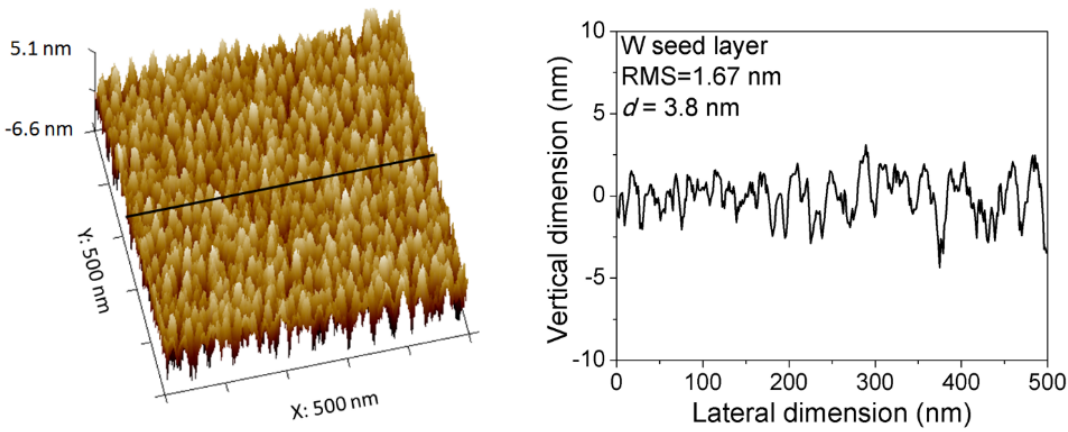

Figure 3.11. Surface morphology of (a) $\mathrm{SiO}_{2}$ substrate dipped in $0.3 \% \mathrm{HF}$, (b) 5-nm a-Si layer, and (c) $W$ seed layer formed by reaction between the a-Si and $W_{6}$. Roughness (RMS) was measured by AFM and is shown in the right-side graphs; the thickness $d$ was obtained by SE. The graphs illustrate the height variation along the black lines drawn in the left-side AFM images. 
(a)
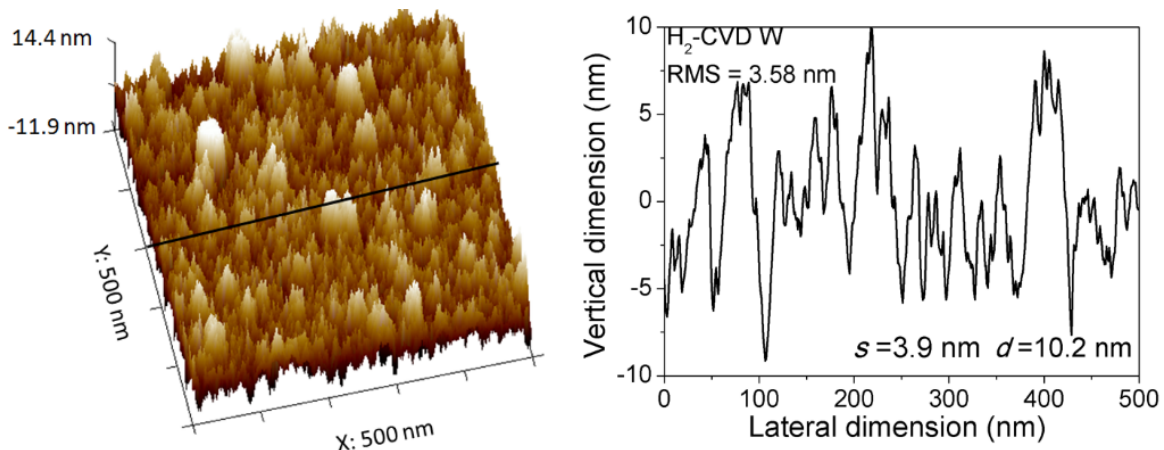

(b)
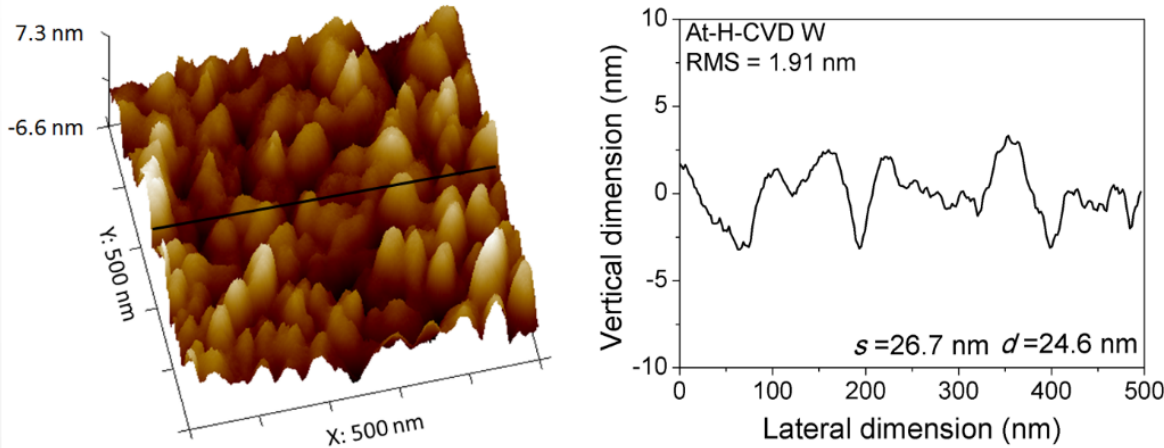

(c)
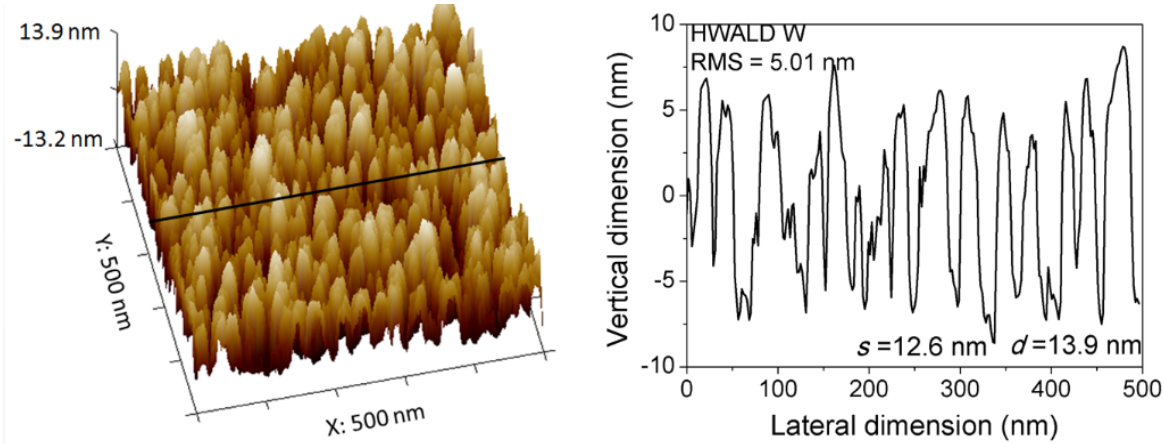

Figure 3.12. Surface morphology of (a) $\mathrm{H}_{2}$-CVD W deposited at $325^{\circ} \mathrm{C}$, (b) at- $\mathrm{H}-\mathrm{CVD}$ W deposited at $315^{\circ} \mathrm{C}$, and (c) HWALD W deposited at $315^{\circ} \mathrm{C}$ (see Table 3.1 for other conditions). The roughness (RMS) was measured by AFM and is shown in the right-side graphs; the thickness $d$ was obtained by SE; the correlation length $s$ was extracted by the Nanoscope Analysis software. The graphs illustrate the height variation along the black lines drawn in the left-side AFM images. 


\subsubsection{Crystallinity}

Apart from the amorphous phase, tungsten is known to exist in $\alpha, \beta$ and $y$ crystal phases ${ }^{[18,22]}$. $\alpha-W$ is the most stable phase; it has a body centered cubic lattice with a lattice constant of $0.316 \mathrm{~nm}^{[23]}$. The $\beta$-phase exhibits a cubic $A_{3} B(A)$ 15) crystal structure and is formed by $\mathrm{W}_{3} \mathrm{~W}$ or $\mathrm{W}_{3} \mathrm{O}$ clusters ${ }^{[24,25]}$ with a lattice constant between 0.503 and $0.504 \mathrm{~nm}^{[26]}$. It is reported that the $\beta$-phase is metastable and can be transformed into the $\alpha$-phase upon annealing at $650-750^{\circ} \mathrm{C}^{[27,28]}$. In addition, the $\gamma^{-}$ phase has only been found at the beginning of sputtering and easily recrystallizes to $\alpha-W^{[17]}$. For applications in semiconductor devices, $\alpha-W$ is most desired because of its low resistivity; while $\beta-W$ is adopted in transition edge sensors due to its superconducting properties where transition temperatures are as high as $4 K^{[26,29]}$.

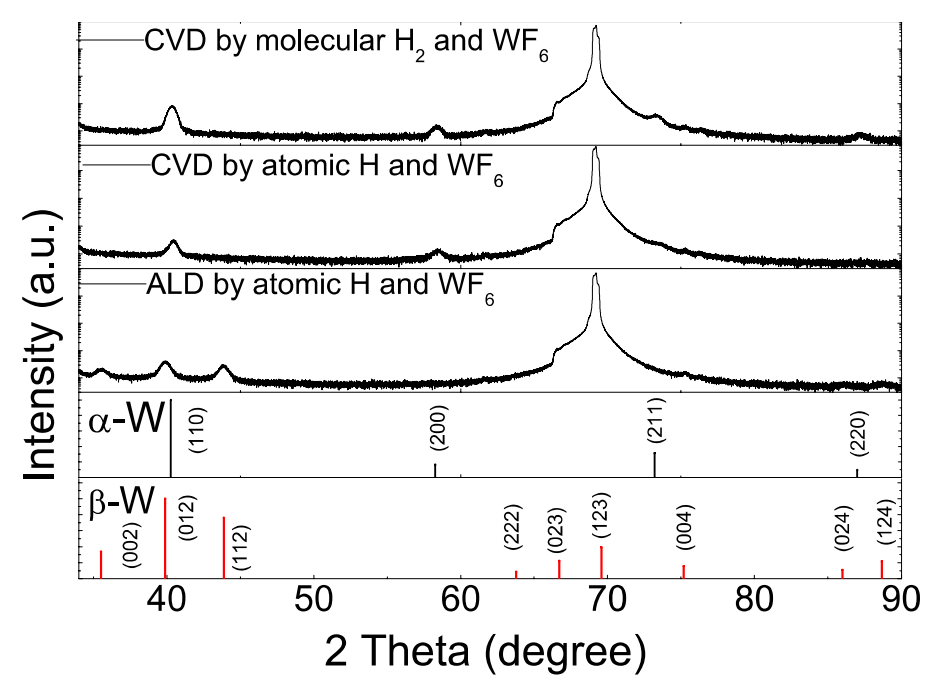

Figure 3.13. XRD patterns of $\mathrm{W}$ films deposited by three different methods. The diffraction peak positions and the corresponding attribution to $\alpha$ - and $\beta$-phases are shown ${ }^{[17,22,30]}$. 
Fig. 3.13 demonstrates the XRD patterns of $\mathrm{W}$ films deposited by the three mentioned methods. The strongest peak at $69^{\circ}$ corresponds to the (100) Si substrate. Because of the high intensity of this Si peak, three peaks of the $\beta$ phase in the range of $60^{\circ}$ to $70^{\circ}$ are not visible. The distinguishable peaks of tungsten are located at $40.2^{\circ}((110)$ plane $), 58.2^{\circ}$ ((200) plane), $73.2^{\circ}\left((211)\right.$ plane) and $87.1^{\circ}$ ((220) plane) for $\alpha-W^{[22]}$, and at $35.5^{\circ}((002)$ plane $), 39.8^{\circ}((012)$ plane $), 43.8^{\circ}((112)$ plane $), 86.2^{\circ}$ ((024) plane) and $88.7^{\circ}\left((124)\right.$ plane) for $\beta-W^{[17,30]}$. It is apparent from the graph that the unique peaks of $\beta-W$ are only present in HWALD $W$, whereas 4 peaks of $\alpha-W$ can be observed in both CVD-films. Based on this measurement it can be concluded that the HWALD $W$ forms the $\beta$ phase in contrast to $\alpha-W$ obtained by both CVD methods.

The lattice constants of the three films in Fig. 3.13 have been calculated from the diffraction peak positions, revealing $0.505 \pm 0.001 \mathrm{~nm}$ for HWALD W, $0.315 \pm 0.001 \mathrm{~nm}$ for at-H-CVD and 0.316 $\pm 0.001 \mathrm{~nm}$ for $\mathrm{H}_{2}-\mathrm{CVD}$. These values are consistent with the lattice constants reported for $\alpha$ and $\beta$ phases in the literature. In addition, density of bulk $\alpha-W$ is reported to be higher ${ }^{[17,18]}$, with a typical value of $19.31 \mathrm{~g} / \mathrm{cm}^{3}$, whereas that of the $\beta$-phase is $19.1 \mathrm{~g} / \mathrm{cm}^{3}$. $\beta-W$ is also known to possess a high resistivity, above 100 and up to $1290 \mu \Omega \cdot \mathrm{cm}^{[25,31-33]}$, compared to $5.6 \mu \Omega \cdot \mathrm{cm}$ for $\alpha-W$. The lower density and higher resistivity of our HWALD film are in good agreement with the properties of $\beta-W$.

Further, based on the XRD peak patterns and Scherrer's equation ${ }^{[34]}$, we evaluated the grain sizes. To note, only grains with planes oriented parallel to the substrate could be observed by a $\theta-2 \theta$ scan. The calculated grain size of $\mathrm{H}_{2}-\mathrm{CVD} W$, at-H-CVD W and HWALD W ranged from 8.3 to $14.1 \mathrm{~nm}, 7.0$ to $21.6 \mathrm{~nm}$ and 5.2 to $10.3 \mathrm{~nm}$, respectively. Hence, HWALD possessed the smallest value and narrowest range of grain size. A smaller grain size suggests a larger number of grain boundaries in the film. This can contribute to an even higher electrical resistivity of the HWALD $\beta-W$ compared to the CVD $\alpha-W$.

It is reported that impurities, especially oxygen, can enhance the formation and stability of $\beta-W^{[35-39]}$. For example, $\beta-W$ is mostly formed during hydrogen reduction of tungsten oxides ${ }^{[40-42]}$. In addition, a transition from the $\beta$ - to the $\alpha$-phase can be achieved by annealing above $700{ }^{\circ} \mathrm{C}$ due to the removal of incorporated 50 
oxygen and enhancing the mobility of $\mathrm{W}$ atoms ${ }^{[27,28]}$. On the other hand, in practice, oxygen is commonly present in PVD and CVD chambers, in residual gases (mainly water vapor). Our experiments were conducted at a background pressure of $10^{-7}$ mbar, giving the impinging flux of background residuals of about 0.1 monolayer/s ${ }^{[43]}$. The deposition rate of HWALD $\mathrm{W}$ was approximately 0.02 monolayer/cycle with a total purge time of $50 \mathrm{~s}$ per cycle. This results in the arrival flux of background residuals to the substrate of 5 monolayer/cycle.

Considering the low growth rate $(0.006 \mathrm{~nm} /$ cycle for HWALD compared to $1.43 \mathrm{~nm} / \mathrm{min}$ for $\mathrm{H}_{2}-\mathrm{CVD}$ and $0.104 \mathrm{~nm} / \mathrm{min}$ for at-H-CVD) and long purge time, the films are therefore expected to be contaminated by oxygen. Namely, when the film is exposed to at- $\mathrm{H}$ after a WF 6 pulse, fluorine adsorbed on the surface can (partially) be removed, leaving a reactive surface of tungsten, possibly with dangling bonds. During the following purge pulse, the background residuals such as water will arrive at the surface in quantities sufficient to fully oxidize it. The film (presumably up to several monolayers below the surface) can further be reduced back to tungsten by the upcoming at-H pulses. This growth mechanism via intermediate oxidation should result, based on the literature, in $\beta$-tungsten instead of $\alpha$-tungsten. To note, compositional analysis of the HWALD $\beta-W$ by XPS (Fig. 3.9) reveals a high-purity tungsten, with the share of $\mathrm{W}$ approaching 99 at.\%. This implies that oxygen is efficiently removed during exposures to at- $\mathrm{H}$, i.e. by reduction.

Cross-sectional HR-TEM images of HWALD W with a-Si capping layer are presented in Fig. 3.14. In Fig. 3.14 (a), a rough film can be observed with film thickness varying between 10 and $18 \mathrm{~nm}$. This height variation is in agreement with the AFM results in Fig. 3.12 (c). Fig. 3.14 (b) shows the same film at a higher magnification and exposes individual crystal grains. The visual grain size in Fig. 3.14 (b) is in the order of $10 \mathrm{~nm}$; the film roughness is probably determined by different grain sizes and orientations. Fig. 3.14 (c) shows a close-up of one grain. The $d$ spacing values calculated by Fast Fourier transform (FFT) are 0.1361 0.0005 and $0.2553 \pm 0.0012 \mathrm{~nm}$, respectively. This corresponds to (123) and (012) planes of $\beta$ W, which confirms the XRD results of Fig. 3.13. 


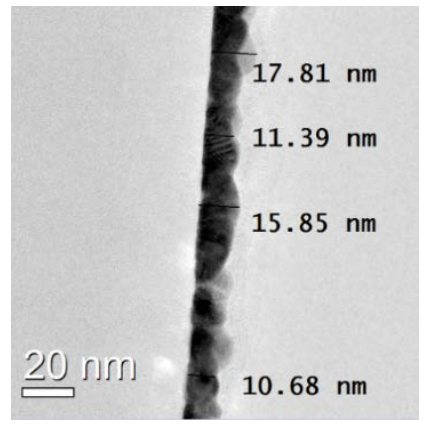

(a)

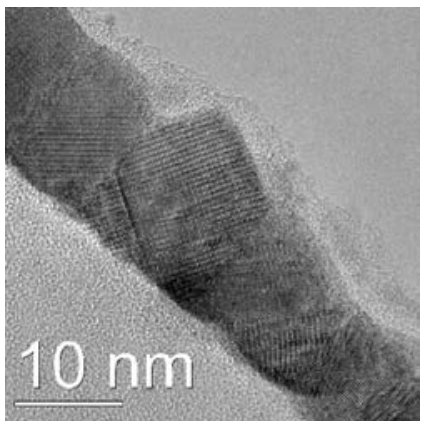

(b)

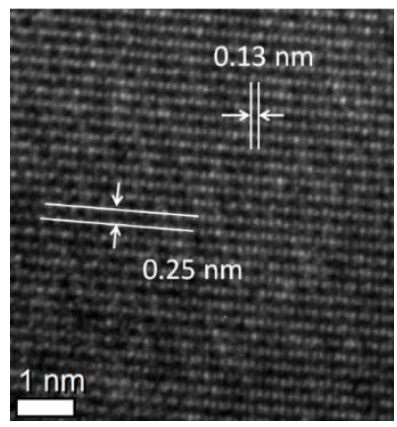

(c)

Figure 3.14. Representative HR-TEM cross-sectional images of a HWALD W film with a 5-nm a-Si capping layer. Individual crystal grains can be clearly seen in (a) and (b). The close-up of one grain and $d$-spacing, as calculated by Fast Fourier transform (FFT), are displayed in (c).

No obvious interfacial layer between the W seed layer and the HWALD W layer is visible; the grains continue from the $\mathrm{SiO}_{2}$ layer to top surface. This phenomenon indicates that the seed layer is likely to have the same crystal structure and is $\beta-W$ as well. It has been reported that tungsten layer can absorb oxygen from surrounding $\mathrm{SiO}_{2}$ during $\mathrm{W} C \mathrm{CV}$ at a $T_{s}$ of $300{ }^{\circ} \mathrm{C}^{[44]}$. On the other hand, a $\mathrm{W}$ seed layer was proven to react with $\mathrm{O}$ at the $\mathrm{W}-\mathrm{SiO}_{2}$ interface in our case, shown in Fig. 3.10 , implying that the $\mathrm{W}$ seed layer in our case can in principle incorporate oxygen from the $\mathrm{SiO}_{2}$ beneath, thereby forming the metastable $\beta$ phase.

Energy-filtered TEM (EFTEM) was employed to provide mapping of carbon, silicon and oxygen in the HWALD W sample with a-Si capping layer. In Fig. 3.15, the intensity of the grey scale and the RGB colors denote the concentrations of mapped elements. The 5-nm thin capping layer can be clearly seen in Fig. 3.15 (a). The visual appearance of $\mathrm{Si}$ inside the $\mathrm{W}$ layer is due to comparable energy loss peaks of $\mathrm{Si}$ and $\mathrm{W}$. Oxygen is absent in the $\mathrm{W}$ layer and is only visible in the $\mathrm{SiO}_{2}$ substrate and the oxidized capping layer, which is consistent with XPS results (Fig 3.9). The RGB image in Fig 3.15 (d) combines all the elements. Together with the XPS results (Fig. 3.9), this confirms the high purity of the $\mathrm{W}$ layer. 


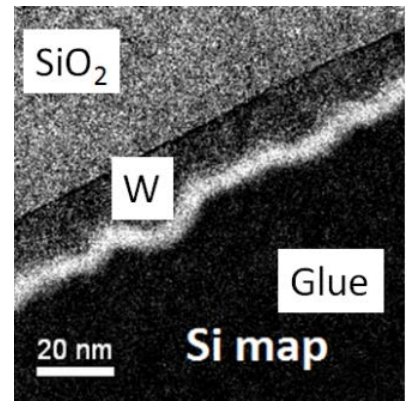

(a)

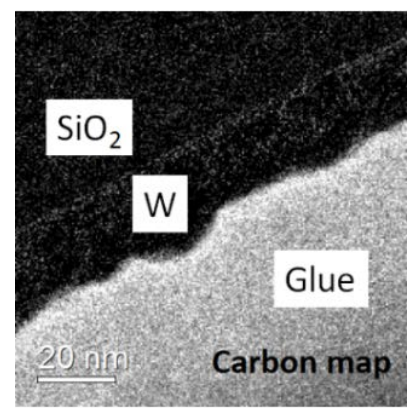

(c)

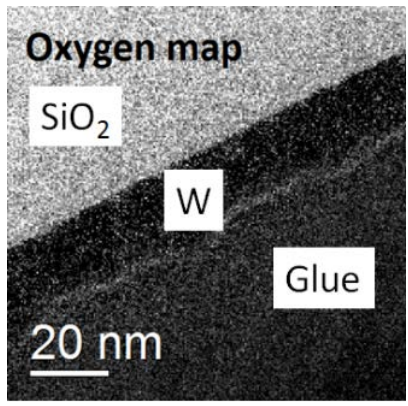

(b)

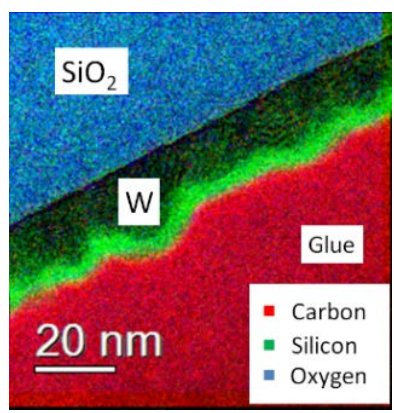

(d)

Figure 3.15. Energy-filtered TEM (EFTEM) images of a HWALD W film with a-Si capping layer: (a), (b) and (c) present element mapping on grey scale (brighter regions denote higher concentrations); (d) is the color mapping combining carbon (red), silicon (green), and oxygen (blue).

\subsubsection{Conclusions}

In this section, tungsten (W) layers deposited by three different methods were characterized and compared: (i) thermal CVD with molecular hydrogen and $W F_{6}$ gas, (ii) thermal $C V D$ by atomic hydrogen and $W_{6}$, and (iii) hot-wire assisted thermal ALD using atomic hydrogen and $\mathrm{WF}_{6}$. Before the deposition, a 3-nm W layer was formed as a seed layer. Among the three methods, W obtained by HWALD possessed the highest resistivity of $100 \mu \Omega \cdot \mathrm{cm}$ and the lowest density of $17.15 \mathrm{~g} / \mathrm{cm}^{3}$, both related to its appearance in the crystalline $\beta$-phase. In contrast, both CVD 
methods resulted in $\alpha$-phase $W$ with a resistivity around $20 \mu \Omega \cdot \mathrm{cm}$ and a density of roughly $19 \mathrm{~g} / \mathrm{cm}^{3}$. XPS revealed a reaction between $\mathrm{W}$ and $\mathrm{SiO}_{2}$ at the interface of the seed layer and the substrate. Besides, no obvious interfacial layer could be seen between HWALD $W$ and the seed layer of $W$.

\subsection{Wrap up}

Despite the influences of back-stream diffusion of $\mathrm{WF}_{6}$ and adsorptions of reactants on walls, HWALD $W$ has been successfully grown by controlling the deposition conditions, particularly the process pressure. The film possesses a very high purity. However, $W$ formed by this HWALD in the cold-wall reactor was in the $\beta$-phase and of a high resistivity, compared to the low-resistivity $\alpha-W$ grown by CVD. Although the resistivity of this $\beta-W$ obtained by HWALD remains the lowest value in the range known for $\beta-W$, its counterpart is more preferable for applications in microelectronics and semiconductor devices. In this light, efforts are required to make to minimize the effects of adsorption of reactants on the cold walls, so as to obtain $\alpha-W$.

\section{References}

[1] J. E. J. Schmitz, Chemical Vapor Deposition of Tungsten and Tungsten Silicides for VLSI/ULSI Applications (Noyes, Park Ridge NJ, 1992).

[2] T. Noma, K. S. Seol, M. Fujimaki and Y. Ohki, J. Appl. Phys. 85, 8423 (1999).

[3] C.-E. Morosanu and V. Soltuz, Thin Solid Films 52, 181 (1978).

[4] T. T. Kodas and M. J. Hampden-Smith, The Chemistry of Metal CVD (Wiley-VCH, 2008).

[5] J. Creighton, J. Electrochem. Soc. 136, 271 (1989).

[6] J. Creighton, J. Vac. Sci. Technol. A 7, 621 (1989). 
[7] P. C. Lemaire, M. King and G. N. Parsons, J. Chem. Phys. 146, 052811 (2017).

[8] D. A. Bell, J. L. Falconer and C. M. McConica, J. Electrochem. Soc. 142, 2401 (1995).

[9] R. W. Boswell and R. K. Porteous, J. Appl. Phys. 62, 3123 (1987).

[10] N. Desatnik and B. E. Thompson, J. Electrochem. Soc. 141, 3532 (1994).

[11] N. Kobayashi, Y. Nakamura, H. Goto and Y. Homma, J. Appl. Phys. 73, 4637 (1993).

[12] J. N. Smith Jr. and W. L. Fite, J. Chem. Phys 37, 898 (1962).

[13] H. Wise and C. M. Ablow, J. Chem. Phys. 35, 10 (1961).

[14] R. Puurunen, J. Appl. Phys. 97, 121301 (2005).

[15] S. M. George, Chem. Rev. 110, 111 (2010).

[16] M. Yang, A.A.I. Aarnink, A. Y. Kovalgin, R.A.M. Wolters and J. Schmitz, Phys. Status Solidi A 212, 1607 (2015).

[17] E. Lassner and W. D. Schubert, Tungsten: Properties, Chemistry, Technology of the Elements, Alloys, and Chemical Compounds (Springer Science \& Business Media, New York, 1999).

[18] R. Warncke, M. L. Gerwien and L. Gmelin, Gmelin handbook of inorganic chemistry: 8th ed., No. 54, Tungsten, Suppl. , Vol. A3 (Springer, Heidelberg, 1989).

[19] D. Ketenoğlu and B. Ünal, Phys. A 392, 3008 (2013).

[20] V. Timoshevskii, Y. Ke, H. Guo and D. Gall, J. Appl. Phys. 103, 113705 (2008).

[21] S. Bystrova, Diffusion barriers for Cu metallisation in Si integrated circuits: deposition and related thin film properties (Ph.D. Thesis, University of Twente, 2004).

[22] F. Allen, O. Kennard, D. Watson, L. Brammer, A. Orpen and R. Taylor, International Tables for Crystallography, vol. C (Dordrecht: Kluwer Academic Publishers, 1995).

[23] W. Morcom, W. Worrell, H. Sell and H. Kaplan, Metall. Trans. 5, 155 (1974).

[24] T. Millner, A. J. Hegedüs, K. Sasvári and J. Neugebauer, Z. Anorg. Allg. Chem. 289, 288 (1957).

[25] P. Petroff, T. Sheng, A. Sinha, G. Rozgonyi and F. Alexander, J. Appl. Phys. 44, 2545 (1973).

[26] S. Basavaiah and S. Pollack, J. Appl. Phys. 39, 5548 (1968).

[27] Y. Shen and Y. Mai, Mater. Sci. Eng. A 284, 176 (2000).

[28] C. Tang and D. Hess, Appl. Phys. Lett. 45, 633 (1984).

[29] A. Lita, D. Rosenberg, S. Nam, A. Miller, D. Balzar, L. Kaatz and R. Schwall, IEEE Trans. Appl. Supercond. 15, 3528 (2005).

[30] A. Bartl, PhD thesis Thesis, TU Vienna, 1997.

[31] Q. Hao, W. Chen and G. Xiao, Appl. Phys. Lett. 106, 182403 (2015).

[32] P. Petroff and W. Reed, Thin Solid Films 21, 73 (1974).

[33] J. R. Rairden, US patent 3504325 A (1970).

[34] A. Patterson, Phys. Rev. 56, 978 (1939).

[35] D. P. Basile, C. L. Bauer, S. Mahajan, A. G. Milnes, T. N. Jackson and J. DeGelormo, Mater. Sci. Eng. B 10, 171 (1991). 
[36] A. Bensaoula, J. C. Wolfe, A. Ignatiev, F. O. Fong and T. S. Leung, J. Vac. Sci. Technol. A 2, 389 (1984).

[37] M. J. O'Keefe and J. T. Grant, J. Appl. Phys. 79, 9134 (1996).

[38] Y. Pauleau, P. Lami, A. Tissier, R. Pantel and J. C. Oberlin, Thin Solid Films 143, 259 (1986).

[39] J. H. Souk, J. F. O'Hanlon and J. Angillelo, J. Vac. Sci. Technol. A 3, 2289 (1985).

[40] M. Charlton, Nature 169, 109 (1952).

[41] M. Charlton, Nature 174, 703 (1954).

[42] G. Mannella and J. O. Hougen, J. Phys. Chem. 60, 1148 (1956).

[43] J. Orloff, Handbook of charged particle optics (CRC press, Boca Raton, 2008).

[44] D. C. Paine, J. C. Bravman and C. Yang, Appl. Phys. Lett. 50, 498 (1987). 


\title{
4 \\ Low-resistivity $\alpha$-phase \\ HWALD W grown in a hot-wall reactor
}

\begin{abstract}
.
In this chapter, the HWALD technique is employed to grow high-purity a-phase tungsten (W) films at a substrate temperature of $275^{\circ} \mathrm{C}$. The films exhibit a high-purity (99 at.\%) W, according to X-ray photoelectron spectroscopy. The X-ray diffraction scans reveal the existence of $\alpha$-phase $W$. The resistivity measurements by means of four point probe, transfer length method test structures and the Drude-Lorentz SE model all reveal a low resistivity of $15 \mu \Omega \cdot \mathrm{cm}$. The high-resolution transmission electron microscopy analysis shows a uniform and conformal coverage of high aspect ratio structures, confirming the effective ALD process and the sufficient diffusion of both $\mathrm{WF}_{6}$ and at- $\mathrm{H}$ into deep trenches. Finally, it is found that $\mathrm{W}$ layers start to become electrically continuous in a thickness range of 2-3 nm.
\end{abstract}

This chapter is based on the publications:

Mengdi Yang, Antonius A.I. Aarnink, Jurriaan Schmitz and Alexey Y. Kovalgin, "Low-resistivity $\alpha$ phase tungsten films grown by hot-wire assisted ALD in high-aspect-ratio structures", Thin Solid Films, 646, 199(2018).

Sourish Banerjee, Rik van der Velde, Mengdi Yang, Jurriaan Schmitz and Alexey Y. Kovalgin, "Electrical test structures for verifying continuity of ultra-thin insulating and conducting films", Microelectronic Test Structures (ICMTS), International Conference of IEEE, pp 1-6 (2017).

Alexey Y. Kovalgin, Mengdi Yang, Sourish Banerjee, Ramazan O. Apaydin, Antonius A.I. Aarnink, Sachin Kinge and Rob A.M. Wolters, "Hot-Wire Assisted ALD: A Study Powered by In Situ Spectroscopic Ellipsometry”, Adv. Mater. Interfaces, 4, 1700058(2017), Invited. 


\subsection{Introduction}

In the last chapter, a novel technique to deposit W by hot wire assisted ALD was established. However, the adsorption of precursors on cold reactor walls causes etching and CVD modes, greatly limiting the performance of HWALD process. To improve the HWALD, the adsorption of precursors should be minimized. In this light, a hot-wall reactor is likely to be a better choice due to a weakened precursor adsorption on its heated walls.

Moreover, the resulted cold-wall-reactor $W$ was in the $\beta$-phase with a resistivity of $100 \mu \Omega \cdot \mathrm{cm}$. This value is prohibitively high considering interconnects in microelectronics, whereas $W$ can reach a much lower resistivity of $15 \mu \Omega \cdot \mathrm{cm}$. To obtain HWALD W of low resistivity, $\alpha$-phase $W$ is demanded. In a cold-wall reactor, precursors, water vapor and other impurities may additionally adsorb on the walls, which may be a reason for the formation of the $\beta$-phase. Considering this, utilizing a hot-wall reactor to suppress all possible wall-absorption effects may result in the $\alpha$ phase. In this chapter, results of HWALD of $W$ in the hot-wall reactor will be presented.

\subsection{Experimental}

\subsubsection{Deposition of HWALD tungsten films}

The tungsten thin films were deposited on top of $100 \mathrm{~nm}$ silicon dioxide $\left(\mathrm{SiO}_{2}\right)$ thermally grown on p-type $\mathrm{Si}(100)$ wafers. Prior to deposition, the wafers were cleaned in fuming (99\%) $\mathrm{HNO}_{3}$ and boiling $69 \% \mathrm{HNO}_{3}$ to remove organic and metallic contaminations, respectively. Then the substrates were immersed in $0.3 \%$ $\mathrm{HF}$ solution for $3 \mathrm{~min}$. To circumvent the very slow nucleation of tungsten on $\mathrm{SiO}_{2}{ }^{[1]}$, a W seed layer of an average thickness from 2 to $5 \mathrm{~nm}$ was pre-formed on $\mathrm{SiO}_{2}$ at a substrate temperature of $325^{\circ} \mathrm{C}$. The formation of the seed layer is the same as described in section 3.2.1 of Chapter 3. 
The HWALD W films were grown using sequential $\mathrm{WF}_{6}$ and at-H pulses at substrate temperatures ranging between 220 and $350{ }^{\circ} \mathrm{C}$, and total pressures between 0.003 and 0.5 mbar. The temperature of the hot wire was set at $1750{ }^{\circ} \mathrm{C}$. The flow rates of $\mathrm{WF}_{6}$ and $\mathrm{H}_{2}$ were fixed at $3 \mathrm{sccm}$ and 50 sccm, respectively; an $\mathrm{Ar}$ purge of $50 \mathrm{sccm}$ was introduced in between the precursor pulses. The pulse and purge durations were optimized to find the HWALD window. Finally, an approximately 10-nm-thick capping layer of a-Si was deposited on top of HWALD W, to prevent tungsten oxidation in air after sample unloading.

Besides planar $\mathrm{SiO}_{2}$ substrates, high aspect ratio (HAR) Si pillars and $\mathrm{Al}_{2} \mathrm{O}_{3}-$ coated Si trenches were used to examine the step coverage of HWALD W. On the pillars, the HWALD process was directly started without the seed layer formation; whereas the seed layer was first formed on the $\mathrm{Al}_{2} \mathrm{O}_{3}$-covered substrates. Due to the narrow trenches (aspect ratio (AR) up to 36), the a-Si thickness for the seed layer was reduced to $0.5 \mathrm{~nm}$ in this case. Further, no a-Si capping layer was applied to the HAR structures after HWALD.

\subsubsection{Ex-situ analysis}

The film thickness at the wafer center was measured real-time by SE during each deposition experiment. For thickness mapping, ex-situ SE was employed.

The crystallinity was measured by XRD using the same instrument as described in Chapter 3. The film surface morphology was characterized by a Bruker Fastscan/ICON model AFM. The film composition was obtained from XPS.

\subsubsection{Resistivity measurements}

In addition to the SE measurements, the resistivity was electrically measured with an automatic Polytec four point probe (FPP) stage for blanket films. Furthermore, 
Transfer Length Method (TLM) ${ }^{[2]}$ test structures were realized to measure $\mathrm{W}$ resistivity in the thickness range $0.65-5 \mathrm{~nm}$. The TLM (also called Shockley method ${ }^{[3]}$ ) allows to reliably obtain contact and sheet resistances by measuring the potential difference between pairs of contacts at a given applied current and plotting these as a function of the pair distance. Two masks were applied: (i) defining Pt electrodes by lift-off and (ii) one-step patterning the HWALD W and capping a-Si layers by conventional photolithography. The TLM fabrication details can be found in the previous work that focused on the properties of titanium nitride thin films ${ }^{[4,5]}$. To note, all the layers (including the $\mathrm{W}$ seed layer) were deposited on pre-formed $\mathrm{Pt}$ electrodes. To etch a-Si at room temperature, $\mathrm{HF}(50 \%), \mathrm{HNO}_{3}(69 \%)$ and deionized $\mathrm{H}_{2} \mathrm{O}$ were mixed at 1:50:40 ratios, respectively; $W$ was patterned in a $31 \% \mathrm{H}_{2} \mathrm{O}_{2}$ solution at $50{ }^{\circ} \mathrm{C}$. The TLM structures were characterized using a Karl-Suss PM8 probe station and a Keithley 4200 semiconductor characterization system.

\subsubsection{Film continuity}

The transformation between discontinuous and continuous layers was explored for conducting tungsten films as well. Standard circular transmission line model $(C T L M)^{[6]}$ structures were fabricated to measure the electrical behavior of $\mathrm{W}$ films varying with thicknesses in the range of $0.3-8 \mathrm{~nm}$. The thickness of the preformed $W$ seed layer was decreased to approximately $0.5 \mathrm{~nm}$ to minimize its influence on film continuity (effects of a-Si seed layer of various thicknesses are discussed in section 6.3.3 of Chapter 6). The two Pt electrodes in CTLM structures were realized on thermally grown $\mathrm{SiO}_{2}$ by sputtering $5 \mathrm{~nm}$ Ti and $25 \mathrm{~nm}$ Pt combined with lift-off ${ }^{[7]}$. On top of the Pt electrodes, HWALD W and capping layers were deposited. Electrical contacts to the Pt electrodes were made using probe needles that scratch through the a-Si/W stack on top. 


\subsection{Results and discussion}

\subsubsection{HWALD window}

Given a certain combination of precursors and reactor geometry, the precursor exposure and purge times are the key parameters determining the ALD window. A properly-tuned ALD process reveals self-limiting surface reactions, leading to a time-independent growth rate per cycle (GPC). As shown in Fig. 4.1 (a), the GPC sharply increased with the at- $\mathrm{H}$ exposure time rising from 2 to $4 \mathrm{~s}$, and remained constant for the exposures longer than $6 \mathrm{~s}$. With respect to the post-at- $\mathrm{H}$ purge time, the GPC stabilized for purges longer than $6 \mathrm{~s}$ (Fig. 4.1 (b)), pointing to the efficient removal of at- $\mathrm{H}$ prior to each $\mathrm{WF}_{6}$ pulse and thus avoiding $\mathrm{CVD}$ reactions. Fig. 4.1 (c) and 4.1 (d) further illustrate the influence of the pulse- and purge-time of $W_{6}$. The GPC was only slightly influenced by $W_{6}$ pulse times from $0.3 \mathrm{~s}$ to $2 \mathrm{~s}$. The GPC continued to rise as the pulse time was longer than $2 \mathrm{~s}$ because the fixed purge time was not enough to remove all $W_{6}$, thus causing CVD. However, the GPC gradually increased as the post-WF 6 purge time exceeded $2 \mathrm{~s}$, as shown in Fig. 4.1 (d). A shorter post-WF $F_{6}$ purge time was inadequate to remove all $\mathrm{WF}_{6}$, leading to a strong suppression of the GPC by the co-existent etching of the deposited $\mathrm{W}$ film ${ }^{[8]}$. The increase of net GPC, while going from 2 to $7 \mathrm{~s}$ of the post-WF$F_{6}$ purge time, is therefore related to the diminishing contribution of etching. The latter is due to the better removal of fluorine-containing species, as mentioned in section 3.3.1 of Chapter 3, from the reaction chamber. Based on Fig. 4.1, a standard HWALD cycle was chosen to consist of a $7 \mathrm{~s}$ pulse of at- $\mathrm{H}$ followed by a $0.5 \mathrm{~s}$ pulse of $\mathrm{WF}_{6}$. An $\mathrm{Ar}$ purge of $7 \mathrm{~s}$ was introduced in between the precursor pulses. 


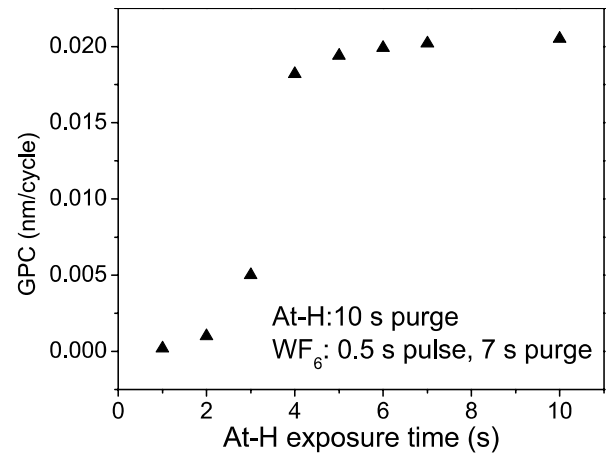

(a)

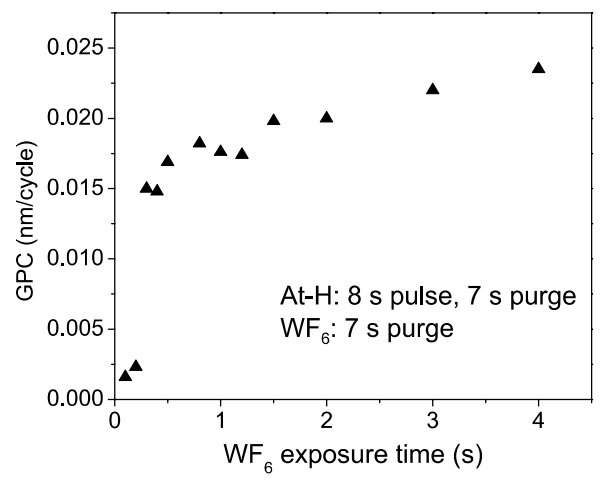

(c)

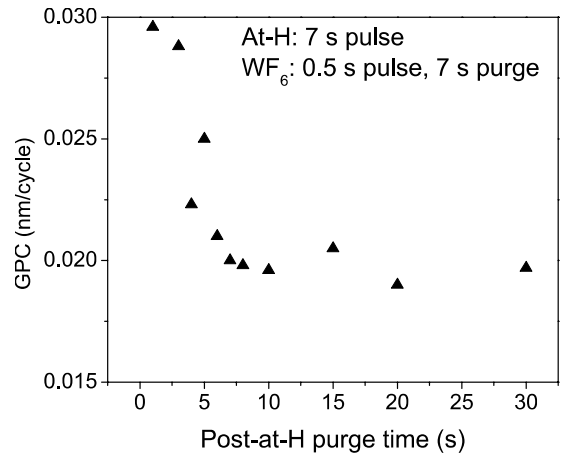

(b)

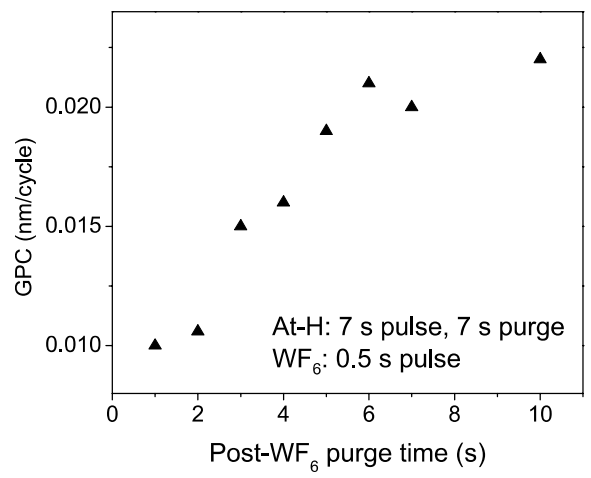

(d)

Figure 4.1. GPC versus the pulse/purge exposure time for determining the HWALD window. Influence of: (a) at- $\mathrm{H}$ pulse time, (b) post-at-H purge time, (c) $\mathrm{WF}_{6}$ pulse time and (d) post-WF 6 purge time. Other conditions: pressure of 0.05 mbar, substrate temperature of $275^{\circ} \mathrm{C}$, $\mathrm{HW}$ temperature of $1750{ }^{\circ} \mathrm{C}, \mathrm{H}_{2}$ and $\mathrm{WF}_{6}$ flow rates of 50 and $3 \mathrm{sccm}$, respectively. The fixed settings are shown in the legend of each graph.

The as-defined ALD window represents the GPC behavior under cleanreactor conditions. Although the GPC was reasonably independent of the pulse/purge durations within the as-defined ALD window, its absolute value could still vary between 0.01 and $0.021 \mathrm{~nm} /$ cycle from experiment to experiment. This means that the practically-obtained GPC effectively depended on the pre-deposition history. Performing a large number of experiments without efficient cleaning steps of the chamber from the residual $W_{6}$ or fluorine after each experiment led to overall lowering of the GPC. This presumably occurred due to the etching of the deposited 
W film by fluorine-containing compounds mentioned above. As elaborated in section 3 of Chapter 3, such compounds can likely adsorb on non-heated parts of the reaction chamber, interfering with the deposition process and resulting in a memory effect. Their background pressure can finally prohibit the film growth, making etching dominant over deposition.

To limit the memory effect, the overall $\mathrm{WF}_{6}$ dose has to be minimized. Fig. 4.2 illustrates the influence of $\mathrm{WF}_{6}$ over-dose on the growth rates. When the $\mathrm{WF}_{6}$ flow rate increased from $3 \mathrm{sccm}$ (standard recipe) to $10 \mathrm{sccm}$, the GPC gradually reduced from 0.02 to $0.01 \mathrm{~nm} /$ cycle with increasing the pulse time (Fig. 4.2 (a)). Moreover, with this flow rate, a linear growth (i.e., constant GPC) could only be maintained for 60 cycles: the GPC decreased afterwards upon the accumulation of WF $_{6}$ in the chamber (Fig. 4.2 (b)). In previous chapter ${ }^{[8]}$, HWALD W was deposited in a cold-wall reactor. This led to excess background pressure of fluorine-containing compounds and possibly resulted in the growth of $\beta$-phase W. Employing a hot-wall reactor in this work presumably enabled $\alpha$-phase W (see further sections). To note, etching was much less prominent in the hot-wall reactor, given that the flow rate of $\mathrm{WF}_{6}$ was limited to $3 \mathrm{sccm}$. Lowering the net GPC due to etching can for example be seen in Fig. 4.1 (d) while shortening the post-WF 6 -purge pulses.

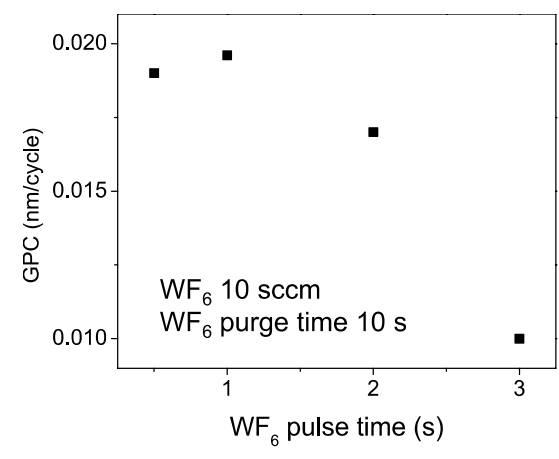

(a)

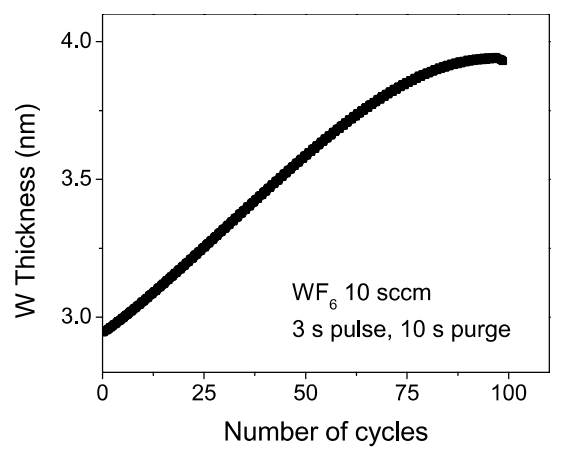

(b)

Figure 4.2. The influence of $W F_{6}$ over-dose on the growth rates of HWALD W. (a) GPC versus WF pulse $_{6}$ time for $W_{6}$ flow increased to $10 \mathrm{sccm}$; (b) GPC evolution during the HWALD process. The WF 6 pulse/purge times are shown on each graph. The at- $\mathrm{H}$ pulse/purge times are kept at $7 \mathrm{~s}$ each. Other conditions: pressure of 0.05 mbar, substrate temperature of $275{ }^{\circ} \mathrm{C}, \mathrm{HW}$ temperature of $1750{ }^{\circ} \mathrm{C}$, and $\mathrm{H}_{2}$ flow rate of $50 \mathrm{sccm}$. 
The GPC variations with substrate temperature $\left(T_{\mathrm{s}}\right)$ are presented in Fig. 4.3 (a). Only a weak dependence is observed for $T_{\mathrm{s}}>275^{\circ} \mathrm{C}$. Furthermore, the GPC hardly depends on the total process pressure in the range from 0.01 to 0.5 mbar (Fig. 4.3 (b)). To avoid the mentioned accumulation of fluorine-containing species and thus minimize the parasitic etch effect, a total pressure of 0.05 mbar was chosen for the HWALD-W process.

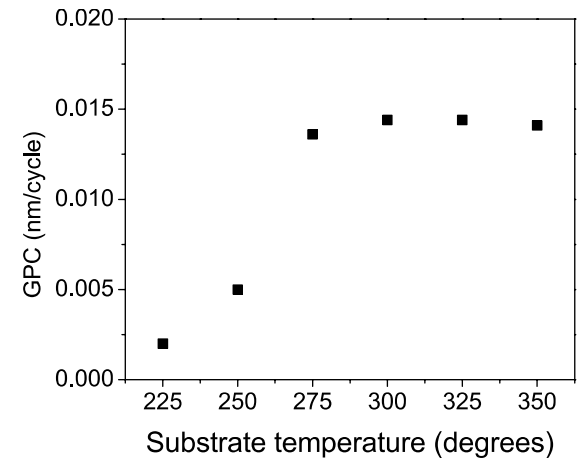

(a)

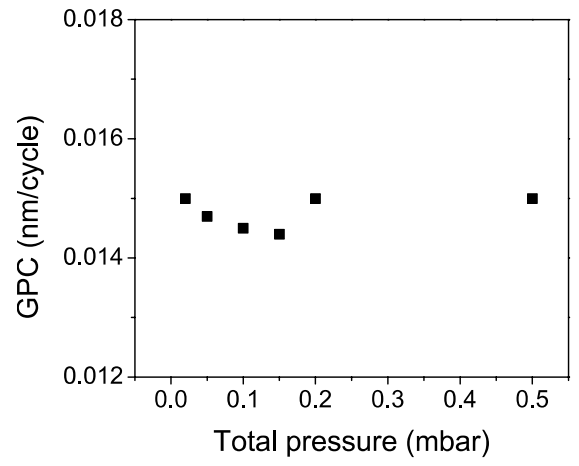

(b)

Figure 4.3. Determining the HWALD window. The influence on GPC of: (a) substrate temperature at a pressure of 0.05 mbar, (b) total process pressure at a substrate temperature of $275^{\circ} \mathrm{C}$. Other conditions: $\mathrm{HW}$ temperature of $1750{ }^{\circ} \mathrm{C}$, standard pulse durations, $\mathrm{H}_{2}$ and $\mathrm{WF}_{6}$ flow rates of 50 and $3 \mathrm{sccm}$, respectively.

Based on these findings, the standard HWALD conditions were fixed for further experiments at a substrate temperature of $275^{\circ} \mathrm{C}$ and a total pressure of 0.05 mbar. Each ALD cycle consisted of 0.5-s-WF $\mathrm{WF}_{6}$ and 7-s-at-H pulses with the corresponding 7-s-Ar purges in between. The flow rates of $\mathrm{H}_{2}$ and $\mathrm{WF}_{6}$ were kept at 50 and $3 \mathrm{sccm}$, respectively. The wire temperature was kept at $1750{ }^{\circ} \mathrm{C}$, consistent with our previous experiments in Chapter $\mathbf{3}^{[8]}$. 


\subsubsection{Surface roughness and film composition}

As discussed in section 3.4.3 of Chapter 3, surface roughness has a big effect on resistivity. In the last chapter, the reported root mean square (RMS) roughness of a standard $\mathrm{W}$ seed layer and an a-Si capping layer revealed the values of 1.67 and $0.02 \mathrm{~nm}$, respectively [9]. Fig. 4.4 shows the surface morphology and roughness of a 9-nm-thick HWALD tungsten film obtained in this work. The RMS value of $1.44 \mathrm{~nm}$ is comparable with that of the seed layer, indicating that the seed layer is the main contributor to the total roughness. The maximum thickness variation is $8.2 \mathrm{~nm}$ according to Fig. 4.4. The RMS value of HWALD W in the hot-wall reactor $(1.44 \mathrm{~nm})$ is much smaller than in the cold-wall reactor $(5.01 \mathrm{~nm})$. The smoother surface in may contribute to a higher conductivity of the thin $\mathrm{W}$ film.

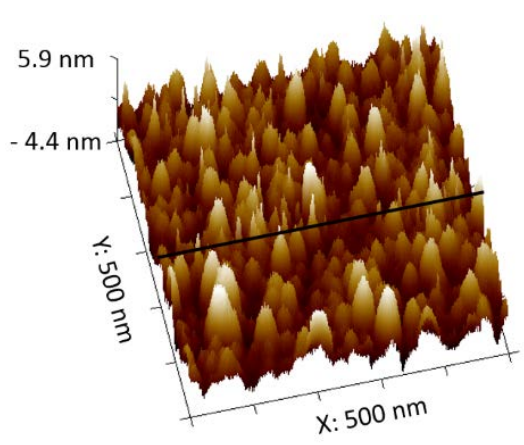

(a)

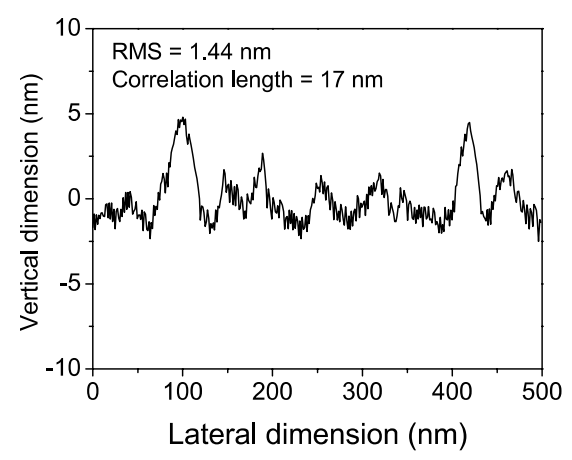

(b)

Figure 4.4. (a) Surface morphology (by AFM) of HWALD W deposited by the standard recipe. (b) The height variation along the black line drawn in (a); the 1.44-nm RMS and the correlation length of $17 \mathrm{~nm}$ were extracted by Nanoscope Analysis software.

A typical XPS sputter-depth profile of an HWALD W film is shown in Fig. 4.5. The layers of a-Si (capping), deposited $\mathrm{W}$ and underlying $\mathrm{SiO}_{2}$ can be clearly identified. Oxygen was only found at the surface of the capping layer and in the $\mathrm{SiO}_{2}$. The fluorine signal was below the detection limit through the entire film thickness, 
indicating an efficient removal of $\mathrm{F}$ by at- $\mathrm{H}$. The high concentration of $\mathrm{W}$, reaching 99 at.\%, revealed the high-purity W deposited by HWALD.

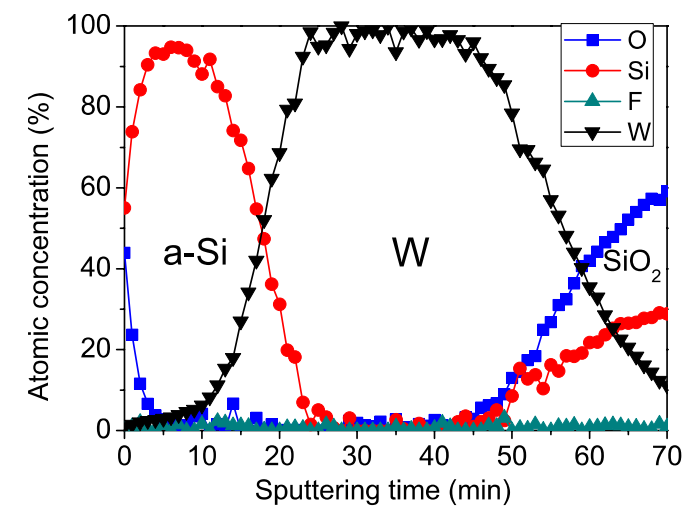

Figure 4.5. Compositional XPS depth profile of an HWALD W film grown by the standard deposition recipe.

\subsubsection{Crystallinity}

As mentioned in the previous chapter, tungsten is known to exist in $\alpha, \beta$ and $\gamma$ crystal phases ${ }^{[10,11]}$. $\alpha$-W possesses a body centered cubic lattice with a lattice constant of $0.316 \mathrm{~nm}^{[12]}$, whereas $\beta$-phase has a cubic $A_{3} B(A 15)$ crystal structure with a lattice constant of $0.504 \mathrm{~nm}^{[13]}$. Bulk $\beta$-phase $W$ is known to possess a higher resistivity, normally above 100 and up to $1290 \mu \Omega \cdot \mathrm{cm}^{[14-16]}$, compared to $5.6 \mu \Omega \cdot \mathrm{cm}$ of bulk $\alpha$-phase $\mathrm{W}^{[17]}$.

The XRD patterns of W films deposited by HWALD in two different (i.e., coldwall versus hot-wall) reactor configurations are compared in Fig. 4.6. To note, only crystals with crystal planes oriented parallel to the substrate can be observed by a $\theta-2 \theta$ scan. The strongest peak at around $69^{\circ}$ corresponds to the Si (100) substrate. This intense peak overlaps with the three peaks of $\beta$ phase in the range of $60^{\circ}-70^{\circ}$, 66 
making them invisible. The four distinguishable peaks, unique for the $\alpha$-phase ${ }^{[10]}$, are located at $40.2^{\circ}((110)$ plane $), 58.2^{\circ}$ ((200) plane), $73.2^{\circ}((211)$ plane $)$ and $87.1^{\circ}$ ((220) plane). The peaks of $\beta-\mathrm{W}$ are located at $35.5^{\circ}$ ((002) plane), $39.8^{\circ}((012)$ plane $), 43.8^{\circ}((112)$ plane $), 86.2^{\circ}((024)$ plane $)$ and $88.7^{\circ}((124) \text { plane })^{[17,18]}$. From Fig. 4.6, it can be concluded that only the peaks of $\alpha$-phase are present in the HWALD W of the hot-wall reactor, whereas only the peaks of $\beta$-phase $W$ appear in the cold-wall-reactor films. Apparently, with the same precursors and deposition methods used, the film crystallinity depends on the actual hardware configuration.

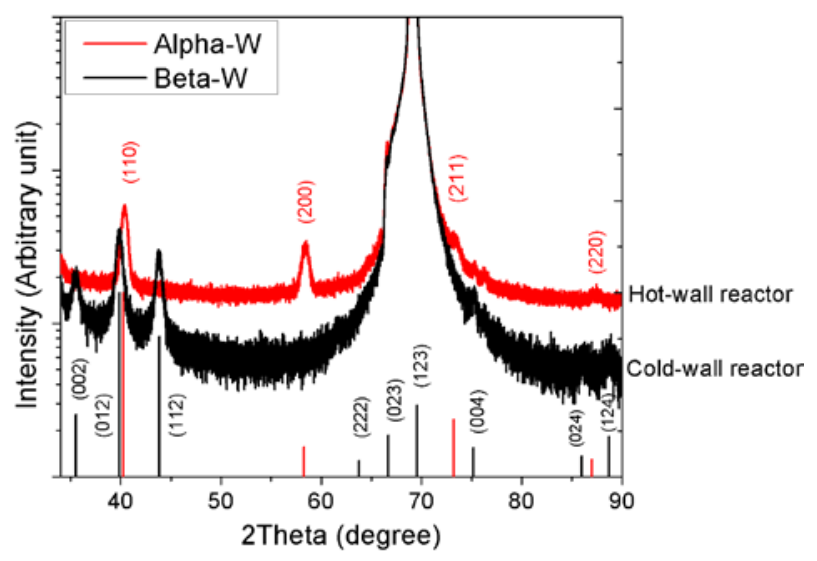

Figure 4.6. A comparison of typical XRD patterns of HWALD W films deposited in two different reactor configurations. The diffraction peak positions and the crystal planes of $\alpha$ - and $\beta$-phases are shown by the corresponding vertical lines ${ }^{[10,17,18]}$.

The lattice constants of both $\alpha$ - and $\beta$-phases have been calculated from the diffraction peak positions shown in Fig. 4.6. The values reveal $0.505 \pm 0.001 \mathrm{~nm}$ for the cold-wall reactor film and $0.315 \pm 0.001 \mathrm{~nm}$ for the hot-wall reactor $W$. These values are consistent with the lattice constants reported for the $\alpha$ - and $\beta$-phases in the literature. Furthermore, the crystal grain sizes were evaluated by HighScore Plus software, using Scherrer's equation ${ }^{[19]}$. The calculated grains ranged in size from 5.2 to $10.3 \mathrm{~nm}$ and from 10 to $32 \mathrm{~nm}$ for the cold-wall and hot-wall reactor films, 
respectively. In addition to XRD, optical functions of HWALD W formed in two reactors were different, measured by SE. The comparison of optical functions is presented in Fig. 4.7.

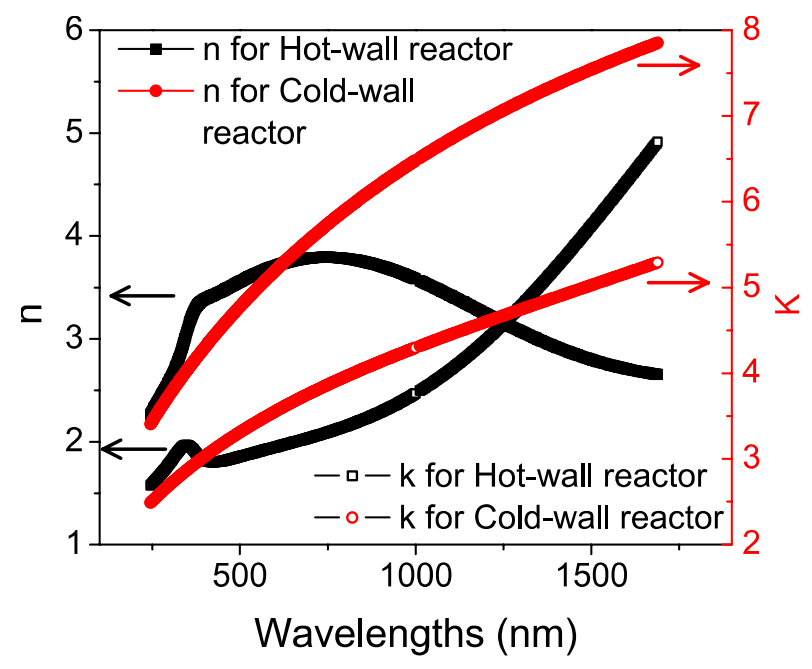

Figure 4.7. Refractive index $(n)$ and extinction coefficient $(k)$ curves of tungsten films deposited in two different reactors.

Cross-sectional HR-TEM images of a hot-wall HWALD W film without a-Si capping layer are presented in Fig. 4.8. (To avoid any confusion: if not mentioned explicitly in the text, all HWALD W films discussed in the remainder of this chapter were deposited in the hot-wall reactor.) In Fig. 4.8 (a), a rough film can be observed with the film thickness varying between 12 and $16 \mathrm{~nm}$. The individual crystal grains of the same film are shown in Fig. 4.8 (b) at a higher magnification. The visual grain size can be estimated at approximately $20 \mathrm{~nm}$. The $d$-spacing values obtained by the reduced Fast-Fourier transform (FFT) method are 0.220 and $0.157 \mathrm{~nm}$, corresponding to $\alpha-W^{[17]}$. Remarkably, the analysis reveals only pure-W (i.e., no oxygen) crystals in the film bulk, even without any protection by the capping a-Si layer. This indicates a weak and slow oxidation of the HWALD W film in air. 


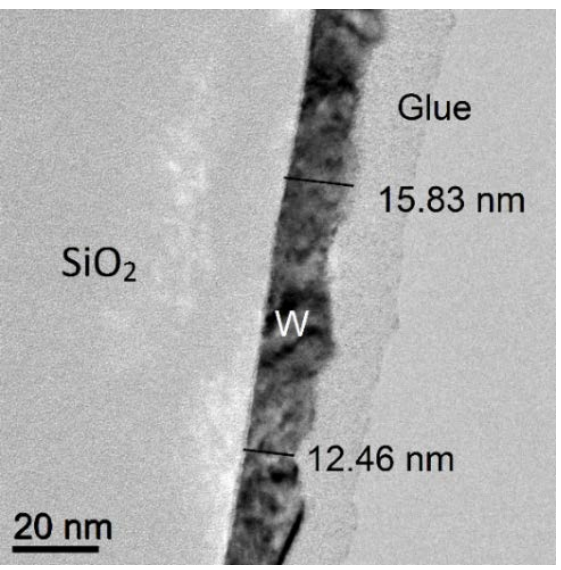

(a)

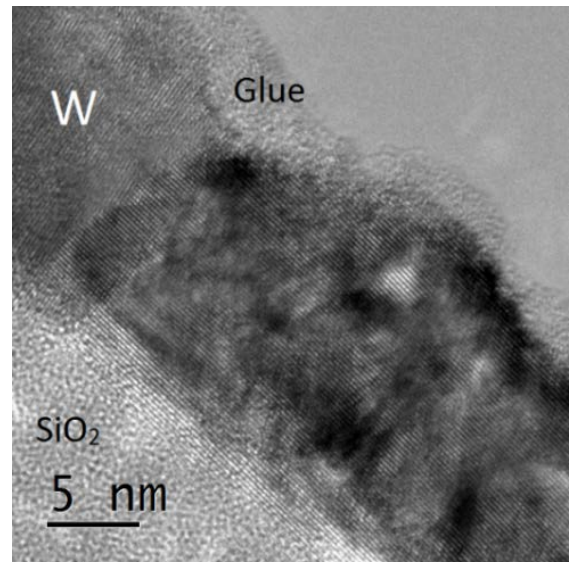

(b)

Figure 4.8. HR-TEM cross-sectional images of a HWALD W film without a-Si capping layer. The film roughness can be seen in (a) and the individual crystal grains in (b). No indications of oxide formation were found.

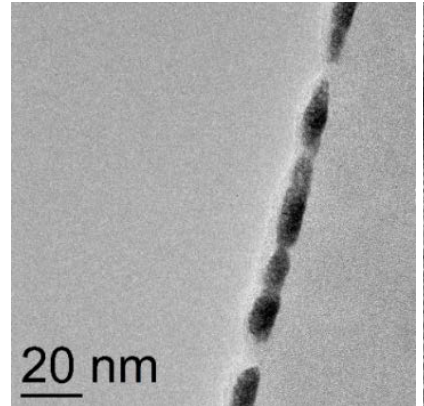

(a)

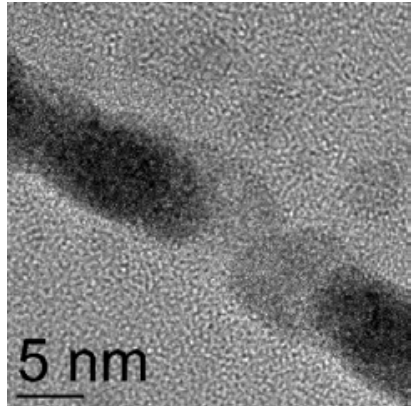

(b)

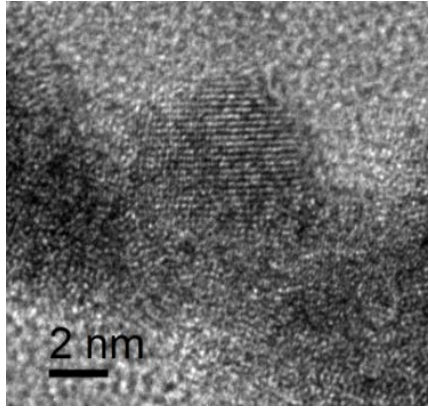

(c)

Figure 4.9. HR-TEM cross-sectional images of a pre-formed $W$ seed layer. SE indicates an average thickness of $3.5 \mathrm{~nm}$, converted from the a-Si layer of around $5 \mathrm{~nm}$. The film discontinuity can be seen in (a) and the crystallinity in (b) and (c).

The cross-sectional HR-TEM images of a pre-formed $W$ seed layer are depicted in Fig. 4.8. The average thickness measured by SE was approximately $3.5 \mathrm{~nm}$, converted from a roughly 5-nm a-Si seed layer. Different from the continuous film in Fig. 4.8 (a), the W seed layer consists of separated clusters with a thickness 
varying between 1 and $6 \mathrm{~nm}$. As XRD could not provide reliable information on the seed layer crystallinity due to the small thickness, the crystal grains were evaluated with HR-TEM, as shown in Fig. 4.9 (b) and (c). In most film areas, the W clusters were dominantly amorphous. A few crystallites were however found (see Fig. 4.9 (c)) with $d$-spacing values of $0.228,0.135 \mathrm{~nm}, 0.216$ and $0.186 \mathrm{~nm}$. While the first two values correspond to $\beta-W$, the latter two likely indicate tungsten oxide ${ }^{[20]}$. Despite the differences in crystallinity between the seed layer and the HWALD W layer formed on top of it, no clear interface between these two layers can be detected in Fig. 4.8 (b). This implies that the seed layer can likely turn into a-phase during the subsequent HWALD process.

\subsubsection{Resistivity and uniformity}

The resistivity of the $\mathrm{W}$ films was measured (i) electrically by the FPP method, (ii) electrically by means of TLM structures and (iii) optically by using the DrudeLorentz SE model. While the entire film thickness (i.e., including the seed layer) is probed by FPP, SE allows to obtain resistivity solely of the HWALD layer by building a proper model. The FFP measurements on a $9 \mathrm{~nm}$ HWALD W film (plus a $4 \mathrm{~nm}$ seed layer) revealed a resistivity of $15 \mu \Omega \cdot \mathrm{cm}$. The SE analysis, solely applied to the same HWALD film produced a very similar value, consistent with $\alpha-W$. It has been reported that the lowest resistivity obtained for CVD $\mathrm{W}$, grown at $400{ }^{\circ} \mathrm{C}$ from $\mathrm{WF}_{6}$ and $\mathrm{H}_{2}$ precursors, can vary between 8 and $18 \mu \Omega \cdot \mathrm{cm}^{[17]}$. Therefore, the HWALD W possesses a remarkably low resistivity, competing with that of CVD W. One can further emphasize the small film thickness and the reduced process temperature in our case. To bear in mind, all HWALD W films earlier deposited in the cold-wall reactor possessed $\beta$-phase and a higher resistivity of $100 \mu \Omega \cdot \mathrm{cm}^{[9]}$, on the same seed layer. Moreover, the smaller grain size of the $\beta$-phase films implies a larger number of grain boundaries per unit film area. This can also contribute to their higher electrical resistivity compared to the a-phase $\mathrm{W}$.

The TLM resistivity measurements were carried out for several HWALD-W film thicknesses: $0.65,0.9,1.3,2.5$ and $5 \mathrm{~nm}$. All the films were passivated by highly70 
resistive a-Si capping layers, which exhibited a non-linear conduction, orders of magnitude lower compared to that of the W films. Fig. 4.10 (a) represents linear current-voltage (I-V) curves of the 0.9-nm film on a standard W seed layer. Such linear behavior was observed for all thicknesses, indicating well-established current paths in the films and an ohmic contact between the W film and the Pt contact pads. The resistance of only the seed layer equaled the capping layer resistance, thereby confirming the earlier conclusion that the W islands seen in Fig. 4.9 (a) were hardly connected to each other. After growing a 0.65-nm HWALD film on top of the seed layer, the electrical conductance was significantly increased, suggesting the dominant contribution of this film to the conductivity. Fig. 4.10 (b) shows the total resistance $(R)$ as a function of gap spacing $(L)$ for the thickest 5-nm film on the seed layer. A sheet resistance of $17 \Omega / \square$ can be obtained from the slope of this linear fit. Calculating the resistivity reveals $17 \mu \Omega \cdot \mathrm{cm}$, taking the thicknesses of both seed and HWALD W layer into account.

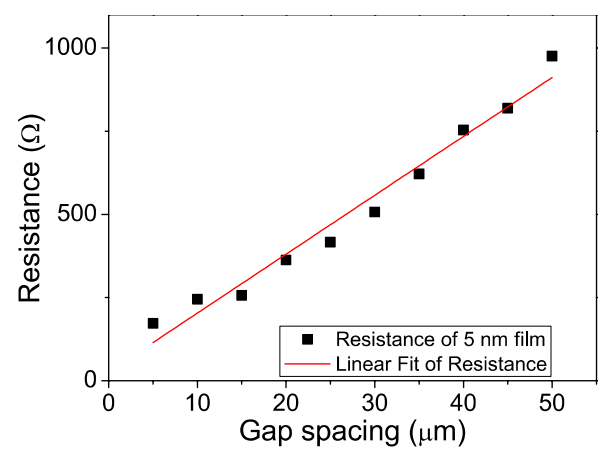

(a)

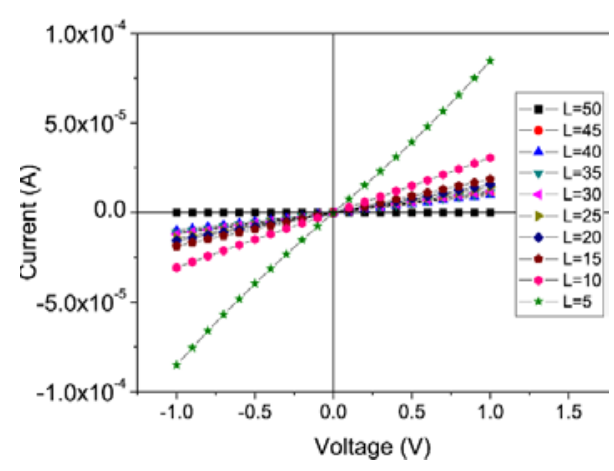

(b)

Figure 4.10. (a) I-V curves measured by means of TLM on a $0.9 \mathrm{~nm}$ HWALD W film for various gap spacing $L$ between two Pt electrodes . (b) The extracted total resistance $R$ versus $L$ for a 5 nm HWALD W film. 


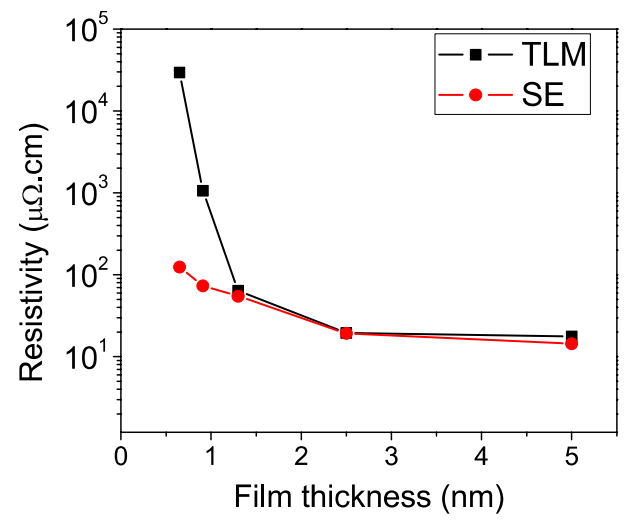

Figure 4.11. A comparison of the resistivity obtained by optical (SE, red circles) and electrical (TLM, black squares) methods. To note, the SE measurements were carried out at a substrate temperature of $275^{\circ} \mathrm{C}$, whereas the TLM measurements were performed at room temperature.

Likewise, the resistivity for all five film thicknesses was calculated (see Fig. 4.11) and compared with the values extracted from in-situ SE measurements. To note, the SE resistivity was measured at a substrate temperature of $275^{\circ} \mathrm{C}$, whereas the TLM measurements were carried out at room temperature. Our previous work ${ }^{[7]}$ performed for ultra-thin TiN films showed only a little disagreement between SE resistivity values measured for the same film at room temperature and at $350^{\circ} \mathrm{C}$. For the films shown in Fig. 4.11, one can see a good agreement between the electricallyand optically-measured resistivity for the thicknesses exceeding $1.3 \mathrm{~nm}$. However, for the thinner films, the electrical resistivity is orders of magnitude higher than the corresponding optical value. As explained by $\mathrm{Liu}^{[21]}$ and Alkhatib ${ }^{[22]}$, this large disagreement can occur due to the absence of the actual current flow in case of optical measurements. Optical measurements exclude numerous electron scattering/trapping effects at the film surface and/or grain boundaries. These effects however play a crucial role during the physical transport of electrons under applied electric field. A decreasing film thickness leads to a significant contribution of the film surface in terms of scattering and trapping, and quantization effects may enter the stage, all increasing the resistivity. With increasing thickness, the resistivity gradually 
stabilizes as both the concentration of conduction electrons and their mobility approach the bulk values.

In order to evaluate film uniformity, ex-situ SE was adopted to map the resistivity and the film thickness across the wafer. As seen in Fig. 4.12, a $9 \mathrm{~nm}$ (measured by in-situ SE in the wafer center) HWALD film was examined. An average resistivity of $15.10 \pm 0.35 \mu \Omega \cdot \mathrm{cm}$ was measured, giving a variation within $4.7 \%$ across the wafer (Fig. 4.12 (a)). The thickness measurements revealed $9.17 \pm$ $0.80 \mathrm{~nm}$, or a $17 \%$ variation (Fig. 4.12 (b)). The thickness distribution could be related to the effect of the underlying seed layer and the surface roughness.

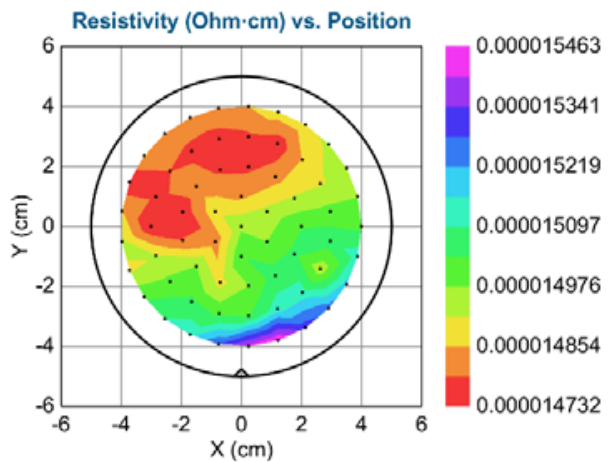

(a)

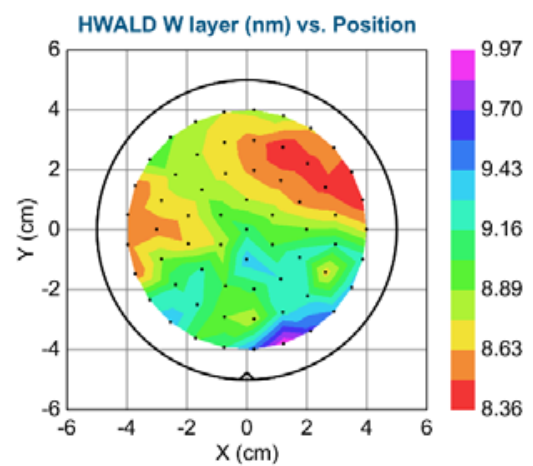

(b)

Figure 4.12. (a) Resistivity and (b) thickness mapping of a HWALD W film deposited at standard conditions.

\subsubsection{Step coverage on HAR substrates}

To test the step coverage, the HWALD films were deposited on HAR Si

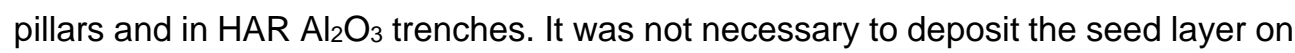
Si pillars since $\mathrm{WF}_{6}$ is readily to react with $\mathrm{Si}$. To enable in-situ SE, a flat Si substrate was placed under the SE light spot, next to the corresponding HAR structure. In Fig. 4.13 (a), two growth regimes (stages) can be observed. The first regime results in the very fast growth of $\mathrm{W}$ up to roughly $11 \mathrm{~nm}$. Although the precursor pulses still followed the optimized recipe, the growth obviously did not occur in ALD mode. The 
$\mathrm{WF}_{6}$ could efficiently react with $\mathrm{Si}$ of the substrate (or $\mathrm{Si}$ of the pillars), forming metallic $\mathrm{W}$ and volatile $\mathrm{SiF}_{4}$. The role of at- $\mathrm{H}$ as a reducing agent was minimized in this regime. In the second regime, the diffusion of $\mathrm{WF}_{6}$ through the as-grown $\mathrm{W}$ became the limiting factor, shifting the film formation mechanism to the HWALD mode with a typical growth rate of $0.012 \mathrm{~nm} /$ cycle.

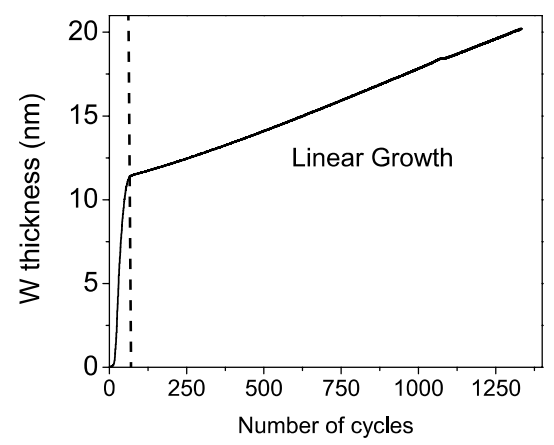

(a)

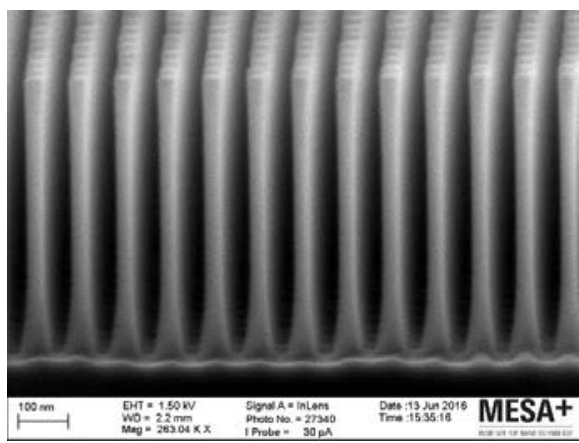

(b)

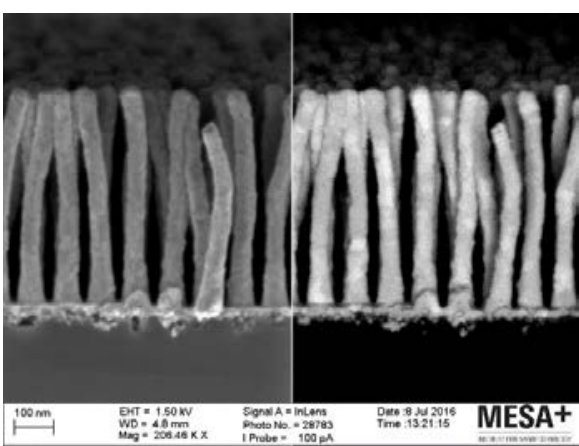

(c)

Figure 4.13. (a) Growth of $W$ on the reference flat Si substrate. The dashed line splits the $W$ growth into 2 regimes (stages) due to (i) direct chemical reaction between $W_{6}$ and Si substrate (left) and (ii) HWALD process (right). A similar growth behavior is expected for the Si pillars. SEM images of the Si-pillar structures with an aspect ratio of 9 , before (b) and after (c) the deposition of a roughly $20 \mathrm{~nm}$ of W. Both normal InLens ((c), left) and energy filtered backscattering ((c), right) images are shown.

Fig. 4.13 (b) shows a cross-sectional SEM image of the original pillars before deposition, possessing a diameter of $30 \mathrm{~nm}$ and an aspect ratio of about 9. In Fig. 
4.13 (c), both InLens and energy filtered backscattering (EFB) images, after deposition, indicate a conformal coverage of the pillars by $\mathrm{W}$. This is visualized by the high contrast between the W layer and Si of the substrate, with the bright layer corresponding to $\mathrm{W}$. After the deposition, the pillar diameter has expanded to $50 \mathrm{~nm}$. The 11-nm $W$ formed in the first growth regime is expected to consume approximately $9 \mathrm{~nm}$ of $\mathrm{Si}$, giving a net pillar-diameter increase from 30 to $34 \mathrm{~nm}$ after the first stage. Adding $2 \times 9 \mathrm{~nm}$ to the diameter after the second stage was fairly consistent with the measured diameter expansion to $50 \mathrm{~nm}$. In addition, a layer of W $(\sim 10-20 \mathrm{~nm})$ was formed at the bottom, in agreement with the total film thickness as expected from Fig. 4.13 (a). The pillar deformation after deposition presumably occurred due to built-in stress.

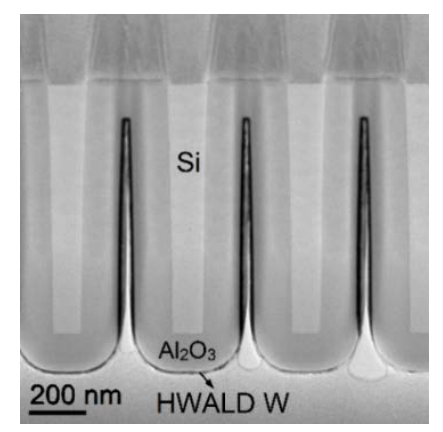

(a)

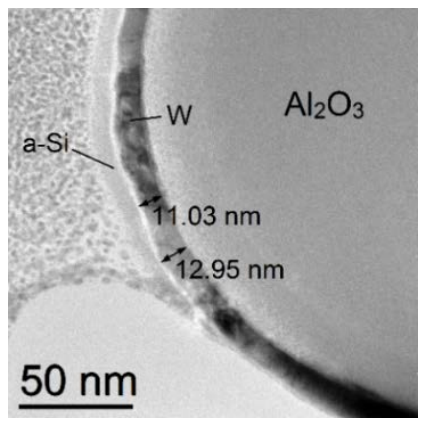

(b)

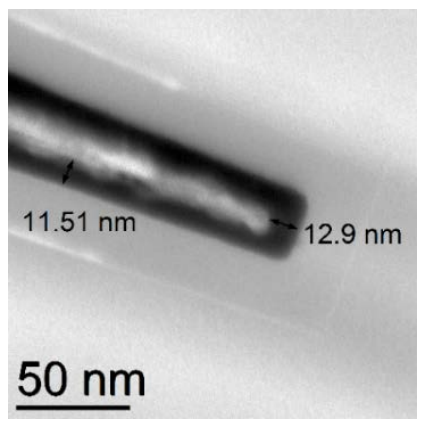

(c)

Figure 4.14. (a) TEM images of a $13 \mathrm{~nm}$ W film grown by HWALD inside $\mathrm{Al}_{2} \mathrm{O}_{3}$-coated $\mathrm{Si}$ trenches. Closeups of the top-corner and the trench-bottom are shown in (b) and (c), respectively.

A W layer of $13 \mathrm{~nm}$ (as measured by in-situ SE on a separate flat $\mathrm{Al}_{2} \mathrm{O}_{3}$ coated substrate placed next to the structure of interest) was further deposited into $\mathrm{Al}_{2} \mathrm{O}_{3}$-coated $\mathrm{Si}$ trenches with an aspect ratio of 36, see Fig. 4.14. Due to the difficult nucleation of $\mathrm{W}$ on $\mathrm{Al}_{2} \mathrm{O}_{3}$, a W seed layer was pre-formed as described in section 3.2.1 of Chapter 3. However, the thickness of the a-Si nucleation layer was limited to $0.5 \mathrm{~nm}$ only, in view of the narrow trenches. In Fig. 4.14 (a), one can see a uniform and conformal coverage of the $\mathrm{Al}_{2} \mathrm{O}_{3}$ surface with HWALD W all the way down to the 
bottom. Fig. 4.14 (b) and (c) show the zoomed-in TEM images taken at different depths, clearly indicating the thickness uniformity. The average thickness of the $\mathrm{W}$ layer at the bottom (approx. $13 \mathrm{~nm}$, see Fig. 4.14 (c)), was very much comparable to that at the top (11-13 nm, see Fig. 4.14 (b)), indicating the effective ALD process and the sufficient diffusion of both $\mathrm{WF}_{6}$ and at- $\mathrm{H}$ into the trenches.

\subsubsection{Continuity}

The fabricated CTLM structure is presented in Fig. 4.15 with all layers indicated. The diameter of the inner circle $\left(R_{1}\right)$ ranged from 75 to $125 \mu \mathrm{m}$ and the gap between the circle and the ring (s) varied between 2.5 and $300 \mu \mathrm{m}$. Then currentvoltage measurements of $\mathrm{W}$ films of varying thicknesses deposited on CTLM structures were performed in order to identify the thickness at which the layer became continuous. Importantly, this study identified the thickness when the W film completely coalesced (or enabled near-Ohmic electrical conductance), as opposed to the thickness-of-formation of the first conducting $W$ link between the CTLM electrodes.

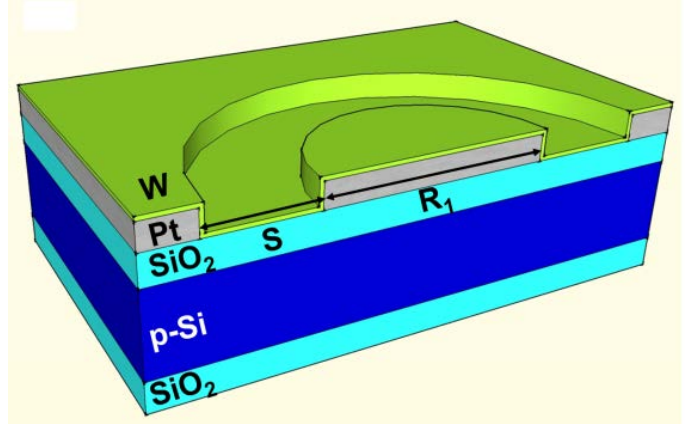

Figure 4.15. CTLM structure for tungsten films. 
In order to identify the thickness of film coalescence with higher accuracy, the method described by Maroof and Evans ${ }^{[23]}$ was followed: the minimum in the $R t^{2}$ vs. $t$ plot (where $R$ is the sheet resistance of the film and $t$ is the film thickness) corresponded to the coalescence thickness. Fig. 4.16 shows this plot for several CTLM structures with different spacing (s). Even though a slight dependence of $R t^{2}$ on $s$ at all $W$ film thicknesses was observed, the minimum of every plot was located between 2 and $3 \mathrm{~nm}$ of $W$ thickness for every CTLM spacing, suggesting the coalescence within this range.

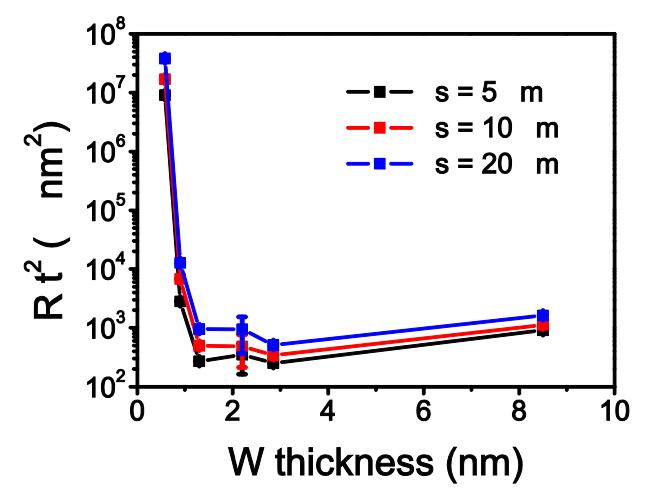

Figure 4.16. Variation of the $R t^{2}$ product as a function of the $\mathrm{W}$ film thickness for different CTLM spacings (s). The minima is located between 2 and $3 \mathrm{~nm}$ for all CTLM spacings.

\subsection{Conclusions}

HWALD W films have been deposited in a home-built hot-wall reactor using WF$_{6}$ gas and HW-generated atomic hydrogen as precursors. The XPS analysis revealed high-purity films, reaching 99 at.\% of $\mathrm{W}$. The fluorine signal was below the detection limit throughout the film, indicating an efficient removal of $\mathrm{F}$ by at- $\mathrm{H}$. The lattice constants calculated from the XRD diffraction peak positions showed $\alpha$-phase $W$. This was consistent with the $d$-spacing values of $\alpha-W$ obtained from HR-TEM images. Despite the differences in crystallinity between the $W$ seed layer 
(amorphous- and $\beta$-phase $\mathrm{W}$ ) and the HWALD W layer ( $\alpha-\mathrm{W}$ ) formed on top of it, no clear interface between these two layers could be detected, implying that the seed layer was likely turned into a-phase $W$ during the subsequent HWALD step. The resistivity measurements by means of FPP, TLM structures and the Drude-Lorentz SE model all reveal a low resistivity of $15 \mu \Omega \cdot \mathrm{cm}$ for the HWALD W. The HR-TEM analysis of the films grown on HAR structures (up to an aspect ratio of 36) showed a uniform and conformal coverage, confirming the effective ALD process and the sufficient diffusion of both $\mathrm{WF}_{6}$ and at- $\mathrm{H}$ into deep trenches. The coalescence thickness of HWALD $W$ was between 2 and $3 \mathrm{~nm}$, as identified from the minima of $R t^{2}$ vs. $t$ plots.

\section{References}

[1] J. E. J. Schmitz, Chemical Vapor Deposition of Tungsten and Tungsten Silicides for VLSI/ULSI Applications (Noyes, Park Ridge NJ, 1992).

[2] D. K. Schroder, Semiconductor material and device characterization (John Wiley \& Sons, 2006).

[3] W. Shockley, W. Hooper, H. Queisser and W. Schroen, Surf. Sci. 2, 277 (1964).

[4] H. Van Bui, A. Y. Kovalgin, J. Schmitz and R.A.M. Wolters, Appl. Phys. Lett. 103, 051904 (2013).

[5] H. Van Bui, Thesis, Twente University Press, 2013.

[6] G. Reeves, Solid State Electron. 23, 487 (1980).

[7] H. Van Bui, A.A.I. Aarnink, A. Kovalgin and R.A.M. Wolters, J. Nanosci. Nanotechnol. 11, 8120 (2011).

[8] M. Yang, A.A.I. Aarnink, A. Y. Kovalgin, R.A.M. Wolters and J. Schmitz, Phys. Status Solidi A 212, 1607 (2015).

[9] M. Yang, A.A.I. Aarnink, A. Y. Kovalgin, D.J. Gravesteijn, R.A.M. Wolters and J. Schmitz, J. Vac. Sci. Technol. A 34, 01A129 (2016).

[10] F. Allen, O. Kennard, D. Watson, L. Brammer, A. Orpen and R. Taylor, International Tables for Crystallography, vol. C (Dordrecht: Kluwer Academic Publishers, 1995).

[11] R. Warncke, M. L. Gerwien and L. Gmelin, Gmelin handbook of inorganic chemistry: 8th ed., No. 54, Tungsten, Suppl. , Vol. A3 (Springer, Heidelberg, 1989).

[12] W. Morcom, W. Worrell, H. Sell and H. Kaplan, Metall. Trans. 5, 155 (1974). 
[13] S. Basavaiah and S. Pollack, J. Appl. Phys. 39, 5548 (1968).

[14] Q. Hao, W. Chen and G. Xiao, Appl. Phys. Lett. 106, 182403 (2015).

[15] T. Millner, A. J. Hegedüs, K. Sasvári and J. Neugebauer, Z. Anorg. Allg. Chem. 289, 288 (1957).

[16] P. Petroff, T. Sheng, A. Sinha, G. Rozgonyi and F. Alexander, J. Appl. Phys. 44, 2545 (1973).

[17] E. Lassner and W. D. Schubert, Tungsten: Properties, Chemistry, Technology of the Elements, Alloys, and Chemical Compounds (Springer Science \& Business Media, New York, 1999).

[18] A. Bartl, PhD thesis Thesis, TU Vienna, 1997.

[19] A. Patterson, Phys. Rev. 56, 978 (1939).

[20] H. E. Swanson, E. Tatge and R. K. Fuyat, Standard X-ray diffraction powder patterns (U.S. Dept. of Commerce, National Bureau of Standards, Washington, D.C. , 1953).

[21] H.-D. Liu, Y.-P. Zhao, G. Ramanath, S. Murarka and G.-C. Wang, Thin Solid Films 384, 151 (2001).

[22] A. Alkhatib, T. Souier and M. Chiesa, Mat. Sci. Eng. B-Solid 176, 840 (2011).

[23] A. Maaroof and B. Evans, J. Appl. Phys. 76, 1047 (1994). 


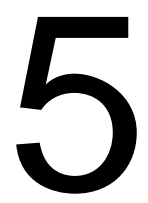

\title{
Effects of oxygen, nitrogen and fluorine on the formation of $\alpha$ - and $\beta$-phase $W$ by HWALD
}

\begin{abstract}
.
As described in the last two chapters, depending on the process conditions, either low-resistivity $\alpha$ - or higher-resistivity $\beta$-crystalline phases of $W$ can be obtained. This chapter aims to clarify (i) which factors are decisive for the formed crystal phase and (ii) the role of residual gases in the film growth mechanism. To this end, the effects of adding impurities $\left(\mathrm{N}_{2} \mathrm{O}\right.$, $\mathrm{O}_{2}, \mathrm{NH}_{3}$ and $\mathrm{H}_{2} \mathrm{O}$ ) were investigated. Oxidizing species have a retarding effect on $\mathrm{W}$ growth but the process can be re-initiated after stopping their supply. In contrast, nitridizing species have a permanent inhibition effect. Further, the effects of $\mathrm{WF}_{6}$ overdose were studied. The surplus of $\mathrm{WF}_{6}$ appeared to be crucial for the process: in many cases this led to the formation of $\beta$-phase $W$ instead of $\alpha$-phase with a memory effect lasting for several deposition runs. Extra fluorine-containing species were thus identified as the likely root cause of $\beta$-phase formation.
\end{abstract}

This chapter is based on the publication:

Mengdi Yang, Antonius A.I. Aarnink, Rob A.M. Wolters, Jurriaan Schmitz and Alexey Y. Kovalgin, "Effects of oxygen, nitrogen and fluorine on the formation of $\alpha$ - and $\beta$-phase tungsten films by novel hot-wire assisted atomic layer deposition”, ECS J. Solid State Sci. Technol., 6, P839(2018). 


\subsection{Introduction}

In our deposition system we have been able to grow both phases of $\mathrm{W}$ by HWALD, depending on the actual reactor design and deposition conditions. However, factors leading to the preferential formation of one of the phases over the other are still to be confirmed. It has been discussed in Chapter 3 that $\mathrm{W}$ can be formed in either low-resistivity $\alpha$ - or higher-resistivity $\beta$-crystalline phases ${ }^{[1]}$. The former is clearly more attractive for applications in electronics. It is suggested that $\beta$-phase can be formed either (i) via intermediate oxidation states or (ii) because of the presence of other impurities. The oxidation states (to be further reduced to pure $\mathrm{W}$ by e.g. at-H) can occur due to the presence of background oxidants, particularly oxygen or water, in the system. Noticeably, even our base pressure of $10^{-7} \mathrm{mbar}$ still provides a water flux of roughly 0.1 monolayer/s to the substrate. Other impurities can originate from the source gases, for example $\mathrm{WF}_{6}$, so the influence of fluorinecontaining species needs to be considered as well. To clarify the occurrence of the $\beta$-phase, this chapter investigates the effects of adding oxidizing and nitridizing gases such as $\mathrm{N}_{2} \mathrm{O}, \mathrm{O}_{2}, \mathrm{NH}_{3}$ and $\mathrm{H}_{2} \mathrm{O}$, as well as $\mathrm{WF}_{6}$ overdose, on HWALD W.

\subsection{Methodology to study the influence of additional gases}

All the experiments were conducted in the hot-wall reactor. The formation of HWALD W was the same as described in Chapter 4. The films were first grown to a certain thickness $(4-10 \mathrm{~nm})$ at standard process conditions. Then, they were exposed to either a continuous flow or short pulses of a selected gas in the same reactor, keeping the gas pressure and temperature unchanged. It should be noted that 1 pulse of a selected gas was added after a number (1 or 3) of full HWALD cycles.

The pulse time was varied between $0.1-2 \mathrm{~s}$ for $\mathrm{N}_{2} \mathrm{O}$ and $\mathrm{O}_{2}$, maintaining a purge time of $7 \mathrm{~s}$ to remove these gases prior to every subsequent HWALD cycle. 
For water vapour $\left(\mathrm{H}_{2} \mathrm{O}\right)$, the pulse and purge times were 5 and $10 \mathrm{~s}$, respectively. The dose of $\mathrm{H}_{2} \mathrm{O}$ was determined by its vapour pressure (approximately 60 mbar) in the bottle and the pulse time. $\mathrm{NH}_{3}$, as a source of nitridizing species, was only introduced at a constant flow of $20 \mathrm{sccm}$ to investigate possible differences between the oxidation and nitridation effects. The $W_{6}$ overdose was achieved by (i) increasing the $\mathrm{WF}_{6}$ flow from 3 to $10 \mathrm{sccm}$, (ii) prolonging the $\mathrm{WF}_{6}$ pulse time from 0.1 to $3 \mathrm{~s}$ and (iii) performing the HWALD process for more than 2 hours with 0.5 -slong $\mathrm{WF}_{6}$ pulses.

\subsection{Results and discussion}

\subsubsection{Influence of $\mathrm{N}_{2} \mathrm{O}$ and $\mathrm{O}_{2}$ on the HWALD W process}

The results of the real-time monitoring of oxidation by a continuous flow of either $\mathrm{N}_{2} \mathrm{O}$ or $\mathrm{O}_{2}$ are shown in Fig. 5.1. The optical functions of HWALD W were successfully parameterized using a Drude-Lorentz description consisting of a Drude term and two Lorentz oscillators ${ }^{[2]}$. The tungsten oxide $\left(\mathrm{WO}_{\mathrm{x}}\right)$ was modelled by a Tauc-Lorentz SE formulation ${ }^{[3]}$. The fitted thickness of the HWALD W was verified by high-resolution scanning electron microscopy (HRSEM), as demonstrated in earlier work ${ }^{[4]}$. However, the thickness of the tungsten oxide (WOx) films could not be confirmed by ex situ techniques due to its small value. The $\mathrm{WO}_{\mathrm{x}}$ thicknesses reported in this article can therefore only be used for qualitative analysis. Nevertheless, the change of oxide thickness in Fig. 5.1 is fully coherent with that of HWALD W, revealing simultaneous oxide growth (by both $\mathrm{N}_{2} \mathrm{O}$ and $\mathrm{O}_{2}$ ) and reduction of the $\mathrm{W}$ film thickness. Assuming the thickness values to be correct, one can conclude that $\mathrm{W}$ oxidizes faster in $\mathrm{O}_{2}$ (Fig. 5.1 (b)) than in $\mathrm{N}_{2} \mathrm{O}$ (Fig. 5.1 (a)), probably due to a higher reactivity and/or diffusivity of $\mathrm{O}_{2}$. 


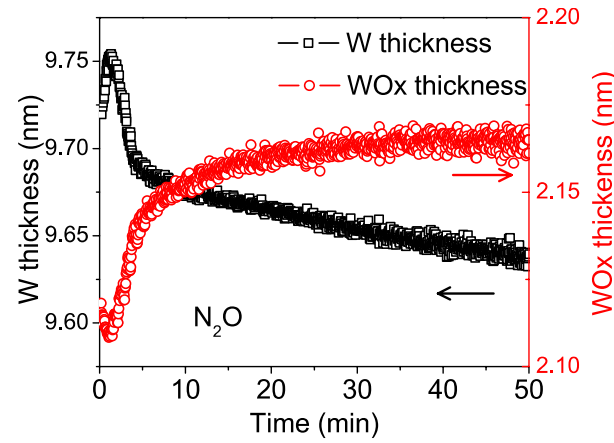

(a)

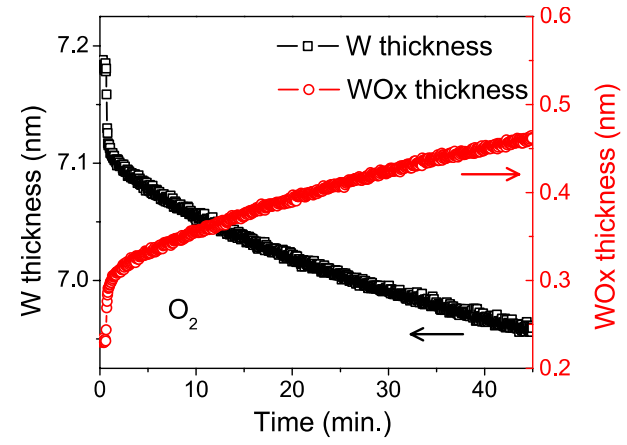

(b)

Figure 5.1. Oxidation measured by in-situ Spectroscopic Ellipsometer (SE) while exposing the pre-grown HWALD W films to a continuous flow (3 sccm) of $\mathrm{N}_{2} \mathrm{O}\left((\mathrm{a})\right.$ - the exposure starts at approx. $2 \mathrm{~min}$.) or $\mathrm{O}_{2}$ (b) at $275^{\circ} \mathrm{C}$ and a pressure of 0.05 mbar. The hot wire was turned off in these experiments.

In Fig. 5.2, a selected oxidant was briefly introduced after every three full HWALD cycles. It can be observed that the GPC was suppressed by these additional pulses and diminished further with increasing pulse duration. The negative GPC seen in Fig. 5.2 (b) for the $\mathrm{O}_{2}$ pulses longer than $0.5 \mathrm{~s}$ can be can be understood as the effect of film oxidation which reduces the $\mathrm{W}$ film thickness. Exposure to $\mathrm{N}_{2} \mathrm{O}$ gas was less effective in reducing the GPC (Fig. 5.2 (a)), which is in agreement with the higher oxidation rate in $\mathrm{O}_{2}$ compared to $\mathrm{N}_{2} \mathrm{O}$ observed in Fig. 5.2. Moreover, the transition from growth to reducing thickness due to oxidation can be clearly seen in Fig. 5.2 (c), where the pulse time of the $\mathrm{O}_{2}$ was increased from $0.1 \mathrm{~s}$ to $0.5 \mathrm{~s}$. The steps represent individual HWALD cycles. Apparently, an $\mathrm{O}_{2}$ pulse of $0.1 \mathrm{~s}$ had little influence on the GPC. However, oxidation started to take over the deposition when the $\mathrm{O}_{2}$ pulse time was increased to $0.5 \mathrm{~s}$, resulting in a gradual decrease of the total W thickness after approx. 23 min (Fig. 5.2 (c)). For $\mathrm{N}_{2} \mathrm{O}$ gas, the film growth still dominated over oxidation for a pulse time of $1.5 \mathrm{~s}$. Once again, one can see a smaller effect of $\mathrm{N}_{2} \mathrm{O}$ compared to $\mathrm{O}_{2}$. 


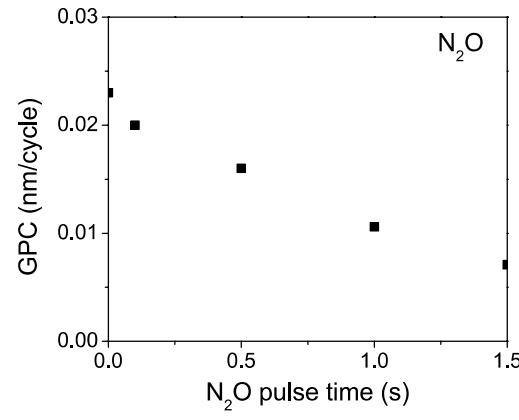

(a)

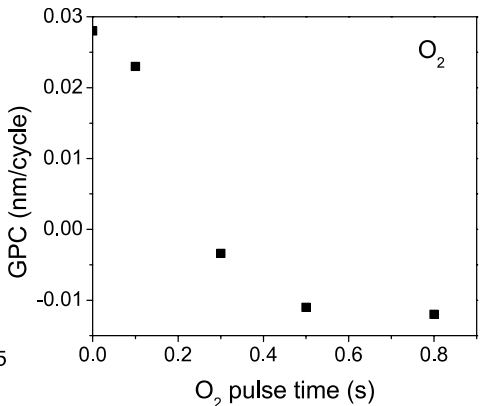

(b)

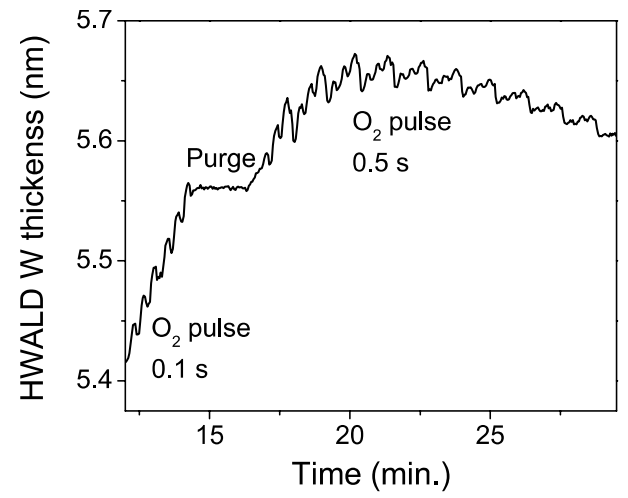

(c)

Figure 5.2. In-situ SE measurements performed at $275^{\circ} \mathrm{C}$ and 0.05 mbar. A decrease of the GPC of HWALD W films is observed while giving additional $\mathrm{N}_{2} \mathrm{O}$ (a) and $\mathrm{O}_{2}$ (b) pulses after each 3 standard HWALD cycles with a $7 \mathrm{~s}$ Ar purge in between. The negative growth rate observed for the longer $\mathrm{O}_{2}$ pulses corresponds to dominating oxidation. (c) Transition from growth to dominating oxidation when $\mathrm{O}_{2}$ pulse duration was increased from $0.1 \mathrm{~s}$ to $0.5 \mathrm{~s}$.

Further, 15-nm thick HWALD W films were deposited with additional pulses (0.1 s) of either $\mathrm{N}_{2} \mathrm{O}$ or $\mathrm{O}_{2}$, as described above. The films were capped with a 10$\mathrm{nm}$ a-Si to prevent their oxidation upon exposure to air. Fig. 5.3 shows XPS depth profiles depicting the elemental composition of these two films. In spite of their periodic exposure to oxidants, a very low concentration of oxygen is present throughout the layer below the a-Si cap, indicating an effective reduction of the tungsten oxide by at- $\mathrm{H}$. The resistivity values, measured by a four-point probe method, varied between 20 and $28 \mu \Omega \cdot \mathrm{cm}$, which is comparable with the values obtained for a HWALD W deposited without additional $\mathrm{O}_{2}$ pulses (i.e., about 


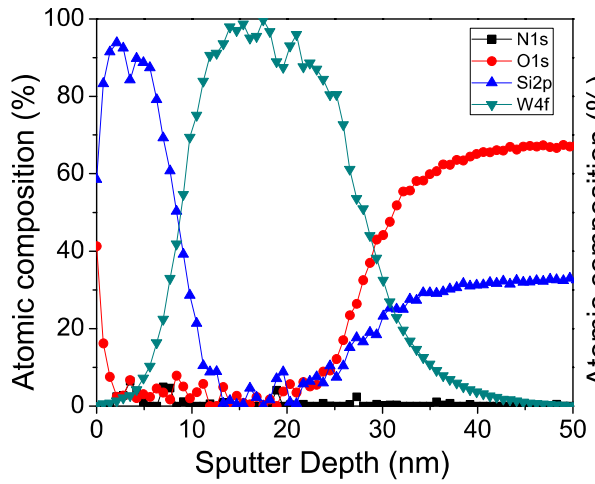

(a)

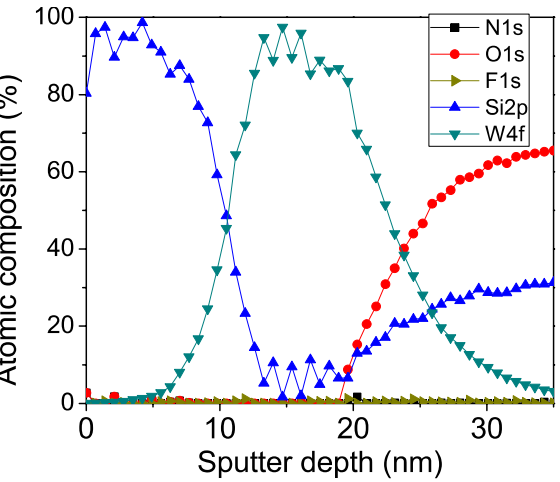

(b)

Figure 5.3. XPS depth profiles of $15-\mathrm{nm}$ thick HWALD W films grown at $275{ }^{\circ} \mathrm{C}$ and 0.05 mbar with additional (a) $\mathrm{O}_{2}$ and (b) $\mathrm{N}_{2} \mathrm{O}$ pulses.

$15 \mu \Omega \cdot \mathrm{cm}$ in Chapter 4). Further, the film grown with additional pulses of $\mathrm{N}_{2} \mathrm{O}$ (Fig. $5.3(b))$ hardly contains any nitrogen.

The low resistivity of HWALD films deposited with $\mathrm{O}_{2}$ pulses implies the presence of $\alpha$-phase $W$, as the resistivity of $\beta$-phase $W$ is normally above $100 \square \mu \Omega \mathrm{cm}^{[1]}$. To verify the crystallinity, an XRD analysis was carried out and the $\mathrm{XRD}$ scan is presented in Figure 4. It should be noted that only crystals with crystal planes oriented parallel to the substrate can be observed by a $\theta-2 \theta$ scan. The four distinguishable peaks, located at $40.2^{\circ}\left((110)\right.$ plane), $58.2^{\circ}$ ((200) plane), $73.2^{\circ}((211)$ plane) and $87.1^{\circ}((220)$ plane $)$, are unique for $\alpha$-phase $W^{[1]}$. The strongest peak at around $69^{\circ}$ corresponds to the $\mathrm{Si}(100)$ substrate. No peaks associated with $\beta$-phase $W$ can be observed. It can be concluded that the HWALD W exists in $\alpha$-phase form, even when exposed to oxidants during the process. 


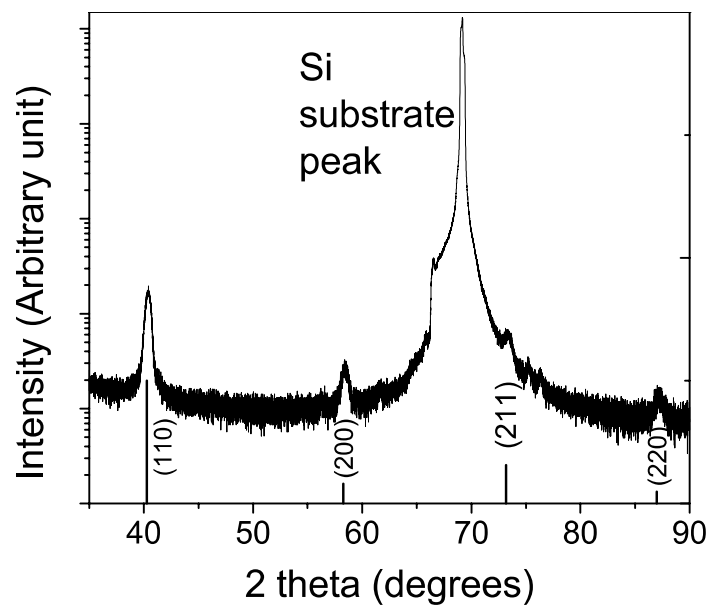

Figure 5.4. XRD pattern of the film presented in Fig. 5.3 (a), showing a-phase W. The vertical straight lines indicate the known peaks of $\alpha$-phase $\mathrm{W}$.

\subsubsection{Influence of $\mathrm{H}_{2} \mathrm{O}$ vapor on the HWALD W process}

As $\mathrm{H}_{2} \mathrm{O}$ vapour is constantly present at the background level (i.e., $10^{-7} \mathrm{mbar}$ ), it might also influence the HWALD process. To investigate the effect of water vapour, an $\mathrm{H}_{2} \mathrm{O}$ pulse of $5 \mathrm{~s}$ was inserted after each HWALD cycle, followed by an Ar purge of $10 \mathrm{~s}$. The GPC was greatly inhibited by $\mathrm{H}_{2} \mathrm{O}$ (Figure 5), decreasing from 0.018 to only $0.006 \mathrm{~nm} /$ cycle after as few as two $\mathrm{H}_{2} \mathrm{O}$ pulses. The very slow growth rate after the water treatment made the preparation of samples thick enough for XPS or XRD practically impossible. Remarkably, the in situ SE monitoring of individual cycles (Figure 5) consistently revealed a thickness change of around $0.05 \mathrm{~nm}$ after the first $\mathrm{H}_{2} \mathrm{O}$ pulse, quickly diminishing for each subsequent $\mathrm{H}_{2} \mathrm{O}$ pulse. This step is much higher than the standard GPC (approx. $0.02 \mathrm{~nm} /$ cycle) without $\mathrm{H}_{2} \mathrm{O}$; it is possible that the first $\mathrm{H}_{2} \mathrm{O}$ pulse enhances the growth rate. However, giving further pulses quickly suppresses the first-pulse effect. The decay of the GPC can be interpreted by blocking (occupation of) the surface sites by water; such adsorption processes often show an exponential dependence in time. 


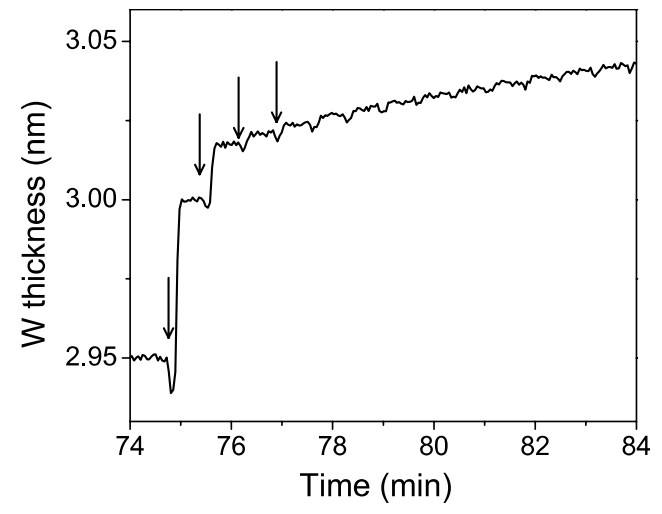

Figure 5.5. The effect of decreasing GPC due to additional $\mathrm{H}_{2} \mathrm{O}$-vapor pulses of $5 \mathrm{~s}$ (followed by a purge of $10 \mathrm{~s}$ ) inserted after each standard HWALD cycle. The steps represent individual cycles visualized by SE. Arrows indicate each $\mathrm{H}_{2} \mathrm{O}$ pulse.

\subsubsection{Growth recovery after oxidation and its termination by nitrogen-containing gases}

Our experiments demonstrated that an oxidized W surface can be reduced by at- $\mathrm{H}$, recovering the film growth after a sufficient reduction time. Namely, after the exposure of a 10-nm-thick HWALD W film to air for 900 hours, a 20-min reduction in at- $\mathrm{H}$ at $275^{\circ} \mathrm{C}$ was sufficient to restart the HWALD process and to reach the standard GPC after 150 cycles. Figure 6 (a) shows a quick GPC recovery after a 5-min exposure to $3 \mathrm{sccm}$ of $\mathrm{O}_{2}$. Remarkably, in this example, the GPC recovered to the original value after an incubation time of around 30 cycles, even without any additional at- $\mathrm{H}$ reduction. This implied that, during the incubation time, the oxides were effectively reduced by the at-H of the HWALD cycles. Similarly, in Figure 6 (b), it can be seen that the GPC could recover within approx. 40 HWALD cycles after the $\mathrm{H}_{2} \mathrm{O}$ treatment. This also implies the reduction of surface oxides by the at- $\mathrm{H}$. 


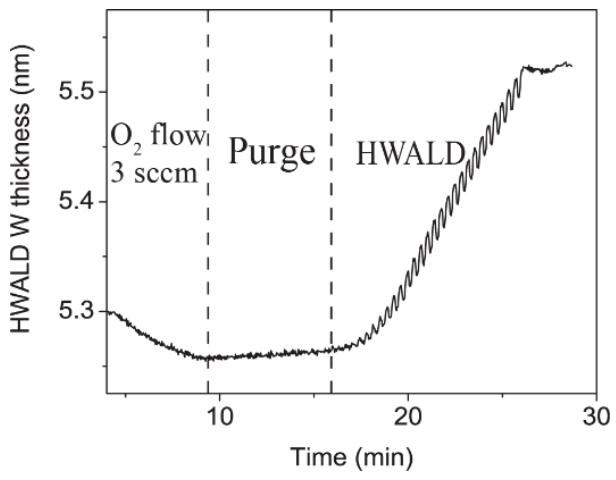

(a)

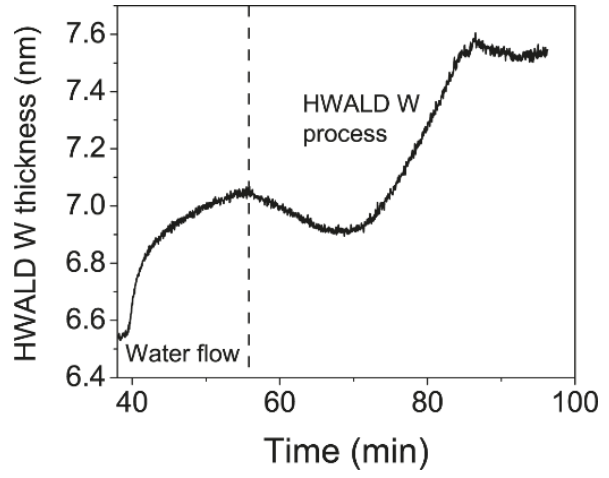

(b)

Figure 5.6. Recovery of the HWALD process after stopping the introduction of a constant (a) oxygen flow and (b) $\mathrm{H}_{2} \mathrm{O}$ flow. The processes are monitored in real time by in-situ SE.

It was additionally found that $\mathrm{N}_{2} \mathrm{O}$-exposure tends to inhibit or even stop the HWALD process, in contrast to an $\mathrm{O}_{2}$ exposure. Namely, no growth was observed for at least 15 min after exposure to an $\mathrm{N}_{2} \mathrm{O}$ flow of $3 \mathrm{sccm}$ for $5 \mathrm{~min}$, see Figure 7 (a), while the same flow rate and comparable time resulted in a successful recovery of the GPC in case of $\mathrm{O}_{2}$ exposure, see Figure 6 (a). This difference suggested a crucial change to the surface, which could well have been caused by a nitrogencontaining species forming at the surface. To investigate this further, $\mathrm{N}_{2} \mathrm{O}$ was replaced by $\mathrm{NH}_{3}$. As shown in Figure 7 (b), after an exposure to $\mathrm{NH}_{3}(20 \mathrm{sccm})$ for 10 min, HWALD cycling did not lead to $W$ deposition for at least $20 \mathrm{~min}$. This confirmed nitridation of the surface as preventing the HWALD W process. Not only did a tungsten nitride surface inhibit HWALD of W; we earlier found no measurable growth of W on TiN after 600 HWALD cycles ${ }^{[5]}$. 


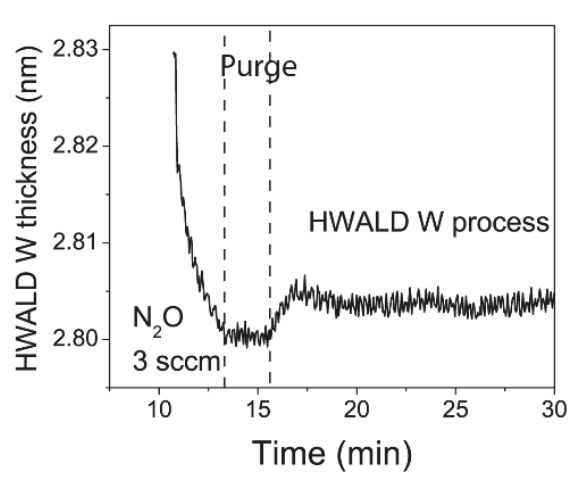

(a)

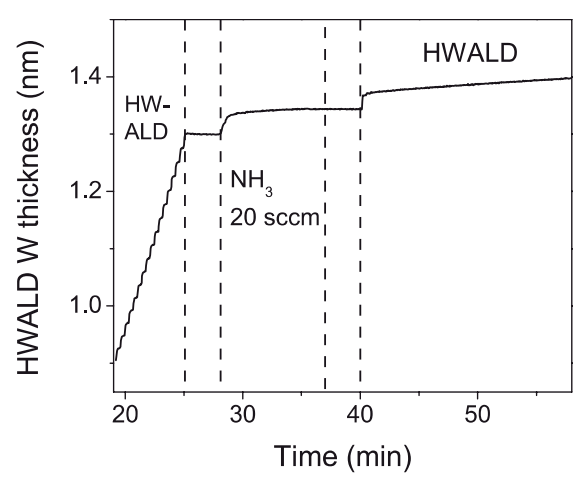

(b)

Figure 5.7. No recovery of the HWALD process after stopping the introduction of a constant (a) $\mathrm{N}_{2} \mathrm{O}$ flow of $3 \mathrm{sccm}$ and (b) $\mathrm{NH}_{3}$ flow of $20 \mathrm{sccm}$. The vertical dashed lines confine the Ar-purge regions in time. The processes are monitored in real time by in-situ SE.

Clarifying the actual film-growth mechanism remains outside the scope of this work and it would require an extended study of the surface chemistry. We however speculate that $\mathrm{WF}_{6}$ can dissociatively adsorb on a metallic (e.g., $\mathrm{W}$ and $\mathrm{Co}$ ) surface, from which the fluorine termination is removed by the subsequent at- $\mathrm{H}$ pulse, forming gaseous $\mathrm{HF}$ and leaving the pure metallic surface. For an oxidized surface, $\mathrm{W}$ or Co oxides can still be reduced by at- $\mathrm{H}$ to pure metals ${ }^{[6]}$. In case of having nonreducible oxides such as $\mathrm{SiO}_{2}$ and $\mathrm{Al}_{2} \mathrm{O}_{3}$, at least in the temperature range studied, existence of the oxide prohibits deposition of $\mathrm{W}^{[6]}$ presumably by inhibiting the chemisorption of $\mathrm{WF}_{6}$. We assume that similar holds for certain nitrides (e.g., TiN) and/or a nitridized $\mathrm{W}$ surface, as they are thermodynamically difficult to reduce back to metals. For example, our earlier studies with in-situ SE show no measurable reduction of TiN by at-H at low temperatures. However, the growth of $\mathrm{W}$ on such surfaces may still be enabled at a higher substrate temperature. 


\subsubsection{Influence of $W_{6} 6$ overdose on the HWALD W process}

The experiments with oxygen- and nitrogen-containing gases did not clarify the root cause of $\beta$-phase formation. In the earlier experiments in a cold-wall reactor growth of $\beta$-phase $W$ was always observed, see Chapter 3. Only the processes carried out in a hot-wall reactor could successfully provide $\alpha$-phase $\mathrm{W}$, see Chapter

4. The wide range of experiments supported the assumption that fluorine remnants in the reactor, possibly adsorbing on the cold walls, play a role in $\beta$-phase formation.

If one recall the results in Fig. 4.2 of Chapter 4: an increase of WF $F_{6}$ pulse time and flow in the hot-wall-reactor ALD cycle led to a long-term excess of fluorinecontaining species $\left(\mathrm{WF}_{\mathrm{x}}, \mathrm{F}_{2}\right.$, atomic fluorine; further to be called as fluorine compounds) in the reactor. For a $W_{6}$ flow rate of $10 \mathrm{sccm}$ (note that $3 \mathrm{sccm}$ corresponds to our standard conditions), the GPC gradually decreased. And this decrease was earlier attributed to film etching by fluorine compounds, due to a coexistence of deposition and etching modes described in Chapter 3. This was likely caused by the excess background pressure of fluorine compounds.

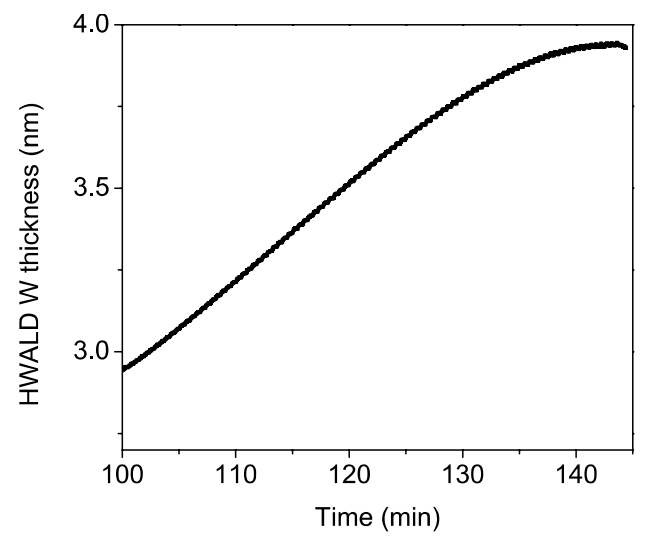

Figure 5.8. The influence of $\mathrm{WF}_{6}$ overdose on the growth rate of HWALD W. Lowering GPC observed after more than 2 hours due to accumulation of fluorine compounds in the reactor with a higher $(10 \mathrm{sccm}$ compared to standard $3 \mathrm{sccm}) \mathrm{WF}_{6}$ flow rate. The processes are monitored by in-situ SE. 
Here, we kept the $W F_{6}$ pulse time at $0.5 \mathrm{~s}$ while maintaining the flow rate of $\mathrm{WF}_{6}$ at $10 \mathrm{sccm}$, which was higher than a standard flow rate of $3 \mathrm{sccm}$. As seen in Fig. 5.8, performing the HWALD process with such prolonged pulses resulted in noticeable lowering the GPC after more than 2 hours. This further confirmed the slow accumulation of fluorine compounds in the reactor under non-optimized $\mathrm{WF}_{6}$ exposure conditions.

All the experiments carried out at excess-fluorine conditions showed a decrease of the GPC. For large overdoses, the as-grown films exhibited a resistivity above $100 \mu \Omega \cdot \mathrm{cm}$, pointing to the formation of $\beta$-phase $W$. This was further confirmed by the XRD spectra in Fig. 4.6 of Chapter 4 . In that chapter, increasing the $\mathrm{H}_{2} / \mathrm{at}-\mathrm{H}$ dose did not cause any beta-phase formation. In this work we have shown that beta phase can readily be formed with a higher background pressure of fluorine-containing compounds. These background fluorine-containing species could comprise $\mathrm{WF}_{6}, \mathrm{HF}, \mathrm{F}_{2}$ (or $\mathrm{F}$ ), and a variety of $\mathrm{WF}_{\mathrm{x}}(\mathrm{x}<6)$ sub-fluorides being generated due to the thermal dissociation of the background $\mathrm{WF}_{6}$ upon the hot wire ${ }^{[]]}$. As mentioned before, beta-phase $\mathrm{W}$ was proposed to be formed if additional gaseous impurities were present during deposition ${ }^{[8-12]}$. It was also reported that the sub-fluorides could react with residual oxygen-containing gases to form volatile compounds ${ }^{[13]}$. All mentioned species could in principle lead to the beta-phase $\mathrm{W}$. Unfortunately, it is difficult to determine the threshold background pressure of fluorine compounds, after exceeding which the formation of $\beta$-phase occurs, without a direct measurement of the gas phase composition. This remains outside the scope of this work, as well as identification of the exact type of these compounds. Nevertheless, a surplus of fluorine compounds in the gas phase is likely to influence film crystallinity even in the hot-wall reactor. With a sufficient $W F_{6}$ overdose, background fluorine compounds can further lead to the formation of $\beta$-phase $\mathrm{W}$ instead of $\alpha$-phase with a memory effect lasting for several deposition runs. Extra fluorine compounds present in the reactor are thus proposed to be the potential root cause of $\beta$-phase formation. 


\subsection{Conclusions}

This chapter investigates the effects of adding $\mathrm{N}_{2} \mathrm{O}, \mathrm{O}_{2}, \mathrm{NH}_{3}$ and $\mathrm{H}_{2} \mathrm{O}$ gasses on HWALD of W. The growth rate per cycle can be suppressed by additional $\mathrm{N}_{2} \mathrm{O}$, $\mathrm{O}_{2}$ and $\mathrm{H}_{2} \mathrm{O}$ pulses and decays with increasing the pulse duration. The as-grown films however exhibit a high purity $\alpha$-phase $W$, indicating an efficient reduction of tungsten oxides by atomic $\mathrm{H}$. Among these oxidants, water appears to have the strongest impact on the suppression of the growth rate. It is however possible to successfully restart the HWALD process (after a certain incubation time) and recover the original GPC after removing $\mathrm{H}_{2} \mathrm{O}$ or $\mathrm{O}_{2}$ from the deposition chamber. In contrast, additional $\mathrm{NH}_{3}$ or $\mathrm{N}_{2} \mathrm{O}$ pulses can entirely terminate the HWALD process, depending on the dose and/or exposure time. This termination is presumably caused by nitridation of the $\mathrm{W}$ surface. Finally, we investigated the influence of a temporary WF $_{6}$ overdose, which led to a long-term excess of fluorine compounds in the reactor. Increasing the $\mathrm{WF}_{6}$ pulse time decreases the GPC due to the coexistence of film etching. With a sufficient $W_{6}$ overdose, the as-grown films exhibit a resistivity above $100 \mu \Omega \cdot \mathrm{cm}$. This indicates the formation of $\beta$-phase $W$, further confirmed by the XRD spectra. We conclude that the surplus of fluorine-containing species is likely to cause the formation of $\beta$-phase $W$.

\section{References}

[1] E. Lassner and W. D. Schubert, Tungsten: Properties, Chemistry, Technology of the Elements, Alloys, and Chemical Compounds (Springer Science \& Business Media, New York, 1999).

[2] F. Wooten, Optical Properties of Solids (Academic Press, New York, 1972).

[3] J. Tauc, R. Grigorovici and A. Vancu, Phys. Status Solidi B 15, 627 (1966).

[4] M. Yang, A.A.I. Aarnink, A. Y. Kovalgin, D.J. Gravesteijn, R.A.M. Wolters and J. Schmitz, J. Vac. Sci. Technol. A 34, $01 A 129$ (2016).

[5] M. Yang, A.A.I. Aarnink, J. Schmitz and A. Y. Kovalgin, Thin Solid Films 646, 199 (2018).

[6] M. Yang, A.A.I. Aarnink, J. Schmitz and A. Y. Kovalgin, "Inherently areaselective hot-wire assisted atomic layer deposition of tungsten films", Thin Solid Films, DOI: 10.1016/j.tsf.2018.01.016.

[7] J. Creighton, J. Vac. Sci. Technol. A 7, 621 (1989). 
[8] D. P. Basile, C. L. Bauer, S. Mahajan, A. G. Milnes, T. N. Jackson and J. DeGelormo, Mater. Sci. Eng. B 10, 171 (1991).

[9] A. Bensaoula, J. C. Wolfe, A. Ignatiev, F. O. Fong and T. S. Leung, J. Vac. Sci. Technol. A 2, 389 (1984).

[10] M. J. O'Keefe and J. T. Grant, J. Appl. Phys. 79, 9134 (1996).

[11] Y. Pauleau, P. Lami, A. Tissier, R. Pantel and J. C. Oberlin, Thin Solid Films 143, 259 (1986).

[12] J. H. Souk, J. F. O'Hanlon and J. Angillelo, J. Vac. Sci. Technol. A 3, 2289 (1985).

[13] T. D. Bestwick and G. S. Oehrlein, J. Appl. Phys. 66, 5034 (1989). 


\title{
Inherently area-selective HWALD of W films on metal/insulator substrates
}

\begin{abstract}
.
This chapter demonstrates area-selective growth of tungsten (W) films by hot-wire assisted ALD (HWALD). With this recently developed technique, low-resistivity a-phase W films can be deposited by using sequential pulses of atomic hydrogen (at- $\mathrm{H}$ ) and $\mathrm{WF}_{6}$ at a substrate temperature of $275^{\circ} \mathrm{C}$. As reported in this chapter, the deposition is highly selective. HWALD tungsten grows with little to no incubation time on W, Co and Si surfaces. On the other hand, no growth is observed on $\mathrm{TiN}, \mathrm{Al}_{2} \mathrm{O}_{3}$ and $\mathrm{SiO}_{2}$ surfaces. The interfaces of $\mathrm{W}$ and various substrates are examined by transmission electron microscopy. The absence of oxygen at the interfaces indicates that the atomic-hydrogen not only serves as a suitable ALD precursor for $\mathrm{W}$, but is here shown to effectively reduce the native oxides of $\mathrm{W}$ and Co at the ALD process conditions, enabling in situ surface preparation before starting the deposition sequence.
\end{abstract}

This chapter is based on the publication:

Mengdi Yang, Antonius A.I. Aarnink, Jurriaan Schmitz and Alexey Y. Kovalgin, "Inherently areaselective hot-wire assisted atomic layer deposition of tungsten films on metal/insulator substrates", Thin Solid Films, DOI: 10.1016/j.tsf.2018.01.016 (2018). 


\subsection{Introduction}

Modern ultra-large-scale integration (ULSI) requires downscaling of devices and circuits with less than $10 \mathrm{~nm}$ feature sizes ${ }^{[1]}$. Conventional etch or deposition/liftoff processes in combination with various lithography techniques, which are employed to achieve film patterning, become increasingly challenging due to the ever-shrinking alignment requirements ${ }^{[2,3]}$. In this light, area-selective ALD (AS-ALD) increasingly attracts attention over the past several years. This for example enables nanoscale patterning and further downscaling of device dimensions ${ }^{[4,5]}$.

The most common approach to AS-ALD is to provide a molecular mask as a "resist" layer disabling deposition over selected areas. Such masks include selfassembled monolayer (SAM) materials ${ }^{[6-9]}$ and polymers ${ }^{[2,10]}$. However, SAMs typically have long assembly times in the order of hours and must be removed after deposition $^{[11]}$. An alternative approach to AS-ALD is to take advantage of differences in nucleation rates on different surfaces for a given ALD process. This offers a costeffective approach to form patterned layers at low material budget. Recently, a few results have been reported on the area-selective ALD using the inherent substratedependent growth initiation based on nucleation delay, or 'inherent AS-ALD' processes $^{[12-14]}$. However, there is more work need to be done to overcome the difficulty in finding and combining the required chemical properties of ALD precursors and deposition substrates.

Chapter $\mathbf{4}$ has demonstrated high-purity a-phase HWALD W films. In this chapter, we demonstrate an inherent AS-ALD of tungsten (W) films by utilizing HWALD.

Many studies about selective growth of $\mathrm{W}$ by chemical vapor deposition (CVD) on $\mathrm{Si} / \mathrm{SiO}_{2}$ substrates were reported in the last decade ${ }^{[15-18]}$; only very little work has however been published on AS-ALD of $\mathrm{W}^{[11]}$. In all these reports, $\mathrm{H}_{2}$ and silane $\left(\mathrm{SiH}_{4}\right)$ were the two main precursors adopted as reductants. Although areaselective CVD and ALD of W were successfully established for a given processing time or number of ALD cycles, extending these parameters to a longer time or a larger number of cycles generally led to undesirable nucleation on all exposed surfaces, thereby losing the selectivity. 
The loss of selectivity in silane-WF 6 based ALD was attributed to the occurrence of $\mathrm{Si}-\mathrm{H}$ terminations on $\mathrm{SiO}_{2}$ surfaces caused by the dissociative adsorption of silane ${ }^{[11,19,20]}$. For selective ALD based on $\mathrm{H}_{2}-\mathrm{WF}_{6}$, articles proposed the by-product hydrogen fluoride (HF) as the culprit ${ }^{[16]}$, which was later claimed not to be the main reason causing the loss of selectivity ${ }^{[21]}$. Instead, the partial decomposition of $\mathrm{WF}_{6}$ into tungsten subfluorides $(\mathrm{WF}, x<6)$ was confirmed to be the cause ${ }^{[18,21,22]}$.

The HWALD process we use employs no silane. Further, introducing separate precursor pulses with a sufficient purge time in between prevents the mixing of $W_{6}$ and hydrogen in the gas phase. This may well suppress the influence of tungsten subfluorides. Our HWALD process therefore bears the promise to remain selective.

In this chapter, we demonstrate the retarded nucleation of HWALD W on $\mathrm{SiO}_{2}, \mathrm{Al}_{2} \mathrm{O}_{3}$ and $\mathrm{TiN}$ surfaces in contrast to its readily-occurring deposition on $\mathrm{W}$ and cobalt (Co) surfaces. The HWALD experiments were monitored in situ by a spectroscopic ellipsometer (SE). Further sample characterization was performed ex situ with the assistance of HR-TEM. Finally, we studied the effect of the a-Si seed layer thickness on the incubation time and growth rate for HWALD on the substrates showing the retarded nucleation.

\subsection{Experimental}

HWALD a-phase W films of low resistivity were grown using sequential pulses of $\mathrm{WF}_{6}$ and $\mathrm{HW}$-generated at- $\mathrm{H}$, as described in Chapter 4, utilizing a homebuilt hot-wall reactor. Briefly, the process conditions were fixed at a substrate temperature of $275^{\circ} \mathrm{C}$ and a total pressure of 0.05 mbar. A standard HWALD cycle consisted of an at-H (50 sccm) pulse of $7 \mathrm{~s}$, a post-at-H purge of $7 \mathrm{~s}$, and a WF 6 (3 sccm) pulse of $0.5 \mathrm{~s}$ followed by a post-WF 6 purge of $7 \mathrm{~s}$. The hot-wire temperature was kept at $1750{ }^{\circ} \mathrm{C}$. The standard growth rate could vary between 
0.01 and $0.02 \mathrm{~nm} /$ cycle for different deposition experiments, depending on the amount of residual fluorine-containing species remaining in the reactor.

Non-patterned substrates were firstly utilized to investigate the nucleation and growth behavior of HWALD W on $\mathrm{SiO}_{2}, \mathrm{Al}_{2} \mathrm{O}_{3}, \mathrm{TiN}, \mathrm{W}$ and $\mathrm{Co}$. $\mathrm{SiO}_{2}$ was thermally grown to a thickness of $100 \mathrm{~nm}$ on p-type Si (100) wafers. W films used as the substrates were deposited by a standard HWALD process on top of thermal $\mathrm{SiO}_{2}$, using a pre-formed W seed layer of $5 \mathrm{~nm}$. Cobalt layers of $10 \mathrm{~nm}$ in thickness were sputtered directly on $\mathrm{SiO}_{2}$. Prior to depositions of all the metals, the $\mathrm{SiO}_{2}$-covered wafers were cleaned up in fuming (99\%) $\mathrm{HNO}_{3}$ and boiling $69 \% \mathrm{HNO}_{3}$ to remove organic and metallic contaminations. $\mathrm{Al}_{2} \mathrm{O}_{3}$ was formed by thermal ALD in a separate Picosun ALD reactor; TiN was however deposited in the same HWALD reactor, without vacuum break and prior to the $\mathrm{W}$ deposition.

After the depositions, the W- and Co-covered wafers were exposed to air for up to $360 \mathrm{hrs}$, forming a layer of native oxide. This was done to study the effectiveness of in-situ (in the reactor) native oxide reduction by at- $\mathrm{H}$. Prior to starting each HWALD-W process, this native oxide could have successfully been reduced by at- $\mathrm{H}$ upon a 20-min exposure to a constant flow of $\mathrm{H}_{2}$ at $275^{\circ} \mathrm{C}$ (see further discussion), leaving a clean $\mathrm{W}$ or Co surface. Except a constant flow of $\mathrm{H}_{2}$ via the hot wire, the same conditions as for the HWALD process were kept for the at-H reduction process.

Patterned $\mathrm{W} / \mathrm{SiO}_{2}$ substrates were provided by $\mathrm{ASM}$ International, with trenches in $\mathrm{SiO}_{2}$ filled in by CVD W and then flattened out by chemical mechanical polishing. The $\mathrm{Co} / \mathrm{SiO}_{2}$ substrates were fabricated at MESA+ Institute by a combination of Co sputtering and lift-off process for further patterning the Co lines on top of $\mathrm{SiO}_{2}$. Importantly, before sputtering of $10 \mathrm{~nm}$ Co upon $\mathrm{SiO}_{2}$, approximately $3 \mathrm{~nm}$ thick titanium (Ti) layer was pre-sputtered for a better adhesion of Co.

Thickness of the a-Si seed layer was varied from $0.01 \mathrm{~nm}$ to $5 \mathrm{~nm}$ to find out the thinnest seed layer enabling HWALD of $\mathrm{W}$ on $\mathrm{SiO}_{2}, \mathrm{TiN}$ and $\mathrm{Al}_{2} \mathrm{O}_{3}$. The thickness was obtained by SE. Importantly, the sub-nanometer thickness values shown in Fig. 6.1 and 6.4 fall beyond the accuracy of SE. The plotted thickness ranges are in other words hardly physical and are only shown to indicate the lack of a measurable thickness change during the corresponding experiments. As mentioned in section 98 
2.3 of Chapter 2, the larger but still few-nm thickness variations (see Fig. 6.2b and 6.3) solely indicate a qualitative trend (i.e., increase, decrease or little change) in thickness behavior and do not provide quantitative information. The sub-monolayer numbers given in Table 1 can at best be interpreted as the average thickness over the $\mathrm{mm}$-scale area probed by SE; this area features discrete nm-scale film islands on an otherwise uncovered surface.

\subsection{Results and discussion}

\subsubsection{Nucleation of HWALD W on substrates of various materials}

The nucleation behavior of HWALD W on a thermally-grown $100 \mathrm{~nm}$ thick $\mathrm{SiO}_{2}$ layer is shown in Fig. 6.1. The figure presents the development of the $\mathrm{W}$ thickness with or without a pre-treatment with at- $\mathrm{H}$. Without the pre-exposure, 850 HWALD cycles resulted in a negligible change in the $W$ thickness, indicating nearly no growth. The same occurs when applying a $20 \mathrm{~min}$ at-H pre-exposure step: no deposition of $W$ occurs for at least 1000 HWALD cycles. Therefore, it can be concluded that $\mathrm{W}$ can hardly nucleate by the HWALD process up to 1000 cycles on a $\mathrm{SiO}_{2}$ surface. Additionally, there is no effective at- $\mathrm{H}$ reduction of $\mathrm{SiO}_{2}$ to $\mathrm{Si}$ at this substrate temperature (otherwise $\mathrm{W}$ deposition would start). Based on the measured growth rate of 0.01 to $0.02 \mathrm{~nm} /$ cycle for the HWALD $\mathrm{W}^{[23]}$, this retarded nucleation on $\mathrm{SiO}_{2}$ implies growing at least 10 to $20 \mathrm{~nm}$ of $\mathrm{W}$ on a suitable substrate, with no deposition on $\mathrm{SiO}_{2}$. 


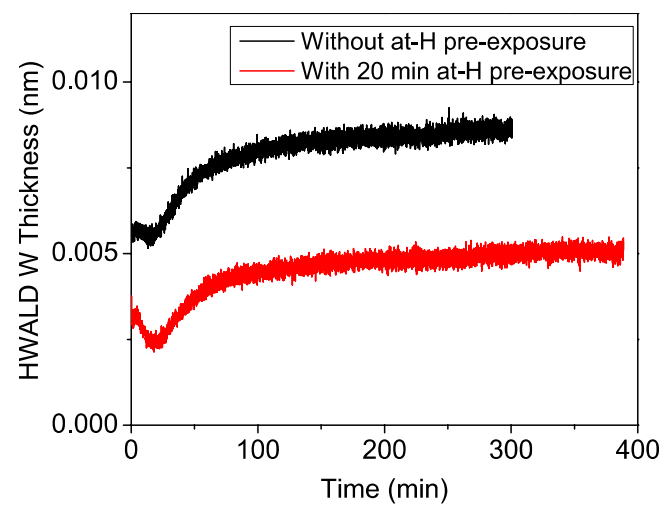

Figure 6.1. HWALD of $\mathrm{W}$ on $100 \mathrm{~nm}$ thick thermally-grown $\mathrm{SiO}_{2}$. The black line depicts the growth for 850 HWALD cycles without preceding at- $\mathrm{H}$ exposure. The red line corresponds to a 20 min in situ preexposure to at- $\mathrm{H}$ followed by 1000 HWALD cycles. During the at- $\mathrm{H}$ exposure, all process conditions were the same as those used in the following HWALD step; the $\mathrm{H}_{2}$ flow rate was $50 \mathrm{sccm}$. Note: the plotted thickness values fall beyond the accuracy of SE measurements and are only shown to indicate no measurable change of the $\mathrm{W}$ thickness after 1000 cycles on a $\mathrm{SiO}_{2}$ surface.

Although HWALD W can barely nucleate directly on $\mathrm{SiO}_{2}$, it can readily grow on W. In the previous works ${ }^{[24-26]}$, it has been shown that HWALD W could nucleate without an incubation time upon a $\mathrm{W}$ seed layer with an average thickness of $5 \mathrm{~nm}$. The seed layer was pre-formed in the same reactor without a vacuum break, aiming to limit the oxidation process and to provide a clean metal surface for the subsequent HWALD of W. To note, this seed layer was not continuous but formed in islands, as proven earlier by HR-TEM in Chapter 4.

In this chapter, we extended the experiments to perform HWALD on natively oxidized $\mathrm{W}$ layers, given a sufficient at- $\mathrm{H}$ reduction of the native oxide before starting the actual deposition. The reduction process is presented in Fig. 6.2 (a). Delta, an optical parameter directly measured by SE and representing the phase difference of light induced by the reflection, changed during the at- $\mathrm{H}$ reduction. The SE technique is sufficiently sensitive to quantify such a small increase of delta, so we witness a change of the W surface when it is exposed to at- $\mathrm{H}$. However, the thicknesses of Woxide in the optical model could hardly be extracted with this minor change of delta, 
which also implied that the native oxide layer was very thin. Nevertheless, the change of delta revealed a measurable influence of at- $\mathrm{H}$ upon a 20 min exposure.

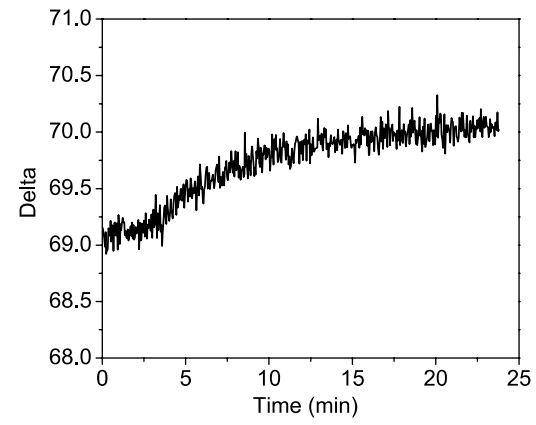

(a)

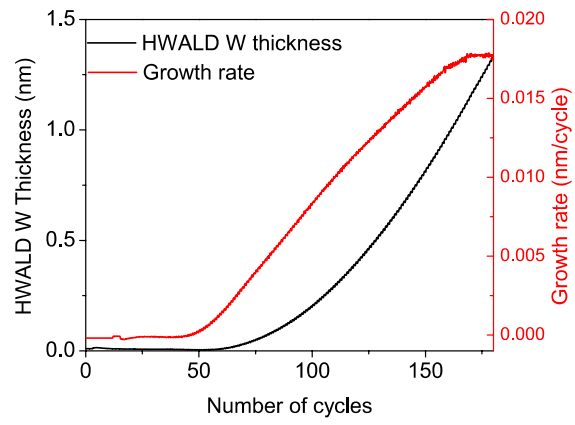

(b)

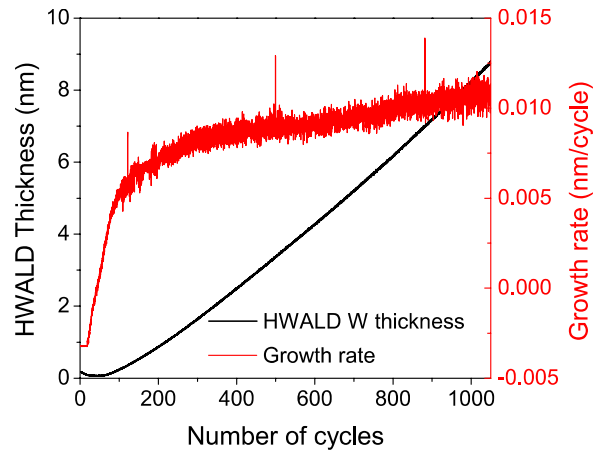

(c)

Figure 6.2. (a) The change of optical parameter delta during at-H reduction of native tungsten oxide. The growth behavior of HWALD W on (b) standard 5-nm-thick W seed layer, pre-exposed to air for $91 \mathrm{hrs,}$ and (c) a layer of HWALD W (10 nm) pre-exposed to air for 900 hrs. Before the deposition, a 20-min reduction by at- $\mathrm{H}$ was applied to samples (b) and (c), to remove the native oxide.

Fig. 6.2 (b) shows the growth behavior of HWALD W on a standard 5-nm thick (discontinuous) seed layer of W, pre-exposed to air for 91 hrs. Before starting the deposition, the native oxide was reduced by at- $\mathrm{H}$ for $20 \mathrm{~min}$ (not shown), as described above. After an incubation period of roughly 150 cycles, the growth rate reached a steady value of $0.017 \mathrm{~nm} /$ cycle, which was comparable to that of our standard HWALD process. Separately, a 10-nm W film was pre-deposited by HWALD and kept in air for 900 hrs. Fig. 6.2 (c) demonstrates that after a 20-min 
reduction by at-H (not shown), HWALD W growth restarted on this air-exposed and then reduced surface after an incubation time of approx. 100 cycles, reaching a standard growth rate of $0.011 \mathrm{~nm} /$ cycle. In contrast, growth of HWALD W on a standard $\mathrm{W}$ seed layer, pre-formed in-situ without vacuum break using a-Si and WF 6 (see Experimental), resulted in zero incubation time. As the latter approach minimizes the chance of formation of interfacial oxide, the former (i.e., the occurrence of 100-150 cycles of incubation) indicates interface deterioration upon exposure to air. The interface can however be made suitable for the subsequent deposition of $\mathrm{W}$ (presumably by reducing native oxide) by an appropriate exposure to at- $\mathrm{H}$.

Apart from tungsten, cobalt (Co) was also examined as a substrate material for HWALD W. First, a 15-nm Co layer was sputtered on top of a $\mathrm{SiO}_{2}$ film and then exposed to air for $360 \mathrm{hrs}$. Prior to starting the HWALD process, the native Co-oxide was reduced by at- $\mathrm{H}$; the SE monitoring is demonstrated in Fig. 6.3 (a). The at-H exposure started at $2 \mathrm{~min}$. The thickness of $\mathrm{Co}$ and its native oxide were measured by $\mathrm{SE}$ with a model consisting of a cobalt oxide/Co/SiO$/ \mathrm{Si}$ layer stack. To be specific, the cobalt oxide was modelled using a Tauc-Lorentz formulation with 1 oscillator ${ }^{[27]}$ whereas Co was modelled by the Drude-Lorentz approach with a Drude term and two Lorentz oscillators ${ }^{[28]}$. The dramatic coherent thickness change of Co and the native oxide at 3-4 min of the at- $\mathrm{H}$ exposure indicated an effective oxide reduction. Although the reduction time was fixed at $20 \mathrm{~min}$ to be consistent with the at- $\mathrm{H}$ exposure applied to $\mathrm{W}$, the cobalt oxide was easier to reduce as a 2-3 min exposure appeared sufficient to remove the entire $\sim 1.3 \mathrm{~nm}$ of native oxide at $275^{\circ} \mathrm{C}$. The slight thickness increase of cobalt oxide after $4 \mathrm{~min}$ of the reduction can be related to the accuracy of SE measurements (see Experimental) or the substrate temperature change. Fig. 6.3 (b) shows the HWALD growth of W on the as-prepared Co surface. Comparable with $\mathrm{W}$ layers, the incubation time was around 120 cycles before achieving a linear growth regime with a stable growth rate around $0.017 \mathrm{~nm} / \mathrm{cycle}$. 


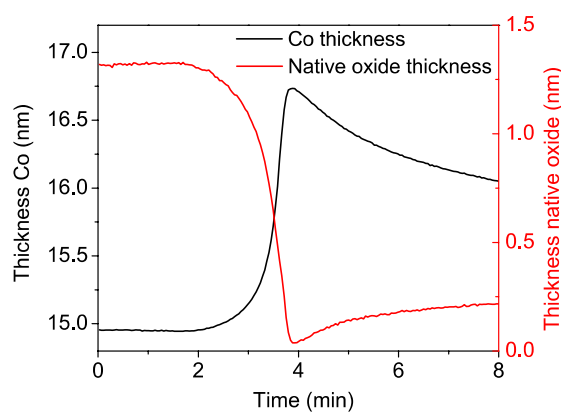

(a)

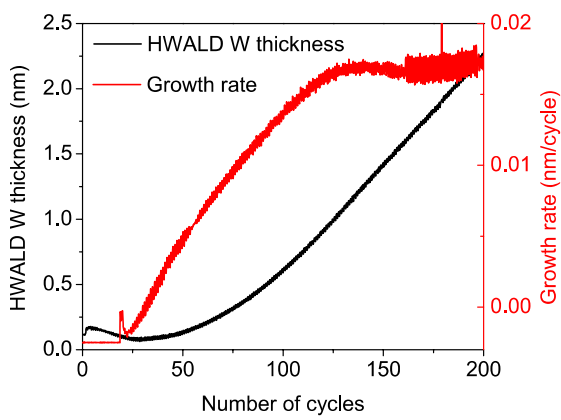

(b)

Figure 6.3. (a) Reduction of native cobalt oxide, grown on a 15-nm Co layer formed by sputtering and then exposed to air for $360 \mathrm{hrs}$, by at- $\mathrm{H}$; the at-H exposure started at 2 min. (b) Kinetics of HWALD of W subsequently being formed on such-prepared layer of $\mathrm{Co}$.

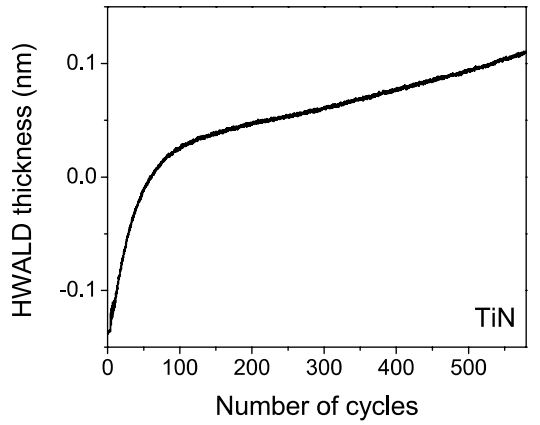

(a)

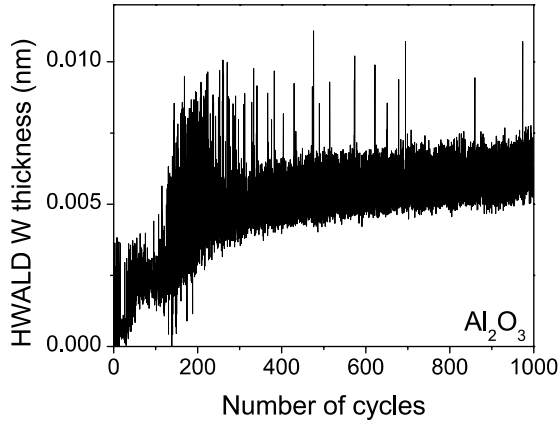

(b)

Figure 6.4. An attempt to grow HWALD W on substrates of (a) TiN and (b) $\mathrm{Al}_{2} \mathrm{O}_{3}$ under standard conditions; no deposition has been observed. No pre-exposure to at- $\mathrm{H}$ was applied. Note: the plotted thickness values fall beyond the accuracy of SE measurements and are only shown to indicate no measurable change of the $W$ thickness after the given number of HWALD cycles.

We further examined the nucleation of HWALD W on ALD-formed TiN and $\mathrm{Al}_{2} \mathrm{O}_{3}$. Specifically, TiN was deposited in the same reactor as HWALD W without vacuum break and $\mathrm{Al}_{2} \mathrm{O}_{3}$ was fabricated in a commercial ALD tool. The HWALD W failed to nucleate on these substrates up to 1000 HWALD cycles. Fig. 6.4 displays 
the growth of HWALD W on both materials and no at- $\mathrm{H}$ exposure was applied to them before HWALD of W. The negative thickness is not physical; it occurs probably because the used model does not account for the surface roughness. Both materials were modelled by the Cauchy SE model[29]. Fig. 6.4 (a) confirms that only very little surface modifications occur after 600 HWALD cycles. However, even a lesser change of the surface state was observed on $\mathrm{Al}_{2} \mathrm{O}_{3}$ up to 1000 cycles. Therefore, selective growth of HWALD W can also be expected on surfaces containing a suitable nucleation layer (e.g., $\mathrm{W}$ or $\mathrm{Co}$ ) in combination with $\mathrm{TiN}$ and/or $\mathrm{Al}_{2} \mathrm{O}_{3}$ patterns.

\subsubsection{Selective growth of HWALD W}

\section{$\mathrm{W} / \mathrm{SiO}_{2}$ substrates}

Based on the results above, we expect HWALD $W$ to selectively grow on patterned $\mathrm{W} / \mathrm{SiO}_{2}$ and $\mathrm{Co} / \mathrm{SiO}_{2}$ substrates. To investigate this, 2200 HWALD cycles were applied to a substrate with CVD W deposited into trenches formed in $\mathrm{SiO}_{2}$. Namely, 85-nm-deep and 160-nm-wide $\mathrm{SiO}_{2}$ trenches were filled with W, with a $200 \mathrm{~nm}$ spacing, see Fig. 6.5 (a). Before the deposition, the standard at- $\mathrm{H}$ preexposure was executed to reduce the native tungsten oxide. Fig. 6.5 presents the cross-sectional HR-TEM images of the $\mathrm{W} / \mathrm{SiO}_{2}$ substrates before and after HWALD of W. After executing 2200 HWALD cycles, a 19-nm thick W layer was obtained, selectively covering the CVD-W trenches. Importantly, after the first 1200 HWALD cycles, the grown $\mathrm{W}$ film was taken out of the reactor and exposed to air for $10 \mathrm{hrs}$. Then, the sample was placed back into the reactor, followed by at- $\mathrm{H}$ reduction and the remaining 1000 cycles. The intermediate exposure to air can explain the lowerthan-standard growth rate per cycle (GPC) of <0.009 nm/cycle; one should keep in mind that standard GPC can be as high as $0.02 \mathrm{~nm} /$ cycle.

The HR-TEM image of Fig. 6.5 (b) clearly demonstrates the presence of HWALD W only on top of the $\mathrm{W}$, with no measurable deposition on the $\mathrm{SiO}_{2}$ surface. 
The close-ups are shown in Fig. 6.6. Noticeably, the triangular-shaped "ears" appear at the edges between CVD W and $\mathrm{SiO}_{2}$, indicating lateral overgrowth of HWALD W at the edges. All these observations confirm the selective growth of HWALD W on CVD W without nucleation on $\mathrm{SiO}_{2}$.

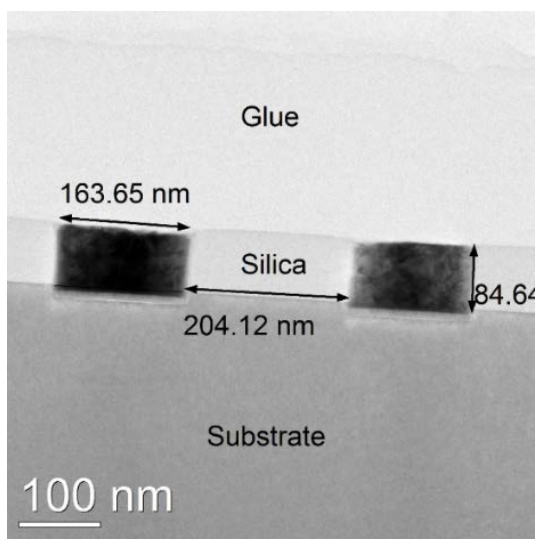

(a)

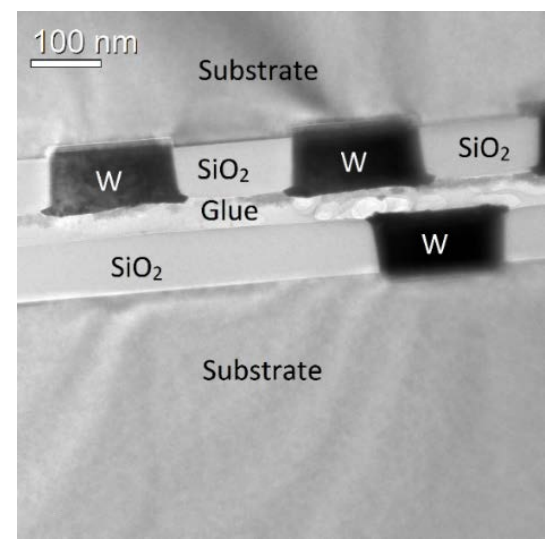

(b)

Figure 6.5. Cross-sectional HR-TEM images of patterned substrates with CVD W and $\mathrm{SiO}_{2}$ : (a) reference sample before deposition and (b) after an exposure to 2200 HWALD cycles; the newly-appeared triangular-shaped extensions ("ears") can be seen at the edges between CVD W and $\mathrm{SiO}_{2}$.

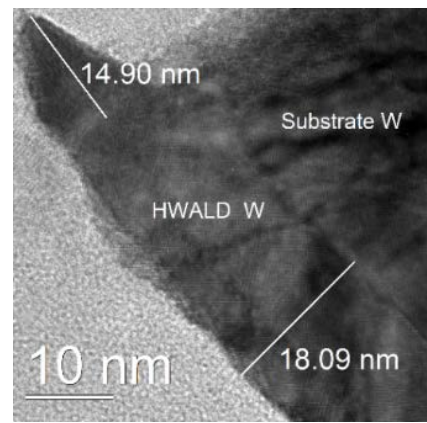

(a)

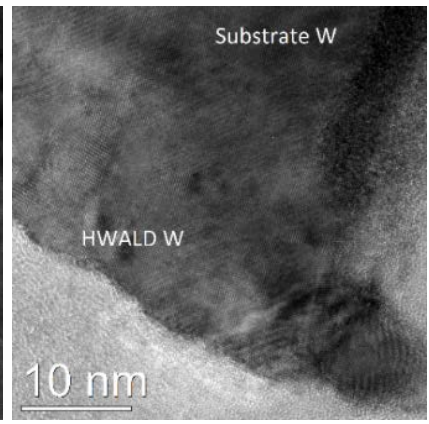

(b)

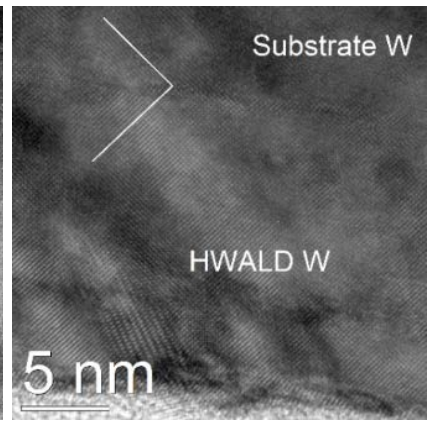

(c)

Figure 6.6. Cross-sectional HR-TEM images of the interfaces between HWALD W and substrate CVD W, visualizing (a) film thickness, the triangular-shaped "ears" and the interface, (b) epitaxial growth, and (c) change of crystal orientation between the two W layers . 
HR-TEM images in Fig 6.6 visualize the interfaces between the HWALDand CVD-W, as well as the atomic arrangements. Noticeably, the HWALD W film thickness of $18 \mathrm{~nm}$ marked in Fig. 6.6 (a) corresponds with the lateral width of the "ear", being $15 \mathrm{~nm}$. This implies a comparable growth rate of HWALD W in both vertical and lateral directions. Moreover, the triangular shape confirms the growth on CVD W but not on $\mathrm{SiO}_{2}$. Fig. 6.5 (b) and (c) show the interfaces between the two layers of $\mathrm{W}$. The interface in (b) can hardly be observed; the atomic arrangements continue from the CVD $W$ to the HWALD $W$ formed on top, indicating an epitaxial growth. However, there is an obvious change of crystal orientation at the interface depicted in Fig. 6.6 (c). Therefore, HWALD W can grow on CVD W either epitaxially or in a polycrystalline form. Applying the FFT method to the observed periodicity in the image yields the $d$-spacing of all $W$ layers, solely revealing a-phase $W$. Noticeably, the interruption of the HWALD process half-way with the subsequent exposure of the layer to air, followed by the at- $\mathrm{H}$ reduction step and the remaining deposition cycles resulted in no (measurable) oxygen contamination at the interface or through the entire HWALD W film. This reconfirmed the efficient interface reduction by at- $\mathrm{H}$.

$\mathrm{Co} / \mathrm{SiO}_{2}$ substrates

We further investigated the selective growth of $W$ using HWALD on patterned $\mathrm{Co} / \mathrm{SiO}_{2}$ surfaces. Fig. 6.7 (a) shows these $\mathrm{Co} / \mathrm{Ti} / \mathrm{SiO}_{2} / \mathrm{Si}$ substrates. The $\mathrm{W}$ has only been formed on $\mathrm{Co}$, leaving the $\mathrm{SiO}_{2}$ surfaces blank and thus affirming the selectivity. Fig. 6.7 (b) shows a close-up of the $\mathrm{Co} / \mathrm{SiO}_{2}$ sample; note the commonly observed feature formed at the Co edge due to the lift-off process. Prominently, a uniform and conformal layer of $\mathrm{W}$ covering both sides of this feature highlights the advantages of the HWALD technique in terms of its uniformity and step coverage. Moreover, single crystal grains are imaged in Fig. 6.7 (c). The thickness of the W layer varies between 9 and $13 \mathrm{~nm}$ due to the surface roughness, consistent with the expectations for 1100 HWALD cycles. Importantly, the d-spacing obtained 


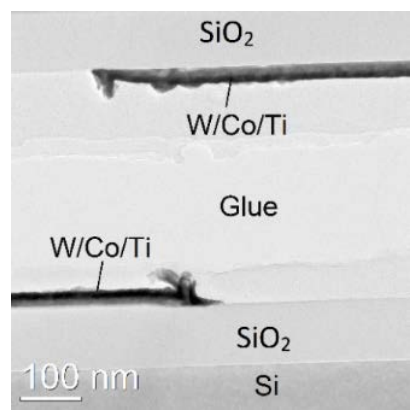

(a)

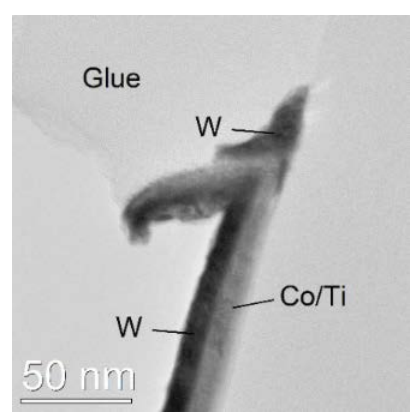

(b)

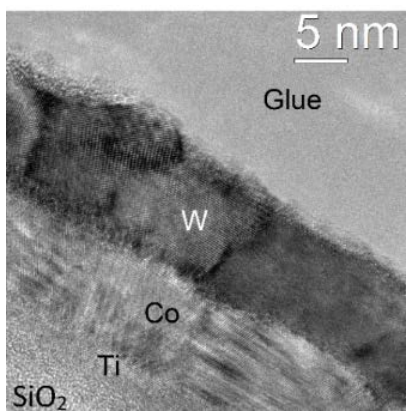

(c)

Figure 6.7. HR-TEM images of $\mathrm{W}$ grown by HWALD (1100 cycles) on patterned $\mathrm{Co} / \mathrm{Ti} / \mathrm{SiO}_{2} \mathrm{Substrates}_{\text {. }}$ (a) Selective growth of $\mathrm{W}$ on $\mathrm{Co}$ without nucleation on $\mathrm{SiO}_{2}$; (b) close-up showing the lateral growth at the $\mathrm{Co} / \mathrm{SiO}_{2}$ edge (similar to the triangular-shaped features of the $\mathrm{W} / \mathrm{SiO}_{2}$ substrates); and (c) individual $\mathrm{W}$ and Co crystal grains.

from the crystals after an FFT analysis again revealed pure a-phase $\mathrm{W}$, the lowestresistivity phase of tungsten ${ }^{[30]}$.

Although selective growth of $\mathrm{W}$ has been achieved in both CVD and ALD earlier $^{[1,15-18,31]}$, extended process times or cycle numbers generally lead to nucleation on all surfaces. Hence, the selectivity window (i.e., the process range where growth only occurs on dedicated surfaces) is crucial and efforts are made to broaden it. In a recent publication, it has been reported that the selectivity window of ALD W on $\mathrm{Si} / \mathrm{SiO}_{2}$ patterns, using $\mathrm{WF}_{6}$ and $\mathrm{SiH}_{4}$, could be broadened from growing $10 \mathrm{~nm}$ to $16 \mathrm{~nm}^{[11]}$. The loss of selectivity beyond $16 \mathrm{~nm}$ was attributed to Si-H bonds on $\mathrm{SiO}_{2}$ surfaces due to the action of $\mathrm{SiH}_{4}{ }^{[11,20]}$. Moreover, Lemaire et al. ${ }^{[1]}$ have claimed that the surface hydroxyls on $\mathrm{SiO}_{2}$ surfaces are a key factor for $\mathrm{SiH}_{4}$ adsorption, causing the loss of selectivity after 10-35 ALD cycles using $\mathrm{WF}_{6}$ and $\mathrm{SiH}_{4}$. However, in our case neither $\mathrm{WF}_{6}$ nor at- $\mathrm{H}$ could efficiently provide nucleation sites on $\mathrm{SiO}_{2}$. As for the established selective CVD W using $\mathrm{WF}_{6}$ and hydrogen at 250$350{ }^{\circ} \mathrm{C}^{[31]}$. the loss of selectivity up to $200 \mathrm{~nm}$ was attributed to the adsorption and incorporation of the by-product tungsten subfluorides $\left(\mathrm{WF}_{\mathrm{x}}\right)$, on $\mathrm{SiO}_{2}{ }^{[21,22]}$. In our HWALD process, the loss of selectivity was not observed at a substrate temperature of $275^{\circ} \mathrm{C}$ up to 2200 cycles, excluding the possible role of subfluorides. 
To summarize, under the optimized process conditions meaning a GPC of $0.02 \mathrm{~nm} /$ cycle, HWALD W is estimated to be selectively grown to a thickness of at least $22 \mathrm{~nm}$ (on basis of 1100 cycles tried so far) on patterned $\mathrm{Co} / \mathrm{SiO}_{2}$ substrates and at least $44 \mathrm{~nm}$ (on basis of 2200 cycles tried so far) on $\mathrm{W} / \mathrm{SiO}_{2}$ substrates. Besides, no nucleation was visible on $\mathrm{TiN}$ and $\mathrm{Al}_{2} \mathrm{O}_{3}$ surfaces after an exposure up to 1000 HWALD cycles, potentially giving a W layer of 10 to $20 \mathrm{~nm}$ on a proper substrate. These thickness estimates may be very conservative as we have not witnessed any growth on $\mathrm{TiN}, \mathrm{SiO}_{2}$ and $\mathrm{Al}_{2} \mathrm{O}_{3}$.

\subsubsection{Nucleation of HWALD W on a-Si seed layer of various thicknesses}

Surfaces on which the HWALD W growth is inhibited, such as $\mathrm{SiO}_{2}$, TiN and $\mathrm{Al}_{2} \mathrm{O}_{3}$, can be modified to allow tungsten to deposit. In previous works, we have reported on a method of forming a $W$ seed layer with an average thickness from 2 to $5 \mathrm{~nm}$ at a substrate temperature of $325^{\circ} \mathrm{C}$. This seed layer was formed in two steps: (i) growing a 5-nm-thin amorphous $\mathrm{Si}$ (a-Si) layer using $\mathrm{Si}_{3} \mathrm{H}_{8}$ gas and (ii) consequently exposing the $\mathrm{a}-\mathrm{Si}$ to $\mathrm{WF}_{6}$ gas, forming a solid $\mathrm{W}$ film and volatile silicon fluorides ${ }^{[24,25]}$. Here, we report on experiments to reduce the a-Si layer thickness in order to determine the thinnest layer still acting as a nucleation seed layer for $\mathrm{W}$.

Dealing with few-nm-thick layers requires a reliable thickness measurement method. SE can provide reliable data for continuous (closed) layers, still requiring a few thickness verification points by other (ex-situ) techniques. In precious chapters, thickness of a 10-nm HWALD W film, measured by SE, was verified by HR-SEM and XRR. However, for very thin films, one should bear in mind the earlier notice: the values can only be used to compare qualitative trends. We have additionally demonstrated that a $\mathrm{W}$ seed layer, obtained from converting a 5-nm a-Si film (measured by SE), was actually in a form of discontinuous clusters (see Fig. 4.9a in Chapter 4) with the height ranging from 1 to $7 \mathrm{~nm}$, instead of being a continuous 


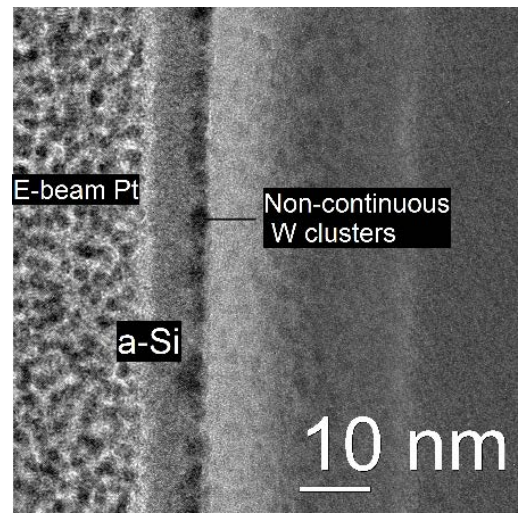

Figure 6.8. HR-TEM images of a W seed layer, obtained from converting an a-Si layer of approximately $0.5 \mathrm{~nm}$, as measured by SE.

layer ${ }^{[23]}$. The average thickness of 3-4 $\mathrm{nm}$ was in agreement with that given by SE (3.5 nm), assuming a continuous layer.

Fig. 6.8 depicts a cross-sectional HR-TEM image of a $\mathrm{W}$ seed layer preformed from a roughly 0.8-nm a-Si seed layer, measured by SE. From Fig. 6.8, the resulting $W$ seed layer (of $\sim 1.6 \mathrm{~nm}$ as measured by SE) consists of separated clusters with a thickness varying between 1 and $3.5 \mathrm{~nm}$. Again, one can see that SE gives roughly average thickness values. Therefore, SE can still provide a meaningful indication of film thickness, even for discontinuous ultra-thin W seed layers.

Table 6.1 presents the experimental results clarifying the seed layer thickness influence. In all the experiments, the as-preformed W seed layers were further exposed to 500 HWALD cycles. Noticeably, an a-Si layer of less than $0.2 \mathrm{~nm}$ already resulted in normal ALD growth, as evidenced by the standard (0.014$0.016 \mathrm{~nm} /$ cycle) GPC, after roughly 100 incubation cycles. With thinner a-Si layers, the growth failed to reach the linear regime. Using an a-Si (indicative) thickness of around $0.5 \mathrm{~nm}$, a HWALD W layer of $10 \mathrm{~nm}$ was successfully deposited on $\mathrm{SiO}_{2}$ with hardly any incubation time. The average resistivity of this film, measured by a fourpoint-probe, was $15.6 \mu \Omega \cdot \mathrm{cm}$. This is comparable to the resistivity $(15 \mu \Omega \cdot \mathrm{cm})$ of a 10-nm HWALD W layer deposited on a W seed layer of $5 \mathrm{~nm}$. We conclude that even 
ultra-thin a-Si seed layers can effectively work to enable HWALD of a-phase W on $\mathrm{SiO}_{2}$ surfaces.

Table 6.1. Growth behavior of HWALD W on seed layers of different thicknesses ${ }^{\text {a) }}$.

\begin{tabular}{cccc}
\hline $\begin{array}{c}\text { a-Si thickness by } \\
\text { SE [nm] }\end{array}$ & $\begin{array}{c}\text { W seed layer } \\
\text { thickness by SE [nm] }\end{array}$ & $\begin{array}{c}\text { Number of incubation } \\
\text { cycles preceding } \\
\text { standard GPC }\end{array}$ & $\begin{array}{c}\text { GPC } \\
\text { [nm/cycle] }\end{array}$ \\
$<0.1$ & $<0.1$ & $>500$ & $0.0005^{\text {b) }}$ \\
$<0.2$ & $<0.2$ & $\sim 100$ & 0.014 \\
$\sim 0.5$ & $\sim 1$ & $<5$ & 0.019 \\
$\sim 5$ & $\sim 7$ & $<5$ & 0.017 \\
\hline
\end{tabular}

a) An indication of film thickness is given, as measured by SE; see the text for further clarification.

b) Growth rate failed to reach standard values after 500 cycles; even no trend to approaching standard GPC was noticed.

\subsection{Conclusions}

This Chapter characterized and compared the nucleation and growth of tungsten films deposited by HWALD on various substrates. No nucleation was found on a thermally-grown $\mathrm{SiO}_{2}$ surfaces nor on (ALD-grown) TiN and $\mathrm{Al}_{2} \mathrm{O}_{3}$ surfaces. On the contrary, HWALD W could be deposited on properly cleaned $W$ and Co surfaces, with an incubation during approximately 100 cycles. The native oxides of these metals were effectively reduced by at-H under the same process conditions as used in the ALD recipe. An area-selective HWALD W process was achieved on $\mathrm{W} / \mathrm{SiO}_{2}$ and $\mathrm{Co} / \mathrm{SiO}_{2}$ patterned surfaces. Furthermore, ultra-thin a-Si seed layers were explored in order to start HWALD of W on surfaces which were inert to the process. Applying an a-Si seed layer far below $1 \mathrm{~nm}$ in thickness appeared sufficient to support the effective nucleation, enabling the standard GPC with little to no incubation time. 


\section{References}

[1] P. C. Lemaire, M. King and G. N. Parsons, J. Chem. Phys. 146, 052811 (2017).

[2] M. Biercuk, D. Monsma, C. Marcus, J. Becker and R. Gordon, Appl. Phys. Lett. 83, 2405 (2003).

[3] J. Goldberger, A. I. Hochbaum, R. Fan and P. Yang, Nano Lett. 6, 973 (2006).

[4] M. Fang and J. C. Ho, ACS Nano 9, 8651 (2015).

[5] A. Haider, M. Yilmaz, P. Deminskyi, H. Eren and N. Biyikli, RSC Adv. 6, 106109 (2016).

[6] R. Chen, H. Kim, P. C. McIntyre and S. F. Bent, Appl. Phys. Lett. 84, 4017 (2004).

[7] M. Yan, Y. Koide, J. Babcock, P. Markworth, J. Belot, T. Marks and R. Chang, Appl. Phys. Lett. 79, 1709 (2001).

[8] J. P. Lee and M. M. Sung, J. Am. Chem. Soc. 126, 28 (2004).

[9] M. H. Park, Y. J. Jang, H. M. Sung-Suh and M. M. Sung, Langmuir 20, 2257 (2004).

[10] A. Sinha, D. W. Hess and C. L. Henderson, Electrochem. Solid-State Lett.

9, G330 (2006).

[11] B. Kalanyan, P. C. Lemaire, S. E. Atanasov, M. J. Ritz and G. N. Parsons, Chem. Mater. 28, 117 (2016).

[12] H.-B.-R. Lee and S. F. Bent, Chem. Mater. 24, 279 (2011).

[13] S. E. Atanasov, B. Kalanyan and G. N. Parsons, J. Vac. Sci. Technol. A 34, 01A148 (2016).

[14] M. M. Kerrigan, J. P. Klesko and C. H. Winter, Chem. Mater. 29, 7458 (2017).

[15] T. Tsutsumi, H. Kotani, J. Komori and S. Nagao, IEEE Trans. Electron Devices 37, 569 (1990).

[16] Y. Pauleau and P. Lami, J. Electrochem. Soc. 132, 2779 (1985).

[17] R. Wilson and A. Williams, Appl. Phys. Lett. 50, 965 (1987).

[18] E. Broadbent and C. Ramiller, J. Electrochem. Soc. 131, 1427 (1984).

[19] S. Dana, M. Liehr, M. Anderle and G. Rubloff, Appl. Phys. Lett. 61, 3035 (1992).

[20] S. Miyazaki, Y. Hamamoto, E. Yoshida, M. Ikeda and M. Hirose, Thin Solid Films 369, 55 (2000).

[21] J. Creighton, J. Electrochem. Soc. 136, 271 (1989).

[22] J. Creighton, J. Vac. Sci. Technol. A 7, 621 (1989).

[23] M. Yang, A.A.I. Aarnink, J. Schmitz and A. Y. Kovalgin, Thin Solid Films 646, 199 (2018).

[24] M. Yang, A.A.I. Aarnink, A. Y. Kovalgin, R.A.M. Wolters and J. Schmitz, Phys. Status Solidi A 212, 1607 (2015).

[25] M. Yang, A.A.I. Aarnink, A. Y. Kovalgin, D.J. Gravesteijn, R.A.M. Wolters and J. Schmitz, J. Vac. Sci. Technol. A 34, 01 A129 (2016). 
[26] A. Y. Kovalgin, M. Yang, S. Banerjee, R. O. Apaydin, A.A.I. Aarnink, S. Kinge and R.A.M. Wolters, Adv. Mater. Interfaces 4, 1700058 (2017).

[27] J. Tauc, R. Grigorovici and A. Vancu, Phys. Status Solidi B 15, 627 (1966).

[28] F. Wooten, Optical Properties of Solids (Academic Press, New York, 1972).

[29] R. Synowicki, Thin Solid Films 313, 394 (1998).

[30] E. Lassner and W. D. Schubert, Tungsten: Properties, Chemistry, Technology of the Elements, Alloys, and Chemical Compounds (Springer Science \& Business Media, New York, 1999).

[31] J. O. Carlsson and M. Boman, J. Vac. Sci. Technol. A 3, 2298 (1985). 


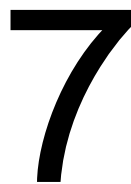

\section{Conclusions}




\subsection{Summary}

This thesis aims to establish a novel technique of atomic layer deposition (ALD) for the future ultra-large-scale integration (ULSI) of microelectronics. In last decades, chemical vapor deposition (CVD) is a dominant means for film deposition. However, the downscaling of modern ULSI manufacturing demands ALD to achieve conformal and uniform thin film with very precise control of thicknesses on structures of increasing complexity. Recently, plasma-enhanced ALD (PEALD) is largely adopted in industries to enable deposition of layers at lower substrate temperatures compared to thermal ALD. Moreover, PEALD can also provide deposition of singleelements such as Si and selected metals. However, plasma has some drawbacks. To provide a possible alternative, in this thesis we develop hot-wire assisted ALD (HWALD), where a heated tungsten (W) filament is utilized instead of a plasma to generate radicals. HWALD is expected to be another candidate for deposition in future ULSI technology. Particularly, this thesis focuses on the application of HWALD for $\mathrm{W}$ deposition by providing sequential pulses of atomic hydrogen (at- $\mathrm{H})$ and $\mathrm{WF}_{6}$.

Chapter 2 describes two reactors which were used for HWALD W. The coldwall reactor has a much larger volume than the hot-wall one. The hot wire in the coldwall reactor is situated much further away from the substrate compared to the hotwall reactor. In both reactors, there is no direct line-of-sight between the hot wire and the substrate. A spectroscopic ellipsometer (SE) is installed to in-situ monitor the film growth. Measured film thicknesses have been verified by other techniques and the optical models have been established and validated. Furthermore, tellurium (Te) etching experiments were conducted to confirm the existence of atomic hydrogen and its delivery to the substrate. The at- $\mathrm{H}$ was generated by cracking $\mathrm{H}_{2}$ on the hot wire and could be transferred to the substrate surface to provide a reasonable etch rate of Te. The total process pressure, Ar flow rates and other parameters affected the etching. Although WF 6 gas was introduced not via the hot wire, it was found to diffuse upwards to the hot wire resulting in back-stream diffusion. This effect has an influence on the subsequent $\mathrm{W}$ deposition.

Chapter 3 presents results of tungsten films deposition in the cold-wall reactor. Besides ALD, CVD and etching modes of the $W$ film were observed. This 114 
can be explained by the back-stream diffusion: WF $_{6}$ could diffuse to the hot-wire, resulting in $W_{6}$ decomposition and generation of a flux of fluorine-containing species, such as fluorine $(F)$ and tungsten subfluorides $\left(W F_{x}, x<6\right)$. The fluorine could cause etching of the grown $\mathrm{W}$ film, whereas $W F_{x}$ could mix with at- $\mathrm{H}$, leading to CVD. And the fluorine containing species would adsorb on the cold walls and evaporate into gas phase during experiments. It is found that a higher gas pressure strengthened etching whereas a lower pressure enhanced CVD. By selecting the proper process pressure and limiting the dose of $\mathrm{WF}_{6}$, optimal conditions have been found to maintain the ALD mode. Under these chosen conditions, HWALD W films were deposited with a W purity approaching 99 at\%. Further, we compared HWALD W with CVD W in terms of growth kinetics and properties. For CVD, the samples were made in a mixture of $\mathrm{WF}_{6}$ and either molecular or atomic hydrogen. Resistivity of the CVD W was around $20 \mu \Omega \cdot \mathrm{cm}$, whereas it was as high as $100 \mu \Omega \cdot \mathrm{cm}$ for the HWALD films. X-ray diffraction (XRD) revealed that the HWALD W crystallized as $\beta$ $\mathrm{W}$, whereas both CVD films were in the $\alpha-W$ phase.

Chapter 4 demonstrates results of HWALD $W$ in the hot-wall reactor. The Xray photoelectron spectroscopy (XPS) analysis revealed high-purity films, reaching 99 at.\% of W. Remarkably, XRD proved the high-purity $\alpha$-phase $\mathrm{W}$, compared to $\beta$ phase $\mathrm{W}$ obtained in the cold-wall reactor. The $\alpha$-phase was further verified by the $d$-spacing values of $\mathrm{W}$ obtained from high-resolution transmission electron microscopy (HR-TEM) images. The resistivity measurements by means of four point probe, transfer length method test structures and the Drude-Lorentz SE model all revealed a low resistivity of $15 \mu \Omega \cdot \mathrm{cm}$ for the HWALD W. The HR-TEM analysis of the films showed a uniform and conformal coverage on high aspect ratio structures (up to an aspect ratio of 36), confirming the effective ALD process and the sufficient diffusion of both $\mathrm{WF}_{6}$ and at-H into deep trenches. Finally, it is found that $\mathrm{W}$ layers start to become electrically continuous in a thickness range of 2-3 nm.

As described in the last two chapters, W obtained in two different reactors possessed different crystalline structure. Thus, Chapter 5 aimes to find the factors which are decisive for the formed. Impurites, i.e. $\mathrm{N}_{2} \mathrm{O}, \mathrm{O}_{2}, \mathrm{NH}_{3}$ and $\mathrm{H}_{2} \mathrm{O}$, were added upon the standard HWALD process to investigate their effects. $\mathrm{O}_{2}$ and water have a retarding effect on $\mathrm{W}$ growth but the HWALD process can be re-initiated after 
stopping their supply. In contrast, nitridizing species $\left(\mathrm{N}_{2} \mathrm{O}\right.$ and $\left.\mathrm{NH}_{3}\right)$ have a permanent terminating effect. However, $\mathrm{W}$ deposited with $\mathrm{O}_{2}$ impurites still resulted in $\alpha$-phase. Furthermore, the effects of $\mathrm{WF}_{6}$ overdose were studied. The surplus of $W_{6}$ appeared to lead to the formation of $\beta$-phase $W$. Extra fluorine-containing species were thus identified as the likely root cause of $\beta$-phase formation.

Chapter 6 proposed an inherent area-selective HWALD of W. The nucleation and growth of HWALD $W$ on various substrates were studied. No nucleation was found on a thermally-grown $\mathrm{SiO}_{2}$ surfaces nor on (ALD-grown) TiN and $\mathrm{Al}_{2} \mathrm{O}_{3}$ surfaces. On the contrary, HWALD W could be successfully deposited on $\mathrm{W}$ and Co surfaces. Moreover, the native oxides of these metals could be reduced by at- $\mathrm{H}$, having no influence on the subsequent deposition of $\mathrm{W}$ by HWALD. Due to the nucleation delays on different surfaces, an area-selective HWALD W process was achieved on $\mathrm{W} / \mathrm{SiO}_{2}$ and $\mathrm{Co} / \mathrm{SiO}_{2}$ patterned surfaces. Furthermore, it is found that applying an a-Si seed layer of thickness even below $1 \mathrm{~nm}$ was sufficient to enable the effective nucleation on surfaces which are inert to HWALD process.

To sum up, this thesis presents results of HWALD W. The deposited $W$ has a supreme property in terms of low resistivity and high purity. However this process can be further developed. At this stage, the growth rate per cycle (varying between 0.01 up to $0.02 \mathrm{~nm} /$ cycle) is comparable with that of other metals deposited by ALD, having however a long cycle time of $21.5 \mathrm{~s}$ due to the extended purge requirements and leading to a long deposition time. More efforts can be made to shorten the cycle time. For example, the purge times can be shortened by further limiting the $\mathrm{WF}_{6}$ dose and adsorption on cold surfaces. Alternatively, a spatial $A L D^{[1]}$ can be adopted to avoid the long purge times. 


\subsection{Outlook}

Apart from W, the HWALD technique can also be applied for other metals. In our latest work, platinum (Pt) nanoparticles were successfully formed using a Pt precursor and at- $\mathrm{H}$. Compared to thermal Pt ALD conventionally realized with oxidizing gases, at- $\mathrm{H}$ enabled deposition of a comparable density of Pt particles at a significantly lower process pressure. Moreover, molybdenum (Mo) is a candidate to be deposited by HWALD. Apart from metals, compounds such as nitrides are attempted to be deposited by HWALD with $\mathrm{NH}_{3}$ dissociating upon the hot wire. Therefore, HWALD provides an attractive alternative to PEALD in ULSI manufacturing.

Admittedly, PEALD provides a solution to grow materials which can be hardly deposited by thermal ALD, as well as to lower the substrate temperature. Currently, PEALD has been adopted in industries as a standard technique. HWALD and other plasma-free REALD techniques are novel and more factors, such as reproducibility, stability and costs, need to be taken into account before being applied to industries. However, the plasma-free REALD techniques offer new possibilities to industries and may be their new choices. Integration of a variety of radical-generation sources (hot wire, photo-dissociation, (super)sonic jet and plasma) in a cluster system can be a route for industries to flexibly develop the suitable deposition technique.

\section{Reference}

[1] P. Poodt, D. C. Cameron, E. Dickey, S. M. George, V. Kuznetsov, G. N. Parsons, F. Roozeboom, G. Sundaram and A. Vermeer, J. Vac. Sci. Technol. A 30, 010802 (2012). 


\section{List of Publications}




\section{Journals}

M. Yang, A.A.I. Aarnink, A. Y. Kovalgin, R.A.M. Wolters and J. Schmitz, "Hot-wire assisted ALD of tungsten films: In-situ study of the interplay between $C V D$, etching and $A L D$ modes”, Phys. Status Solidi A, 212, 1607 (2015).

M. Yang, A.A.I. Aarnink, A. Y. Kovalgin, D.J. Gravesteijn, R.A.M. Wolters and J. Schmitz, "A Comparison of Tungsten Films Grown by CVD and Hot-wire Assisted ALD in a cold-wall reactor”, J. Vac. Sci. Technol. A, 34, 01A129 (2016).

M. Yang, A.A.I. Aarnink, J. Schmitz and A. Y. Kovalgin, "Low-resistivity $\alpha$-phase tungsten films grown by hot-wire assisted ALD in high-aspect-ration structures”, Thin Solid Films, 646, 199 (2018)..

M. Yang, A.A.I. Aarnink, R.A.M. Wolters, J. Schmitz and A. Y. Kovalgin, “Effects of oxygen, nitrogen and fluorine on the formation of $\alpha$ - and $\beta$-phase Tungsten films by novel hot-wire assisted Atomic Layer Deposition”, ECS J. Solid State Sci. Technol., 6, P839 (2017).

M. Yang, A.A.I. Aarnink, J. Schmitz and A. Y. Kovalgin, "Inherently area-selective hot-wire assisted atomic layer deposition of tungsten films on metal/insulator substrates”, Thin Solid Films, DOI: 10.1016/j.tsf.2018.01.016 (2018).

A. Y. Kovalgin, M. Yang, S. Banerjee, R. O. Apaydin, A.A.I. Aarnink, S. Kinge, and R.A.M. Wolters, "Inherently area-selective hot-wire assisted atomic layer deposition of tungsten films on metal/insulator substrates” Adv. Mater. Interfaces 4, 1700058 (2017), Invited.

\section{Conferences:}

M. Yang, A.A.I. Aarnink, A. Y. Kovalgin, R.A.M. Wolters and J. Schmitz, “Hot-wire assisted $A L D$ of tungsten films: In-situ study of the interplay between CVD, etching and ALD modes", EuroCVD 20, Sempach Switzerland, 2015. Best oral presentation.

M. Yang, A.A.I. Aarnink, A. Y. Kovalgin, D.J. Gravesteijn, R.A.M. Wolters and J. Schmitz, “A Comparison of Tungsten Films Grown by CVD and Hot-wire Assisted ALD”, ALD 2015, 120 
Portland, OR, US.

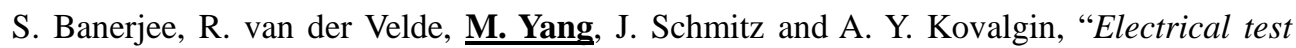
structures for verifying continuity of ultra-thin insulating and conducting films", Microelectronic Test Structures (ICMTS), International Conference of IEEE, pp 1-6 (2017), Grenoble.

M. Yang, A.A.I. Aarnink, J. Schmitz, R.A.M. Wolters, and A. Y. Kovalgin, "Effects of oxygen, nitrogen and fluorine sources on the formation of $\alpha$ - and $\beta$-phase Tungsten films by hot-wire assisted ALD”, Joint EuroCVD 21 - BalticALD 15, Linköping, Sweden, 2017.

\section{Patent:}

A. Y. Kovalgin, M. Yang, A.A.I. Aarnink and R.A.M. Wolters, "Selective Deposition of Tungsten”. US patent application 15/615,489. 


\section{Acknowledgement}

The four-year $\mathrm{PhD}$ life is a long journey to me. I never thought I would complete a $\mathrm{PhD}$ in my life before, so I have done something beyond my imagination.

Here, I would like to send my acknowledgments to those who have helped and supported me through my $\mathrm{PhD}$ study. I try my best to include as many people as possible, but if I missed someone, please accept my apologies.

First, I would like to start to thank Dr. Raymond J.E. Hueting (Ray). The PhD position which I applied was actually not about this ALD topic. I firstly applied for the "LED optical coupling” project since my Bachelor and Master were all about photonics. However, the "LED" project required more skills and experiences in simulation, whereas my competency lies in experiments. So, I was rejected for the "LED” project by the Ray. Surprisingly, Ray forwarded my CV to Dr. Alexey Kovalgin, who was leading a new project in "plasma-free ALD". Ray thought the "ALD" project was more about experiments and I might be a suitable candidate, even though I had no experience in ALD. Without Ray's recommendation, I myself would never try to apply for an “ALD” project and would definitely miss this pleasant $\mathrm{PhD}$ experience.

I will forever be thankful to my daily supervisor and also my co-promoter, Dr. Alexey Y. Kovalgin for his scientific support and guidance. I have no idea about “ALD” before I started this $\mathrm{PhD}$. However, Alexey still trusted me in accomplishing this project. I still remember whenever I was lost in experiments, Alexey could give me a clear guidance and dragged me out of the trivial experiments. Sometimes when I was stuck in experiments, Alexey could stop me wasting time in less meaning full experiments. When the experimental results of Reactor 1 were less satisfactory, I was a little disappointed; however, Alexey could still come up with the idea of transferring the results into scientific publications. I learn from Alexey that science is to explore and no results are meaningless and bad. 
I am very grateful to Professor Jurriaan Schmitz for accepting me as a $\mathrm{PhD}$ student in this group, being my promoter and also for his broad knowledge. Because you are busy we could not meet very frequently, but you were still very open and welcome to discussions whenever needed. The discussions with you are definitely inspiring. They have helped me continually shape my way of critical thinking. You even spent several hours instructing me how to prepare a rebuttal letter to a journal editor. I really appreciate the way you help PhD in self-development: you offer freedom to PhDs but also provide guidance when they need until they become independent researchers. Besides, thank you very much to have recognized my work.

And I must give special thanks to Alexey and Jurriaan. I asked for pregnancy and parental leave in the last year of my $\mathrm{PhD}$, and you helped me arrange my work during the leave and offer me full back-ups. After I returned to work, you also supported me to keep a balance between work and personal life.

I also give my special thanks to SC colleagues. First of all, Tom, thank you so much for your assistance in the complex experimental systems. At the beginning of this project, you instructed me how to operate the system very patiently and clearly. Whenever there was a problem with the system, I turned to you and you always gave very in-time and efficient help. Besides, when I have confusions in my personal life, you could also provide very valuable pieces of advice. Sander, thank you for helping me with software issues and the experience in assisting the lab courses is very pleasant. I am very thankful to Remke for all the help with organizing all kinds of paperwork through my $\mathrm{PhD}$ and for advice to me about my personal life. Thanks to the $\mathrm{PhD}$ colleagues who are sharing the office with me. Your discussions with me helped me a lot and thank you for sharing your knowledge with me. And you made me feel very relaxed and comfortable in the office. I don't list all your names here, but because of you all, I really enjoyed my 4 years' time in the office. For those who have already graduated, good luck to your career; for those who are still staying in the office, best wishes to your $\mathrm{PhD}$ !

I would like to acknowledge my graduation committee members: Professor Ruud van Ommen (Delft University of Technology); Professor Guus Rijnders (University of Twente); very special thanks to Professor Rob Wolters (University of Twente) for the 
fruitful discussions on experimental results and for the suggestions and advice on the mechanism of experiments; thanks to Professor Fred Roozeboom (Eindhoven University of Technology) for the checking typos of this thesis thoroughly and providing suggestions on the improvement of English; greatly grateful to Dr. Jan Willem Maes (ASM International N.V.) for all the discussions of selective growth and molybdenum deposition.

Next, I would like to express my thanks to our industrial partners from ASM International N.V. The substrates of $\mathrm{Si}$ pillars and $\mathrm{Al}_{2} \mathrm{O}_{3}$ covered trenches used in Chapter 4, and the substrates of patterned $\mathrm{W} / \mathrm{SiO}_{2}$ used in Chapter 6 were provided by this company. Especially thank Jan Willem and Dr. Hessel Sprey for the discussions of selective deposition and all the guidance to end up with our patent. Without your help and pieces of advice, the precious results of Chapter 6 would elude us.

Let take this chance to acknowledge some special individuals at MESA+ for the technical support, training and measurement: Marion Nijhuis (wet bench and furnace), Hans Mertens (sputtering), Gerards Kip (XPS), Mark Smithers (HR-SEM), Robert Wijn (AFM), Henk van Wolferen (FIB), Rico Keim (HR-TEM) and Peter Scheeren (cluster system).

I would like to thank my Chinese friends. With all of you, the four years' life in Enschede is easier than imagined. I would not list all your names because that will occupy one page...I will never forget the time we spent with each other, we talked, laughed and enjoyed dinner together. Also, you helped us with moving! Some of you have left Enschede or even left the Netherlands, but we will keep in touch and take any possible chance to meet again!

Last, I am eternally grateful to my family. Thank you so much for your tolerance, understanding, and supports. I am too lazy to type all the words to thank you. I am a lazy person, you know that. So I will stop here, and I know you all know my appreciation from the bottom of my heart.

Apologies to whom I might have forgotten to mention here, but cordially thank you.

Sincerely,

Mengdi Yang 


\section{Samenvatting}

Deze thesis heeft als doel een nieuwe techniek van atomic layer deposition (ALD) te introduceren voor de toekomstige ultra-large scale integration (ULSI) van microelektronica. In de laatste tientallen jaren is chemical vapor deposition (CVD) de dominante techniek geweest voor het deponeren van dunne lagen. ULSI vereist echter uniforme lagen met precieze dikte op complex gestructureerde substraten, waarvoor ALD vereist is. Recent heeft de industrie de stap van thermal ALD naar plasma-enhanced ALD (PEALD) gemaakt om lagen te deponeren bij lagere temperaturen. Bovendien maakt PEALD de depositie mogelijk van elementen zoals Si en enkele metalen. Het gebruik van plasma heeft echter nadelen. Een mogelijk alternatief dat in deze thesis wordt gepresenteerd is hotwire-assisted ALD (HWALD), waarbij radicalen gemaakt worden door een verwarmd wolfraam filament in plaats van plasma. De focus van deze thesis is op de toepassing van HWALD voor de depositie van wolfraam (W), aan de hand van opeenvolgende pulsen atomair waterstof $(a t-H)$ en $W_{6}$.

Hoofdstuk 2 beschrijft twee reactors die zijn gebruikt voor HWALD. De koudewandreactor (KWR) heeft een groter volume dan de warmewandreactor (WWR). In de KWR bevindt de hotwire zich verder van het substraat dan in de WWR. In beide reactors is er geen rechtstreekse zichtlijn tussen hotwire en substraat. Het groeiproces wordt in-situ bijgehouden middels een spectroscopische ellipsometer (SE). De gemeten laagdikten zijn bevestigd door andere methoden en de optische modellen zijn gevalideerd. Verder zijn telluur (Te) ets experimenten uitgevoerd om de aanvoer van waterstof atomen naar het substraat te bevestigen. De atomen worden gemaakt door kraken van $\mathrm{H}_{2}$ moleculen op het filament. Het etsproces wordt beïnvloed door de totale procesdruk, Ar flow, en andere parameters. Hoewel WF 6 niet langs de hotwire wordt geïntroduceerd, is gebleken dat het gas door diffusie de hotwire kan bereiken. Dit heeft invloed op de W depositie.

Hoofdstuk 3 beschrijft de resultaten van W depositie in de KWR. Naast ALD zijn ook CVD processen en etsprocessen van $W$ waargenomen. De verklaring hiervoor is dat $\mathrm{WF}_{6}$ door diffusie de hotwire bereikt en wordt ontleed in $F$ en $\mathrm{WF}_{\mathrm{x}}$ 
$(x<6)$. De W laag kan worden geëtst door $F$ atomen, terwijl een CVD proces mogelijk is wanneer WFx in contact komt met $\mathrm{H}$ atomen. Tijdens het proces kunnen fluorverbindingen die zijn geadsorbeerd op de koude wand overgaan in de gasfase. Het is gebleken dat het etsproces wordt versterkt bij hogere druk en het CVD-proces bij lagere druk. De optimale procesdruk en $\mathrm{WF}_{6}$ dosis zijn bepaald om de ALD mode te behouden. Onder deze omstandigheden zijn HWALD W lagen gedeponeerd met een zuiverheid die 99 atoomprocent benadert. Daarnaast hebben we de groeikinetiek en eigenschappen van HWALD W vergeleken met die van CVD W. De CVD monsters zijn gemaakt in een mengsel van $\mathrm{WF}_{6}$ en atomair of moleculair waterstof. De soortelijke weerstand van CVD W was $20 \mathrm{u} \Omega \mathrm{cm}$, vergeleken met $100 \mathrm{u} \Omega \mathrm{cm}$ voor de HWALD lagen. Uit X-ray diffractie (XRD) blijkt dat het HWALD $\mathrm{W}$ als beta $\mathrm{W}$ is gekristalliseerd, terwijl CVD de alfa fase produceerde.

Hoofdstuk 4 toont resultaten van HWALD W in de WWR. Analyse middels $X$-ray fotoelektron spectroscopie (XPS) toont lagen van hoge zuiverheid, tot 99 atoomprocent $W$. Uit XRD analyse volgt de opvallende conclusie dat HWALD in de WWR leidt tot alfa fase W, in tegenstelling tot het beta fase W uit de KWR. De dspacing bepaald uit hoge resolutie transmissie elektronen microscopie (HRTEM) geeft een verdere bevestiging van de productie van alfa fase $W$. Een lage soortelijke weerstand van $15 \mathrm{u} \Omega \mathrm{cm}$ is bepaald voor HWALD W met een vierpuntsmeting, de transfer length method en een Drude-Lorentz fit op SE data. Uit HRTEM blijkt een uniforme en conforme bedekking op structuren met aspect ratio tot 36 . Dit bevestigt dat het ALD proces effectief is en dat zowel $\mathrm{WF}_{6}$ als $\mathrm{H}$ voldoende kunnen diffunderen in diepe kieren. Tot slot is gevonden dat de $\mathrm{W}$ lagen elektrisch continu worden vanaf 2-3 nm dikte.

Uit de vorige twee hoofdstukken bleek dat $\mathrm{W}$ verschillende kristalstructuren heeft afhankelijk van de gebruikte reactor voor de depositie. Hoofdstuk 5 heeft als doel de factoren in kaart te brengen die bepalend zijn voor de kristalstructuur van het product. Onzuiverheden zoals $\mathrm{N}_{2} \mathrm{O}, \mathrm{O}_{2}, \mathrm{NH}_{3}$ en $\mathrm{H}_{2} \mathrm{O}$ zijn doelbewust toegevoegd om het effect te bepalen. Het HWALD proces wordt vertraagd door $\mathrm{O}_{2}$ en $\mathrm{H}_{2} \mathrm{O}$, maar zodra de aanvoer wordt gestopt, kan de groei worden voortgezet. Nitriderende gassen zoals $\mathrm{N}_{2} \mathrm{O}$ en $\mathrm{NH}_{3}$ leiden daarentegen tot een permanente stop van de groei. Bij aanwezigheid van $\mathrm{O}_{2}$ in de WWR groeit $\mathrm{W}$ nog steeds in de alfa-fase. Verder zijn 
de effecten van $\mathrm{WF}_{6}$ overdosis bestudeerd. Het overschot lijkt te leiden tot vorming van beta-fase $\mathrm{W}$. Op grond hiervan worden extra fluor-bevattende gassen aangewezen als de waarschijnlijke oorzaak van beta-fase groei.

Hoofdstuk 6 stelt een HWALD proces voor W voor met inherente oppervlakte-selectiviteit. De nucleatie en groei van HWALD $W$ is bestudeerd op verschillende substraten. Op thermisch gegroeid $\mathrm{SiO}_{2}$, ALD gegroeid TiN en ALDgegroeid $\mathrm{Al}_{2} \mathrm{O}_{3}$ is geen nucleatie waargenomen. Daarentegen is $\mathrm{W}$ met succes gegroeid op $\mathrm{W}$ en Co oppervlakten. Bovendien zijn de native oxides van deze metalen gereduceerd door waterstof atomen zonder beïnvloeding van de daarop volgende $\mathrm{W}$ depositie. Door gebruik te maken van de vertraging in nucleatie op verschillende oppervlakten, is een oppervlakte-selectief HWALD W proces uitgevoerd op oppervlakten met $\mathrm{W} / \mathrm{SiO}_{2}$ en $\mathrm{Co} / \mathrm{SiO}_{2}$ patterning. Tot slot is gevonden dat een amorf silicium (a-Si) seed layer van minder dan $1 \mathrm{~nm}$ dik toereikend is om effectieve nucleatie mogelijk te maken op oppervlakten die van zichzelf inert zijn voor het HWALD proces.

Samengevat beschrijft deze thesis resultaten van HWALD van W. De W lagen hebben uitstekende geleidbaarheid en zuiverheid. Desondanks kan het proces verder ontwikkeld worden. Op dit moment is de groeisnelheid per cyclus vergelijkbaar met andere ALD processen voor metalen ( 0.01 tot $0.02 \mathrm{~nm}$ per cyclus). Een cyclus duurt echter 21.5 seconde door de lange spoeltijd, waardoor het totale depositieproces lang duurt. De spoeltijd zou verkort kunnen worden door de WF $_{6}$ dosis verder te verlagen en koude oppervlakten waar adsorptie op plaats kan vinden, te elimineren. Een andere oplossing zou het toepassen van spatial ALD kunnen zijn. 